FINAL REPORT

FHWA/IN/JTRP-2003/20

\title{
THE DEVELOPMENT OF A HIGHWAY TORT LIABILITY RISK MANAGEMENT SYSTEM FOR THE INDIANA DEPARTMENT OF TRANSPORTATION
}

\author{
By \\ Thomas Giraud \\ Graduate Research Assistant \\ Vorasett Chovichien \\ Graduate Research Assistant \\ Samuel Labi \\ Visiting Assistant Professor \\ and \\ Kumares C. Sinha \\ Olson Distinguished Professor \\ School of Civil Engineering \\ Purdue University
}
Joint Transportation Research Program
Project No. C-36-78I
File No.: 3-10-9
SPR-2662
Prepared in Cooperation with the Indiana Department of Transportation and The U.S. Department of Transportation
Federal Highway Administration

The contents of this report reflect the views of the authors who are responsible for the facts and the accuracy of the data presented herein. The contents do not necessarily reflect the official views of the Federal Highway Administration and the Indiana Department of Transportation. The report does not constitute a standard, a specification, or a regulation.

Purdue University

West Lafayette, Indiana, 47907

December 2003 
TECHNICAL REPORT STANDARD TITLE PAGE

\begin{tabular}{|c|c|c|}
\hline $\begin{array}{l}\text { 1. Report No. } \\
\text { FHWA/IN/JTRP-2003/20 }\end{array}$ & 2. Government Accession No. & 3. Recipient's Catalog No. \\
\hline \multirow{2}{*}{\multicolumn{2}{|c|}{$\begin{array}{l}\text { 4. Title and Subtitle } \\
\text { The Development of a Highway Tort Liability Risk Management System for the } \\
\text { Indiana Department Of Transportation }\end{array}$}} & $\begin{array}{l}\text { 5. } \quad \text { Report Date } \\
\text { December } 2003\end{array}$ \\
\hline & & 6. Performing Organization Code \\
\hline \multicolumn{2}{|c|}{$\begin{array}{l}\text { 7. Author(s) } \\
\text { Thomas Giraud, Vorasett Chovichien, Samuel Labi and Kumares Sinha }\end{array}$} & $\begin{array}{l}\text { 8. Performing Organization Report No. } \\
\text { FHWA/IN/JTRP-2003/20 }\end{array}$ \\
\hline \multirow{2}{*}{\multicolumn{2}{|c|}{$\begin{array}{l}\text { 9. Performing Organization Name and Address } \\
\text { Joint Transportation Research Program } \\
1284 \text { Civil Engineering Building } \\
550 \text { Stadium Mall Drive, Purdue University } \\
\text { West Lafayette, IN 47907-1284 }\end{array}$}} & 10. Work Unit No. \\
\hline & & $\begin{array}{l}\text { 11. Contract or Grant No. } \\
\text { SPR-2662 }\end{array}$ \\
\hline \multirow{2}{*}{\multicolumn{2}{|c|}{$\begin{array}{l}\text { 12. Sponsoring Agency Name and Address } \\
\text { Indiana Department of Transportation } \\
\text { State Office Building, } 100 \text { North Senate Avenue } \\
\text { Indianapolis, IN } 46204\end{array}$}} & 13. Type of Report and Period Covered \\
\hline & & 14. Sponsoring Agency Code \\
\hline \multicolumn{3}{|c|}{$\begin{array}{l}\text { 15. Supplementary Notes } \\
\text { Prepared in cooperation with the Indiana Department of Transportation and Federal Highway Administration. }\end{array}$} \\
\hline \multicolumn{3}{|c|}{ 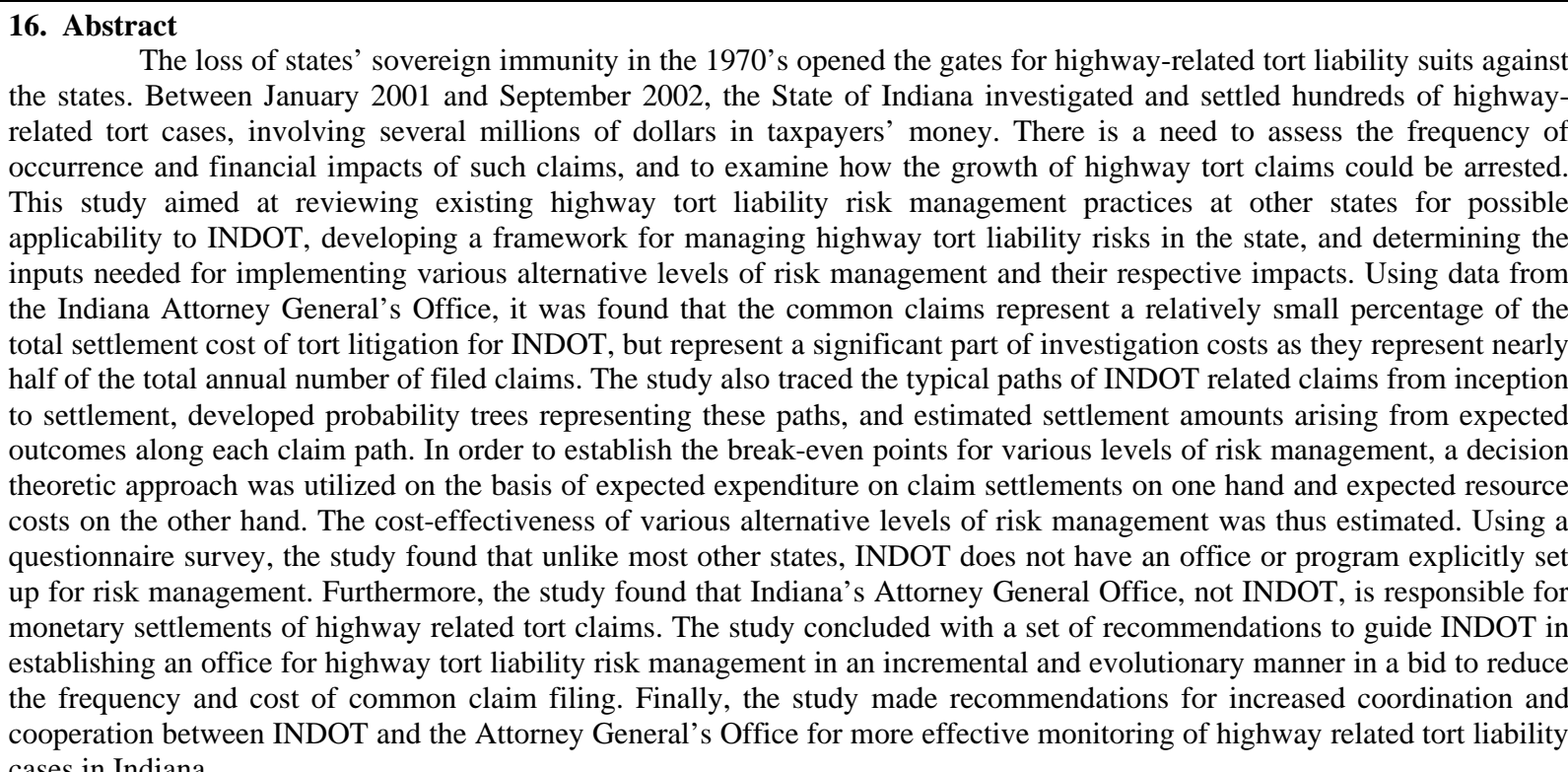 } \\
\hline
\end{tabular}
cases in Indiana.

\section{Key Words \\ 18. Distribution Statement}

Tort Liability, Risk Management, Sovereign Immunity, Common Claims, Palliative Risk Management, Pre-emptive Risk Management, Decision Theoretic Approach, Break-even Analysis, Costeffectiveness.

No restrictions. This document is available to the public through the National Technical Information Service, Springfield, VA 22161

\begin{tabular}{|c|c|c|c|}
\hline $\begin{array}{c}\text { 19. Security Classif. (of this report) } \\
\text { Unclassified }\end{array}$ & 20. Security Classif. (of this page) & 21. No. of Pages & 22. Price \\
\hline
\end{tabular}




\section{TECHNICAL Summary}

Technology Transfer and Project Implementation Information

\section{THE DEVELOPMENT OF A HIGHWAY TORT LIABILITY RISK MANAGEMENT SYSTEM FOR THE INDIANA DEPARTMENT OF TRANSPORTATION}

\section{Introduction}

With the loss of states' sovereign immunity in the 1970's, many states, including Indiana, are experiencing increased frequency and expenditure for highway-related tort liability cases. Each year, the State of Indiana investigates and settles hundreds of highway-related tort cases involving several millions of dollars in taxpayers' money. There is a need to monitor and assess the frequency and financial impacts of such claims and to examine how the growth of highway tort claims could be reduced.

This study aimed at reviewing existing highway tort liability risk management practices in other states for possible applicability to the Indiana Department of Transportation (INDOT), developing a framework for managing highway tort liability risks in the state, and determining the inputs and respective impacts of various levels of risk management. Data on highway tort liability frequency and dollar amounts for various claim types in Indiana were collected from the Attorney General's Office. Efforts were also made to obtain and review the circumstances and outcomes of past highway-related tort cases against the state.

A questionnaire survey was carried out to document and evaluate the current state of risk management practice at state departments of transportation. In developing an analytical framework for risk management program evaluation, the study traced the typical paths of INDOT-related claims from inception (filing by claimant) to settlement, developed probability trees representing these paths, and estimated settlement amounts arising from expected outcomes along each claim path. Various levels of risk management practice were established with the implicit assumption that increasing risk management efforts (such as personnel strength) translates to higher risk management effectiveness. To establish the break-even points for various levels of risk management, a decision theoretic approach was utilized on the basis of expected claim settlement expenditures on one hand and expected resource costs on the other. The cost-effectiveness of implementing various levels of risk management was thus estimated.

The study concluded with a set of recommendations to guide INDOT in establishing an office for highway tort liability risk management in an incremental and evolutionary manner in a bid to reduce the frequency of incidents that typically lead to common claims. Specific recommendations were also made for reducing the number of common claims filed against the state as a result of various field operations. Finally, the study proposed various ways to increase coordination and cooperation among various divisions at INDOT, as well as the Attorney General's Office, for more effective monitoring and management of highway-related tort liability cases in Indiana. 


\section{Findings}

Using data from the Indiana Attorney General's Office, it was found that the common claims represent a relatively small percentage of the total settlement cost of highway related tort litigation but represent a significant part of investigation costs, as they constitute nearly half of the total annual number of filed claims.

In Indiana, the Attorney General's Office, not INDOT, is responsible for payments to settle any tort claims arising from the use of highway infrastructure.

From the questionnaire survey, it was found that unlike most other states, INDOT does not have an office or program explicitly set up

for risk management. Furthermore, the study determined that a systematic decision theoretic approach can be followed in the assessment of various levels of a risk management program. The developed methodology is useful not only in evaluating the cost-effectiveness of the program, but also in the development of appropriate management strategies that can affect the number of claims and various probabilities associated with a claim sequence as well as the monetary values of settlements. On the basis of recent experience with INDOT-related tort cases and their settlements, the study found that an explicit and incremental risk management program at INDOT can be economically justified.

\section{Implementation}

Personnel from INDOT’s Legal Division, and the Indiana Attorney General's Office worked with the research team and the Study Advisory Committee (SAC) regarding implementation issues and are expected to play lead roles in the implementation process. Other divisions expected to play significant roles in the study implementation are the Operations Support Division, Safety Management Unit of INDOT's Program Development Division, Contracts and Construction Division, Design Division, and the Systems Technology Division.

The initial effort towards implementing a risk management program should focus on strengthening existing links between the Attorney General's Office and INDOT. Implementation can be carried out in phases. Implementation of preemptive risk management involves taking actions to minimize occurrence of tort liability incidents. This can be done using legal and administrative procedures (such as promoting laws that reduce the State's exposure to highway tort liability, and reducing claim filing deadline periods), improving communication within INDOT divisions (through regular risk management seminars, for instance), and also between INDOT and road users (through the use of the media). Also, implementation of pre-emptive highway tort risk management can also be enhanced by increased levels of law enforcement (through policies and regulations, driver education, and higher penalties).
Furthermore, continuation of INDOT innovations in design and materials, as well as construction and maintenance work zone improvements, can help reduce the frequency of highway incidents that could lead to tort liability.

Implementation of palliative risk management would involve actions that are typically carried out in the post-accident phase place in an effort to minimize its consequences. From the legal and administrative perspective, implementation can be achieved by enhancing the current database maintained by INDOT's Legal Division for the purpose of reliable forecasting of future tort claims. Also, engineering designs, and maintenance and operational procedures that are identified as inadequate should be addressed promptly to reduce the number of incidents that may ultimately lead to tort liability lawsuits. Design and maintenance decisions based on budgetary or other economic constraints are generally seen as discretionary in nature and consequently are generally immune from tort suits. However, as demonstrated in past cases, a transportation agency that argues that its failure to remedy a defective design due to funding priorities can be held liable if it presents no evidence on planning, ordering of priorities, or limitations on available funding. In this regard, the current development of safety and congestion management systems for INDOT and the ongoing refinement of the already developed 
pavement and maintenance management systems, are critical for risk management implementation because by providing evidence on planning and

\section{Contacts}

For more information:

Prof. Kumares C. Sinha

Principal Investigator

Purdue University School of Civil Engineering

550 Stadium Mall Drive

West Lafayette IN 47907

Phone: (765) 494-2211

Fax: (765) 496-7996 programming of investments, such programs will subsequently reduce the exposure of the state to tort.

\section{Indiana Department of Transportation}

Division of Research

1205 Montgomery Street

P.O. Box 2279

West Lafayette, IN 47906

Phone: (765) 463-1521

Fax: (765) 497-1665

\section{Purdue University}

Joint Transportation Research Program

School of Civil Engineering

West Lafayette, IN 47907-1284

Phone: (765) 494-9310

Fax: (765) 496-7996 


\section{ACKNOWLEDGMENTS}

The authors hereby acknowledge the contributions and constant support provided by Jim Poturalski of INDOT's Operations Support Division and Samy Noureldin of INDOT's Research Division throughout the execution of the study. Julie Welp of INDOT's Legal Division, Tim Bertram of INDOT's Contracts and Construction Division, and Karen Mathis Stippich of FHWA served on the initial study advisory committee and made contributions at various stages of the project. Brad Steckler of INDOT's Environment, Planning and Engineering Division, and Scott Newbolds of the Special Projects Division joined the study advisory committee at a later stage and made valuable contributions to the study, particularly at the review stage. Also, the authors recognize the support of Teresa Giller of INDOT Legal Division, Dennis Kuchler of INDOT Operations Support Division, and David Pamplin of FHWA who also joined or were associated with the study advisory committee at later stages of the study. Kelly Whitman of INDOT's Legal Division played an important role by readily providing general information and guidance on various aspects of the study, while Scott Sunderman of the Indiana Attorney General's Office was instrumental in providing tort-related data. The overall support provided by Barry Partridge, Chief of INDOT's Research Division is very much appreciated, and we are

grateful to the JTRP coordinator, Karen Hatke, for the important role she played throughout the course of this project. 
TABLE OF CONTENTS

Page

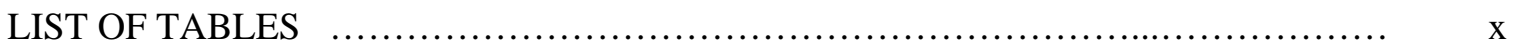

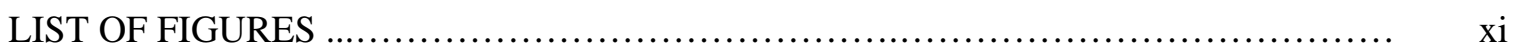

CHAPTER 1 INTRODUCTION

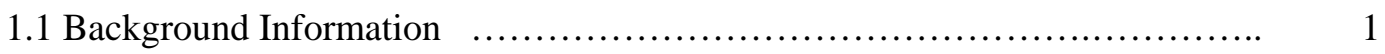

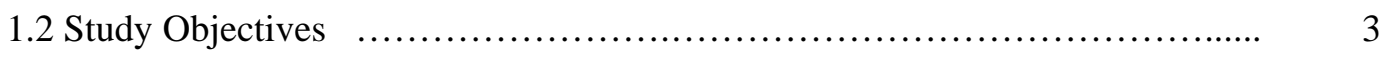

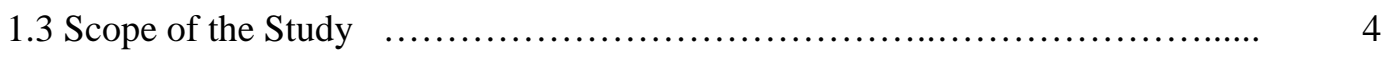

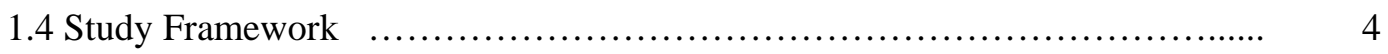

\section{CHAPTER 2 REVIEW OF AVAILABLE LITERATURE ON HIGHWAY TORT} LIABILITY RISK MANAGEMENT

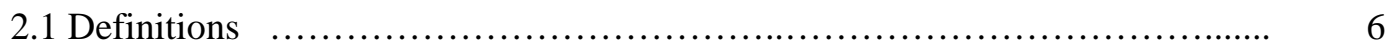

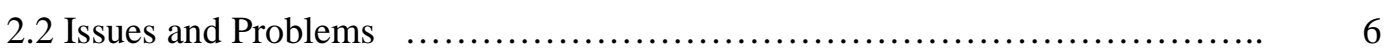

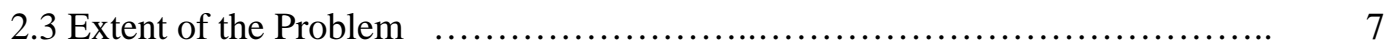

2.4 Areas of Concern .......................................................... 7

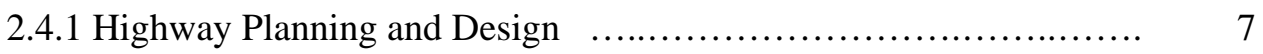

2.4.1.1 Design Immunity Statutes ............................. 8

2.4.1.2 Duty to Improve the Design Due to Changed

Circumstances .................................... 9

2.4.1.3 Absence of General Duty to Install Warning Signs, Traffic Lights, or Pavement Markings ................ 9

2.4.1.4 Duty to Warn of or Correct Known Dangerous Conditions ...................................... 10

2.4.1.5 Traffic Lights ................................. $\quad 10$

2.4.1.6 Pavement Markings ............................. $\quad 10$

2.4.1.7 Guardrails and Barriers ......................... $\quad 10$ 


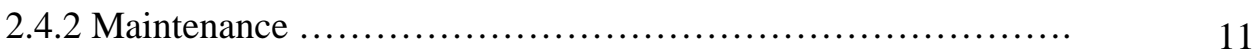

2.4.2.1 Surface Defects ...................................... 12

2.4.2.2 Snow and Ice Control .................................. 13

2.4.3 Other Areas of Concern in Risk Management....................... 15

2.4.3.1 Pedestrian Safety ...................................... 15

2.4.3.2 Intelligent Transportation Systems ...................... 15

2.4.3.3 Environment ...................................... 15

2.4.3.4 Hazardous Materials Routing ......................... 16

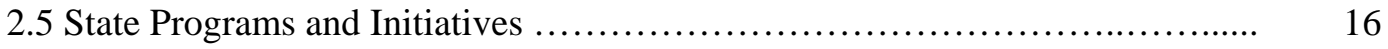

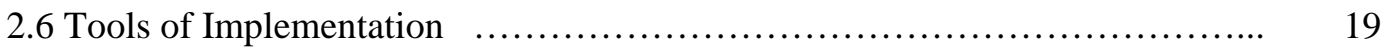

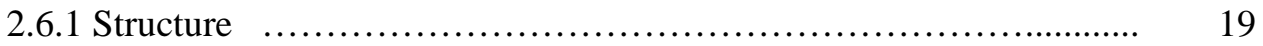

2.6.2 Database .................................................. 20

2.6.3 Training ........................................................ 20

2.7 Chapter Summary .................................................... 21

\section{CHAPTER 3 STATE-OF-PRACTICE AGENCY SURVEY OF HIGHWAY TORT LIABILITY RISK MANAGEMENT}

3.1 Status of Tort Liability ................................................ 23

3.2 Status of Risk Management Programs ..................................... 23

3.2.1 Hazardous Situation Identification ............................. 24

3.2.2 Hazardous Situation Response ................................ 24

3.2.3 Time Limits for Responses ................................... 24

3.2.4 Priorities Determination ...................................... 25

3.2.5 Settlement ............................................... 25

3.2.6 Additional Strategies ........................................... 25

3.3 Risk Management Program Objectives .................................. 26

3.4 Risk Management Program Evaluation ................................. 26

3.4.1 Risk Management Effectiveness .............................. 26

3.4.2 Funds for Future Claims .................................... 26

3.5 Chapter Summary ..................................................... 27 
CHAPTER 4 A PERSPECTIVE OF CURRENT HIGHWAY TORT LIABILITY CLAIMS IN INDIANA

4.1 Claims Management .............................................. 28

4.2 Claims Sources Associated with Highway Infrastructure ..................... 29

4.3 Trends in Tort Liability Cases ........................................... 31

4.3.1 Data Collection for All Claims ................................... 31

4.3.2 Categories of Common Claim ........................................ 33

4.3.2.1 Chuckhole Claims .................................... 35

4.3.2.2 Mailbox Claims ........................................ 37

4.3.2.3 Mower Claims ...................................... 39

4.3.2.4 Paint Claims ........................................ 40

4.4 Estimating the Expected Annual Number of Paid Common Claims .............. 41

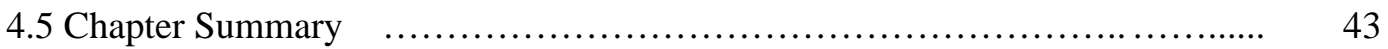

\section{CHAPTER 5 PROPOSED OPERATIONAL FRAMEWORK FOR A HIGHWAY} TORT LIABILITY RISK MANAGEMENT SYSTEM AT INDOT

5.1 The Framework ........................................................... 45

5.2 Aspects of Pre-Emptive Risk Management $\quad$..................................... 47

5.2.1 Legal/Administrative Aspects ................................. 47

5.2.2 Information and Training ................................... 48

5.2.2.1 Road Users ........................................ 48

5.2.2.2 INDOT Employees...................................... 49

5.2.3 Enforcement .............................................. 49

5.2 .4 Engineering.............................................. 50

5.2.4.1 Design ........................................... 50

5.2.4.2 Construction ..................................... 50

5.2.4.3 Maintenance ..................................... 50

5.2.4.4 Management Systems................................ 51

5.2.4.5 Other Operations.................................... 51

5.3 Aspects of Palliative Risk Management ................................ 51

5.3.1 Legal/Administrative ...................................... 51

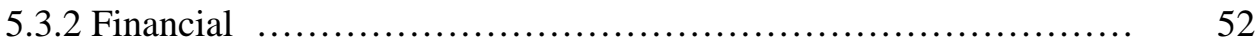


5.3.2.1 Tort Cost Forecasting .................................. 52

5.3.2.2 Tort Cost Allocation ................................... 53

5.3.2.3 Insurance Issues .................................... 54

5.3.2.3.1 Commercial Insurance ....................... 55

5.3.2.3.2 Self-Insurance ............................... 55

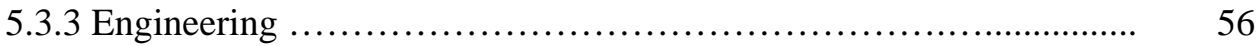

5.4 Chapter Summary ........................................................... 56

\section{CHAPTER 6 RESOURCES AND ORGANIZATIONAL SETUP FOR A HIGHWAY} TORT LIABILITY RISK MANAGEMENT PROGRAM FOR INDOT

6.1 Introduction ............................................................. 58

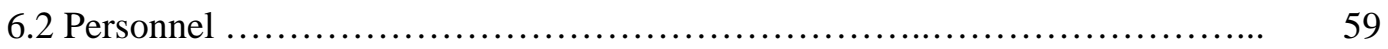

6.2.1 Risk Manager .............................................. 59

6.2.2 Claims Analyst ............................................ 60

6.2.3 Database Specialist .......................................... 60

6.2.4 Other Risk Management Positions ............................... 61

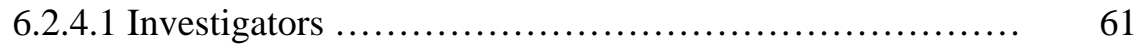

6.2.4.2 Inspectors ......................................... 61

6.2.4.3 Risk Management Committee .......................... 61

6.2.4.4 Experts ........................................... 62

6.2.4.5 Full-Time In-House Experts ......................... 62

6.2.4.6 External Experts ................................... 63

6.3 Levels of Highway Tort Liability Risk Management ........................ 63

6.4 Risk Management System Organization ................................ 64

6.4.1 Effective Agency-User Communication for Risk Management ...... 64

6.4.2 Estimated Cost of Establishing an Office for Highway Tort

Liability Risk Management ..................................... 65

6.5 Suggested Site Improvements for Reducing the Frequency of

Common Claims ..................................................... 65

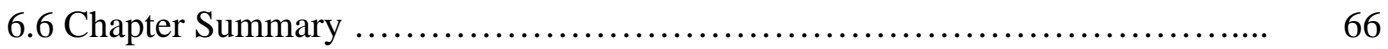




\section{CHAPTER 7 COST EFFECTIVENESS EVALUATION OF HIGHWAY TORT LIABILITY RISK MANAGEMENT AT INDOT USING A DECISION THEORETIC APPROACH}

7.1 Introduction

7.2 Assumptions

7.3 Basic Principles 68

7.4 Description of Claim Sequence 69

7.5 Determination of Probability Values at Each Stage of Claim Life 69

7.5.1 Probability of Incident Occurrence and Claim Filing

7.5.2 Probability of Denial/Settlement of Filed Claims

7.5.3 Probability of Claimant's Acceptance or Rejection of Claim

Denial/Settlement

7.5.4 Probability of Outcomes of Court Cases

7.5.4.1 Claim-Denial Court Cases

7.5.4.2 Settlement-Denial Court Cases

7.6 Evaluation of Cost-effectiveness of Various Levels of Risk Management 75

7.6.1 Reductions in Settlement Probability and Frequency of Filed Claims

7.6.1.1 Sample Calculation for Percent Reduction in Probability of Settlement

7.6.1.2 Sample Calculation for Reduction in Number of Filed Claims 


\section{APPENDICES}

Appendix A: A Newspaper Article on Tort Liability Expenditure in Indiana ............. 87

Appendix B: Goals and Objectives of a Risk Management Program …................ 88

Appendix C: General and Specific Objectives of Risk Management Systems............. 89

Appendix D: Entities Responsible for Risk Management in Selected States ............. 90

Appendix E: Tasks and Personnel for Virginia DOT’s Risk Management System ........ 91

Appendix F: Amounts Claimed and Paid for Settled Chuckhole Claims ...................... 92

Appendix G: Amounts Claimed and Paid for Settled Mailbox Claims ................... 94

Appendix H: Amounts Claimed and Paid for Settled Mower Claims ................... 96

Appendix I: $\quad$ Amounts Claimed and Paid for Settled Paint Claims .................... 98

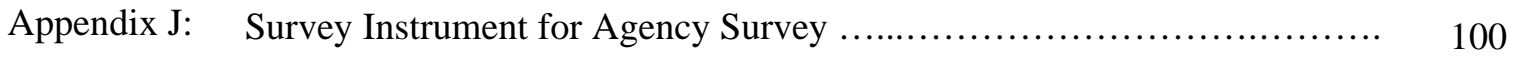




\section{LIST OF TABLES}

Table

Page

Table 1: Definitions of Various Categories of Negligence .......................... 18

Table 2: $\quad$ Selected Cases Involving Highway-Related Claims ........................ 32

Table 3: Annual Primary and Secondary Costs for Common and Other Claims .............. 35

Table 4: Frequency and Amounts of Common Claims in Indiana in the 2001 ............... 44

Table 5: Level of Risk Management and Corresponding Staff Strength .................. 63

Table 6: $\quad$ Average Values of Variables Associated with Claim Cost Estimation (\$2001).. 77

Table 7: $\quad$ Percent Reductions in Probability of Settlement and Reductions in Number of Filed Claims for Various Claim Type, Cost Consideration, and Risk Management Level Combinations ...................................... $\quad 78$ 


\section{LIST OF FIGURES}

Figure

Page

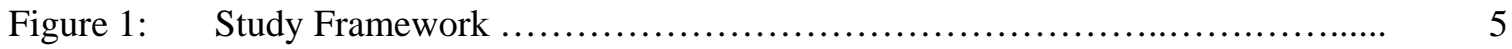

Figure 2: $\quad$ Sources of Highway Related Tort Liability Claims ....................... 29

Figure 3: $\quad$ Highway Tort Liability Claim Trends in Indiana, 1999-2001............... 32

Figure 4: $\quad$ Trends in Frequency of Filed Claims (All Claim Types and Common Claims) ........................................................... 33

Figure 5: $\quad$ Temporal Distribution of Frequency of Total and Paid Common Claims ....... 35

Figure 6: Temporal Distribution of Frequency of Filed and Paid Chuckhole Claims.... 36

Figure 7: $\quad$ Amounts Claimed and Paid for Settled Chuckhole Claims ...................... 36

Figure 8: $\quad$ Temporal Distribution of Frequency of Filed and Settled Mailbox Claims.... 37

Figure 9: $\quad$ Amounts Claimed and Paid for Settled Mailbox Claims ....................... 38

Figure 10: Temporal Distribution of Frequency of Filed and Settled Mower Claims...... 39

Figure 11: Amounts Claimed and Paid for Settled Mower Claims ........................ 39

Figure 12: Temporal Distribution of Frequency of Filed and Settled Paint Claims......... 40

Figure 13: Amounts Claimed and Paid for Settled Paint Claims ...................... 41

Figure 14: Theoretical and Observed Annual Number of Paid Common Claims ......... 43

Figure 15: Proposed Operational Framework for a Highway Tort Liability Risk Management System in Indiana ........................................ 46

Figure 16: Distribution of Highway Tort Claims Expenditure at Kentucky, 1981-1989... 53

Figure 17: Claim Sequence .................................................. 68

Figure 18: Claim Probability Tree for a Given Claim Type and Category, and Given Level of Risk Management .......................................... $\quad 70$

Figure 19: Breakeven Analysis on the Basis of Abbreviated Decision Theoretic Approach ........................................................... 76 


\section{CHAPTER 1: INTRODUCTION}

\section{$\underline{\text { 1.1 Background Information }}$}

The operation of any industrial and commercial facility or process is associated with some amount of risk of harm to (and harm from) operators, users and non-users of that process or facility. "Operators", in the context of highway infrastructure, may include highway workers in a construction or maintenance work zone, while "users" refers to vehicle operators, passengers, and pedestrians. The risk can be in terms of personal, physical, or property damage. In addition, any possible adverse impact on the natural environment in general may also be considered as a risk. Such risks are an inevitable part of everyday life. However, management of such risks can lead to their reduction, with subsequent benefits to all parties directly or indirectly involved with the usage or administration of the highway facility.

The year 1978 marked a watershed in the liability of the State of Indiana to tort. In that year, the sovereign immunity section of Indiana's Legal Code was amended. Under the old code, the state and its employees were largely immune from tort claims brought by citizens, companies or workers. With the passage of the new law, the state abandoned its strict adherence to the doctrine of sovereign immunity, and therefore removed its immunity from liability in state court proceedings for damages resulting from exercise of its proprietary or governmental functions. This was part of a general trend in the United States that had begun with the passage of the Federal Tort Claims Act in 1946. With the removal of such immunity, the state became liable to law suits arising from death, injury, or property damage resulting from negligent design, construction, or maintenance of state highway facilities. Section 24 of Article 4 of the Indiana Code, states: "Right to sue the state: Section 24. Provision may be made, by general law, for bringing suit against the State; but no special law authorizing such suit to be brought, or making compensation to any person claiming damages against the State, shall ever be passed.”

Highway tort liability is the compensation for damages caused by inaction, careless, or negligent actions by state transportation agency employees. With the removal of sovereign immunity in 1978, the number of highway-related tort claims settled by the Attorney General's Office has increased over the years. Between 1999 and 2001 for instance, the number of claims paid by the state 
grew 25\%, from 307 to 396. This trend is similar to that for other states [Smith et al., 2000]. Increases in the costs associated with tort claims against state and local highway agencies have resulted, directly or indirectly, in a reduction in the available funds for other vital functions such as construction, congestion mitigation, safety enhancement, and maintenance. The adverse impact of such development on the state's budget is considered critical at the present time that is characterized by increasing demands and higher user expectations vis-à-vis severe resource constraints.

Tort liability expenses incurred by highway and transportation agencies are generally hard to estimate or predict, and available figures are often not precise. About a decade ago, the annual cost for settlements and judgments for all state highway agencies was estimated between \$145 and \$345 million [Lewis, 1994]. This cost is considered as the "primary cost", consisting only of the amount awarded to plaintiffs. Adjusted for inflation using the all-urban consumer index (CPI-U) from the U.S. Department of Labor's Bureau of Labor Statistics, this cost represents between \$190 and \$450 million in 2001 dollars. Additional costs, which are not included in the primary costs, consist of expenses associated with investigation and prosecution. Such "secondary costs" include the wages of agency staff involved in investigations, production of documents, admissions, and appearances as witnesses, wages of the litigation staff, expert fees, jury fees, and associated direct expenses and overheads [Lewis, 1994]. Secondary costs generally render the overall liability costs much higher than just the expenses associated with settlement.

To counter the growing highway tort liability problem, many states have begun the development of various programs to manage the risks associated with highway tort, and to handle tort claims. Typically, such programs are not specifically labeled as risk management programs or systems. In a 1990 survey, it was found that 21 states out of 38 responding states had in place some form of risk management program, and that 3 other states were in the process of developing one [Demetsky and $\mathrm{Yu}, 1993$ ]. In many cases, these programs were not well defined and they were not uniform across the U.S., as each state had its own legislation and unique circumstances. However, highway agencies of certain states have acquired considerable knowledge in risk management, and it would be useful to draw on such experience and knowledge for purposes of the present study.

Past research has aptly recognized that the future holds problems as well as solutions regarding highway tort liability. If current trends are projected, a larger number of claims are expected in the future. Also, the adoption of new technologies for operating and maintaining the state's highways may lead to increased potential of new types of risks and liabilities, and transportation agencies will likely face new challenges in both the application of technology and its results. On the other hand, new technologies hold great potential for improving the monitoring, 
detecting and responding to possible situations that could otherwise result in tort liability cases [Smith et al., 2000].

A systematic highway tort liability risk management system would help the Indiana Department of Transportation (INDOT) to improve the performance of its facilities as well as reliability of service, while strategically reducing risks to facility users, and also to non-users and agency workers. Reduced expenditure for payments to settle tort liability cases could translate to increased funding for other sectors of transportation infrastructure management.

\subsection{Study Objectives}

The primary objective of the present study was to collect and collate information on the state-of-the-art as well as the state of practice of risk management at various state DOTs, and to synthesize such findings into an organized report that would provide the basis of developing a possible future highway tort liability risk management system (RMS) for the Indiana DOT.

However, the study was taken a step further to define the organizational setup and needed resources for various levels of risk management, to evaluate the cost-effectiveness of such levels, to assess the need for such a system at the present time, and to investigate the viability of an incremental and evolutionary approach to the establishment of such system.

Another study objective was to develop an operational framework for a proposed risk management system. The study also sought to identify elements of such framework (pre-emptive and palliative risk management) and to establish a set of recommendations for further improvements in the management of claim data.

With a fully developed highway tort liability risk management system in Indiana, it is expected that the state can reduce the impact of INDOT related tort liability and be better prepared for unavoidable claims. It was roughly estimated that the cost of highway-related tort liability in Indiana in 2001 was approximately $\$ 1.9$ million for primary costs, excluding several hundreds of thousands of dollars expended on secondary costs of investigations and prosecutions. These estimates were obtained using data from the Attorney General's Office for the Associated Press, shown as Appendix A (Purdue Exponent, 2002). It is envisaged that the development of a fully operational RMS would ultimately help the State of Indiana to effectively coordinate and track all state highway related claims and litigation, manage a tort liability loss-mitigation program, and minimize the adverse effects of litigation on the state and the general public. Furthermore, overall highway safety could be enhanced as a risk management system includes identification and quick 
response to hazardous situations that may lead to high frequencies or amounts of tort costs. Addressing such situations would reduce the state's exposure and loss due to highway related tort liability.

Appendices B and C present typical examples of goals and objectives of highway tort liability risk management programs at a state level. Appendix B reproduces the schematic framework of cost minimization goal of risk management associated with objectives developed in an earlier Virginia DOT study, while Appendix C presents the three most cited RMS objectives in literature, and provides definitions of such objectives offered by various sources.

\subsection{Scope of the Study}

The scope of the present study was restricted to tort liability arising from the usage of state's road facilities. As such, other cases such as employee suits against the State for racial and sexual harassment were excluded. In the analysis of tort related expenditures, both "primary" and "secondary costs" were considered. Primary costs refer to judgments and settlements awarded to plaintiffs. Secondary costs refer to the expenses associated with investigation and prosecution. The study presents the trends in frequencies and amounts claimed and paid, for various categories of the common types of tort claims in Indiana.

\subsection{Study Framework}

The framework for the present study is provided as Figure 1. The various components presented in this figure are discussed in detail in subsequent chapters of this report. Generally, the study framework consists of the following activities:

- a literature review, which helped assess the state-of-the-art and the state of practice of highway tort liability risk management at several states in the United States. This included identification of tort liability problems and actions at state departments of transportation,

- identification and definition of the possible sources of highway tort liability risk on the state's road network. Highway elements associated with high risk of incidents were identified. Also an analysis was carried out for various categories of common claim types using the historical data made available by the Attorney General's Department,

- theoretical analyses to assess the cost-effectiveness of various levels of highway tort liability risk management, and to subsequently determine any need for a risk management office at INDOT or the Attorney General's office, and 
- recommendations for an incremental and evolutionary approach towards the establishment of a system for managing highway related tort liability risks in the State of Indiana.

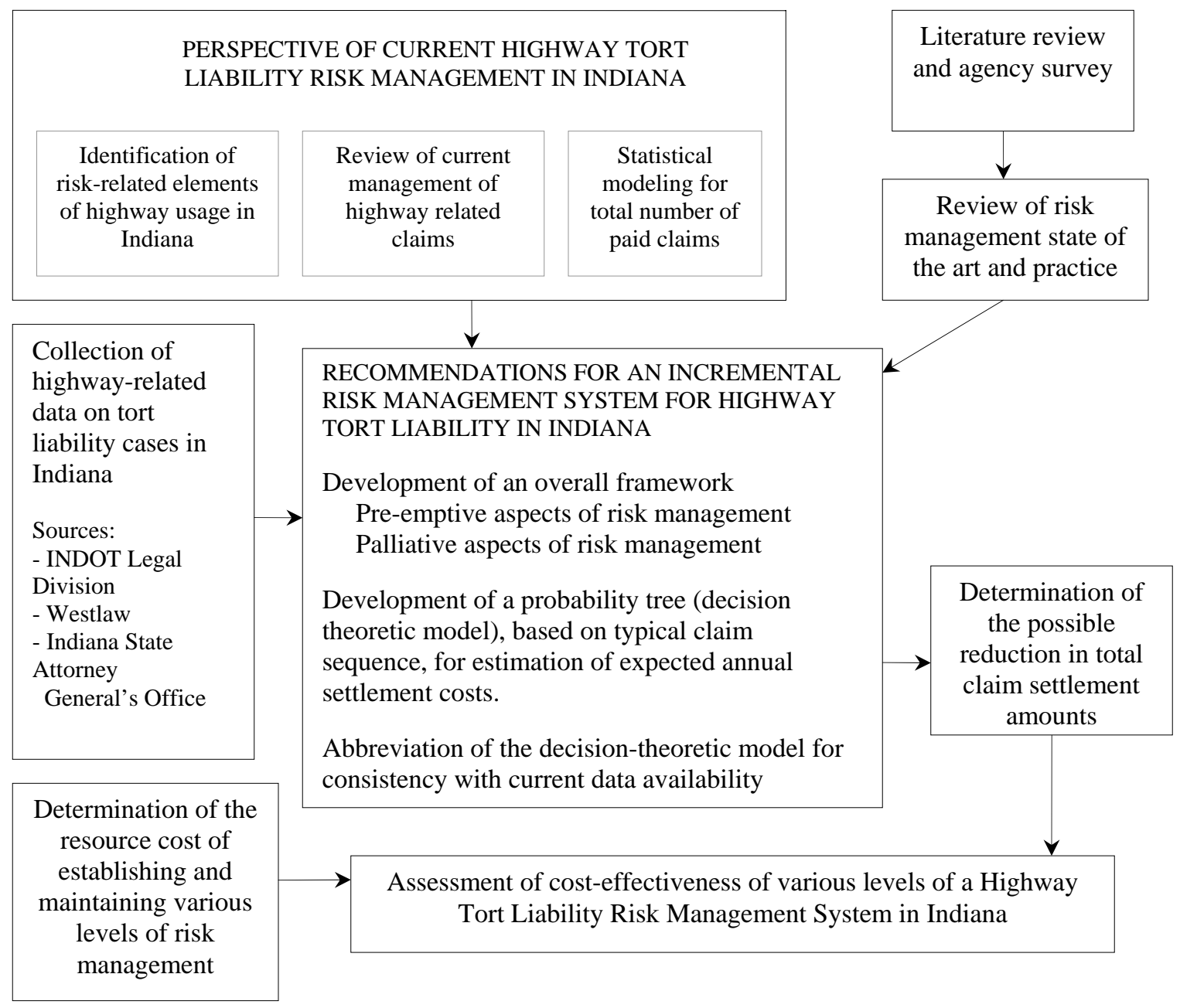

Figure 1: Study Framework 


\section{CHAPTER 2: REVIEW OF AVAILABLE LITERATURE ON HIGHWAY TORT LIABILITY RISK MANAGEMENT}

The literature review for the present study was carried out to highlight various definitions, risk management issues and problems, extent of the problem, and areas of concern in highway tort liability risk management. Also past research on state programs and initiatives were reviewed. Finally, a review of past work on the requisite tools for implementation of a highway tort liability risk management program was made and is briefly presented in this chapter.

\subsection{Definitions}

One of the earliest work done in the area of transportation related risk management was by Edson [1980], who defined risk management as "the management of a work program that is implemented after all possible impacts are analyzed in an effort to minimize the aggregate expenditure of funds.” That study proposed that such expenditure should be the dollar value of all impacts to the agency, citizen, or motorist. The researcher cautioned that in developing a risk management program, it would be important to determine the objectives, to identify risks acceptable to the agency, and to evaluate the alternatives to accepting the risk either through elimination or transfer of the risks to another source. Datta [1996] defined risk management as "the identification, measurement and treatment of exposure to potential crashes and tort liability”.

\section{$\underline{2.2}$ Issues and Problems}

Through a summary of information on highway tort suits as reported in literature and in a survey of state practice and experience, Hoel et al. [1991] illustrated the tort liability issues and problems faced by state DOTs. The authors stated that because most highway tort claims were settled out of court or at the level of a state's court of claims, and because very few states published opinions of their courts of claims, very little specific information had been published. The study listed the common areas and preventive measures and concluded with guidelines on how states might use risk management to reduce tort liability. 


\subsection{Extent of the Problems}

Anderson [1990] reviewed the findings from a previous TRB-sponsored study concerning tort liability cases. He found that annual claims increased from about 2,000 in 1972 to about 25,000 in 1986, and that total tort claims expenditure, in constant dollars, increased by about 350\% between 1978 and 1987. The review found that types of claims differed from state to state, and included flying objects, slip and fall, insufficient warning of hazard, defective road surface, defective design, potholes, and failure to maintain. Finally, that study determined that most states had in place some form of tort claims act, which allowed for jury trial and established a ceiling on the amount of monetary damages that could be awarded to claimants.

\section{$\underline{2.4 \text { Areas of Concern }}$}

From the literature review, major areas of concern included: highway planning and design, maintenance, traffic maintenance (work zones) during construction, and other areas such as general safety, intelligent transportation systems (ITS), and hazardous materials routing. Past studies that addressed highway tort liability risk management issues from these perspectives are discussed below.

\subsubsection{Highway Planning and Design}

The issue of highway tort liability risk management has been addressed from the perspective of highway facility design standards. Thomas [2003] stated that if there is one area of highway activity that may be considered to be generally immune as a protected exercise of discretion, it is the one of highway design. Anderson [1986] discussed nation-wide risk management concerns from the perspective of facility adequacy, vehicle size, and driver characteristics, and stated that stopping sight distances, as of the time of study, were generally inadequate for trucks. He proposed that road agencies and legislators should pay more attention to driver qualifications and improved truck design, and called for studies to quantify the hazards resulting from allowing increased truck sizes on existing inadequate roads. Cooley [1996] contended that risk management should evolve from the focus on physical facility characteristics to enhancement of the language and clarity of design standards in order to avoid ambiguities in interpretation and to reduce to frequency of lawsuits. Arguing that an appreciation of the benefits of risks identification and analysis was needed in the early phase of metropolitan transportation planning and public sector investment in general, Mehndiratta et al. [2000] analyzed results of interviews and discussions made with highway and 
transportation planners. The researchers concluded that there was still room for improving many of the current responses to risks associated with transportation investments.

According to NCHRP's publication titled "Selected Studies in Transportation Law" the primary defense to a state's tort liability for negligent design and maintenance is based on the theory that certain actions taken by state government are "discretionary" in nature and are therefore immune from suit. In this regard, transportation agencies may claim immunity for all decisions involving the planning and designing of projects, even if the approved plan or design either has a defective feature or omits a required feature [Thomas, 2003]. The publication further states that some courts recognize that design generally involves the consideration of broad policy factors protected by the discretionary function exemption, but provide exceptions to immunity, for example, where the plan or design was approved without due deliberation or study, or where it was unreasonable or arbitrary. At a later time when the plan is found defective or inadequate (and subsequently, poses a danger to the traveling public) due to for instance, changed physical conditions, then the state may be responsible for remedying the unsafe condition or to giving adequate notice to the traveling public. In some states, design immunity statutes have been enacted by legislature, but such statutes may not absolutely protect the state from any tort action associated with its duty of designing public property. Duly noting that an effective risk management program was essential for improving road safety and a coordinated legal defense effort, Anderson [1992] discussed the experience of the State of California, where the modification of its design immunity led to changes in perceptions of risk management. The researcher suggested that it would be beneficial for road agencies to collect and analyze cases won and lost by highway agencies, as well as the underlying reasons for any court losses.

\subsubsection{Design Immunity Statutes}

NCHRP's publication titled “Selected Studies in Transportation Law” stated that a few states not only have a provision in the tort claims act exempting discretionary activities from liability, but have also sought to give further impetus to the rule that an approved highway plan or design is not actionable for injuries resulting therefrom. The NCHRP publication refers to case where it was stated that the rationale behind statutory design immunity is to avoid the situation where a jury would reweigh the same factors that had already been considered by the governmental entity that approved the design. According to NCHRP publication, for the state to have design immunity, it must establish a causal relationship between the plan or design and the accident, discretionary approval of the plan or design prior to construction, and the existence of substantial evidence supporting the reasonableness of the adoption of the plan or design. Regarding approval, it has been held in most past cases that a detailed plan drawn up by a competent engineering firm and approved by the city 
engineer in the exercise of his discretionary authority was "persuasive evidence" of the element of prior approval. It is worth noting that even in states having a design immunity statue, such protection may not necessarily provide for immunity in every situation involving an allegedly defectively designed transportation project: there may be an exception to design immunity where the highway in actual use has a design feature that was not approved in the overall plan or design of the highway.

\subsubsection{Duty to Improve the Design Due to Changed Circumstances}

NCHRP's publication titled "Selected Studies in Transportation Law" further stated that the initiation of design studies, recommendations for highway improvements, and the commencement of improvements are themselves discretionary and do not constitute a burden on the state to complete the preliminary work [Thomas, 2003]. The NCHRP publication states that there may be limited immunity for negligent design under the exemption for discretionary activity. However, such immunity may not be available if it can be demonstrated to the court that the design decisions were made arbitrarily or without an adequate or reasoned basis. Design immunity statutes may be important to the transportation agency in protecting design decisions from liability, but such immunity may not be available in cases where it is established that a design has become dangerous in actual use or that a hazardous condition exists because of changed physical circumstances.

\subsubsection{Absence of General Duty to Install Warning Signs, Traffic Lights, or Pavement Markings}

The NCHRP publication further stated that providing highway warning signs, traffic signals, or pavement markings are important tasks for transportation agencies in providing safe roads and highways [Thomas, 2003]. Therefore, such agencies may be held liable for negligence in providing or in failing to provide adequate facilities as required by the circumstances. The courts have held, however, that in the absence of a statute, the state has no general duty to install or provide highway signs, signals, or markings. The NCHRP publication noted that a duty may arise to install such devices at the location of a dangerous condition, a "point of hazard," or a "point of special danger." The initial inquiry, thus, is whether the state has any duty in the first instance to provide highway warning signs, traffic signals, or pavement markings. According to the NCHRP report, numerous cases hold that failure to provide such highway aids is not actionable, particularly if the state had discretion regarding what action or response was appropriate. 


\subsubsection{Duty to Warn of or Correct Known Dangerous Conditions}

The NCHRP report states that where the state or other governmental entity has actual or constructive notice of a dangerous condition, it has a duty either to correct the condition or to give notice thereof by warning signs or signals [Thomas, 2003].

\subsubsection{Traffic Signals}

In a discussion of past cases involving specific roadway elements, the NCHRP report observed that there is a split of authority as to whether the state or other public agency is liable for failure to erect traffic signals, but notes that most jurisdictions appear to hold that the decision whether or not to provide traffic signals is either the exercise of immune discretion or the performance of a purely governmental function [Thomas, 2003].

\subsubsection{Pavement Markings}

Issues associated with pavement markings may be also be a source of highway tort liability, and there have been cases where states have been held liable for improper, inadequate, or misleading pavement markings [Thomas, 2003]. In a case in New York, for instance, the claimant sued the state for negligence in constructing, maintaining, and safeguarding a highway - because there were no pavement markings, the road seemed to proceed straight ahead, when, in fact, it curved to the east. In its judgment, the court held that the curve was dangerous and that the state was negligent in failing to provide proper warnings and barriers. In a few cases involving pavement markings, transportation agencies were held liable for negligence in providing an improperly marked and striped portion of the highway, as the courts ruled that the agency's actions were low level and that operational maintenance activities did not fall within any immunity for discretionary functions [Thomas, 2003].

\subsubsection{Guardrails and Other Barriers}

NCHRP's publication "Selected Studies in Transportation Law” stated that the discretionary function exemption has occasionally been successfully asserted as a defense in tort cases involving absence of guardrails or other barriers. In such claims, the courts have generally held that the provision of similar improvements elsewhere is not evidence of negligence or a basis for the state's liability. Furthermore, a delay in installing or erecting a guardrail or other type of barrier may not be unreasonable in view of the scope of the overall larger project of which such installation of protective devices forms a part. In a past guardrail-related court case involving a car that struck the buried end of a guardrail, the court held that it was reasonably foreseeable that a motorist would leave the road at excessive speeds and vault over the guardrail. In affirming a judgment against the 
state, the court noted that the state had reasonable notice of a prior accident in the same vicinity of the guardrail in question. The NCHRP publication therefore stated that a state may be liable for failure to upgrade or correct a guardrail defect during highway pavement resurfacing [Thomas, 2003]. In a past case, a court even held that the state was negligent in spite of the discretionary function exception and even though the driver was intoxicated and traveling at a high speed. In that case, it was held that the discretionary exception did not apply to the transportation agency's decision to reconstruct a bridge to standards below that which were applicable at the time of reconstruction. Also, in a case involving the reduced height of a bridge railing, the court held that the decision was an operational one to which the discretionary exception did not apply. The NCHRP publication also referred to a case in Indiana where the court held that the State was not immune from suit under a 20-year design immunity statute where it held that the State "substantially redesigned the guardrail in 1980 when it removed over100 feet of the existing guardrail and installed the BCT end-treatment.” However, it was also held that the State was immune to the extent that the plaintiffs' case rested on the State's allegedly negligent construction of the original guardrail [Thomas, 2003].

Design decisions based on budgetary or other economic constraints are generally seen as discretionary in nature. In a past case, a local transportation agency in New York argued that its failure to replace a barrier was due to funding priorities. However, the agency presented no evidence on planning, ordering of priorities, or limitations on available funding, and was therefore held liable for injuries caused by the defective barrier [Thomas, 2003].

\subsubsection{Maintenance}

Thomas [2003] stated that the primary defense to the state's tort liability for negligent design and maintenance is based on theory that certain actions taken by government are "discretionary" in nature, and, are therefore immune from suit. The publication contended that it is not possible simply to categorize decisions involving construction or maintenance activities as purely operational in character and, therefore, not worthy of protection under the discretionary function exemption. In a similar line of reasoning, the publication stated that the mere labeling of an activity as being either a “design" or a "maintenance” function has often been rejected as an unsatisfactory test to determine whether a particular activity should be immune under the discretionary function exception. It is obvious that when the transportation agency has knowledge of a hazardous condition, the agency has a duty to correct the defective condition or to give adequate warning. Thomas [2003] observes that the courts have held that the discretionary function exception is not applicable to protect the agency from liability for negligence where there was a failure to respond to a hazardous condition. In some 
instances where it can be demonstrated that a policy decision was made not to provide warning signs, there may be immunity from tort cases arising due to the absence of such facilities. However, where the agency decides to install a sign at an intersection, it has a duty to maintain it until it exercises its discretion to remove it or replace it with a more appropriate sign. The discretionary function exception may not protect the state from alleged negligence for failing to provide an adequate warning sign when the highway presents a hazardous condition [Thomas, 2003].

\subsubsection{Surface Defects}

The term "defect" has been defined as any opening, hole, depression, washout, or breakup in the road surface resulting from natural causes, ordinary wear and tear, or erosion and attrition due to weather [Thomas, 2003], but what constitutes a defect has been the subject of much controversy. The state's duty to observe roadway defects is often an issue, particularly in the absence of a statute that requires the state to have written or other notice. Past cases in various states have considered various means of imputing notice of the condition to the state. Some courts have generally held that a police officer's knowledge of a defect may be imputed to the state, or that evidence that a road had several surface defects at the accident location, was sufficient for constructive notice. However, it has also been held that the transportation agency's prior repair of a defect in the surface did not constitute notice of the defect that caused the plaintiff's accident: even with sufficient proof of notice of the defect, there may be a significant dispute concerning whether the defect was the proximate cause of the accident. According to NCHRP's publication on selected highway tort cases, cases, one court held that proximate cause existed even though the vehicle did not actually hit the pothole, while another court (on the basis of expert testimony) held that a hole of the dimensions of the involved defect was not the proximate cause of the fatal accident and that there were other possible causes of the accident [Thomas, 2003]. Anderson [1985] investigated the risk borne by vehicles as they strike potholes on the pavement surface, and examined the diverse factors that influence the degree of danger posed by any one pothole. The researcher stated that because potholes occur at new locations near recent repairs, pictorial proofs of repairs could be helpful in defending against claims and suits. The researcher advocated that pothole maintenance should be given a high priority in both risk management and maintenance management programs. Furthermore, the researcher made an important point in asserting that the minimum size of a pothole that constituted a hazard was not well defined by the courts or by research. 


\subsubsection{Snow and Ice Control}

Salting and sanding operations, dangerous conditions caused by snow or ice, use of warning signs, spot sanding operations, plowing operations, and artificial conditions that cause recurring icing may cause casualty incidents that may in turn lead to tort actions against INDOT. Thomas [2003] stated that courts generally hold that transportation agencies have no duty to undertake precautionary or remedial action to remove snow and ice conditions, unless the duty is required by law or unless the highway was so inherently dangerous that it constituted a hazard to a traveler exercising reasonable care. Courts have generally held that in the absence of a statute, there is no duty to remove general accumulations of ice and snow from the streets and highways, except when a public entity has notice, either actual or constructive, of a dangerous or hazardous condition caused by snow and ice on the highway. In such a situation, the state has a duty to exercise reasonable care, either to alleviate the hazard or to give warning of its existence [Thomas, 2003].

Furthermore, Thomas [2003] observed that a plaintiff's right to recover from a city for negligence in snow and ice removal also need not always be authorized by statute. The duty of incorporated municipalities to alleviate specific snow and ice hazards, in contrast to natural accumulations of snow or ice, existed as common law. In past cases where municipalities were held liable for negligent failure to remove snow and ice, the courts had deemed such activity to be proprietary, not governmental, in nature. In contrast, the right to sue state transportation agencies has been authorized by statute or by the courts when they abrogated sovereign immunity. However, Thomas [2003] observed that statutes that merely empower a transportation agency to take action to alleviate snow and ice hazards generally do not give a plaintiff a private right of action in tort against the agency: the generally accepted rule is that there is no duty, in the absence of statute, to remove general accumulations of ice and snow from the streets and highways. As such, where a transportation agency has notice, either actual or constructive, of a hazardous condition caused by snow and ice on the highway, there may be a duty to exercise reasonable care either by alleviating the hazard or by giving adequate warning of it. In the situation where the law imposes a duty to act on the part of the transportation agency, then the jury, or fact finder, ordinarily will be permitted to determine whether the agency has acted properly under the circumstances [Thomas, 2003]. It has been held that it would be unduly burdensome to require transportation agencies to maintain the roads free of ice at all times. Moreover, the dangers presented by icy conditions are generally known and assumed by highway travelers. In cases presented by NCHRP's synthesis of selected cases, it was found that the law did not require what was unreasonable, nor did it condemn an act or omission as negligent that could be done or prevented only by extraordinary exertion or by the expenditure of extraordinary sums of money. It was also found that liability also may be based on a condition 
created by actions of the transportation agency, such as allowing a defect to exist in a street that contributed to or caused an icy condition. The NCHRP publication further stated that in an effort to define when snow and ice conditions are hazardous (and for which the agency may be held liable) the courts have considered whether the ice or snow was rough, uneven, or rutted. Such conditions aid in determining whether traffic or pedestrians have altered a natural accumulation of snow and ice, thus creating a dangerous condition of which the public entity should have notice because of the physical change. Past cases in various states showed that transportation agencies were not liable where they had exercised due diligence in applying chemicals or abrasives to icy road hazard, such as where an accident occurred "very shortly" before the road was treated, and the authority diligently attempted, though unsuccessfully, to remedy the icy condition. It was stated that liability could be avoided where the road has been well covered by chemicals or abrasives [Thomas, 2003].

The question of whether a transportation agency may be held liable for snow and ice conditions has arisen in a variety of situations, such as for ice on bridges; for ice caused by runoff water on the road; for alleged improper warning of icy conditions; for conditions on gravel roads; for "spot sanding” of roads; and for the crews' mounding of snow against guardrails during plowing operations. With particular regard to plowing operations, there may be an issue under the applicable statute as to whether an ordinary duty of care applies or whether the plaintiff must show that there has been a breach of a "reckless disregard” standard of care. According to the NCHRP publication, although there is no duty to remove general accumulations of snow or ice that occur in the usual course of a winter storm, the courts have imposed a duty on transportation agencies to use chemicals or abrasives on the highway when they had notice of a particular or isolated hazardous condition and failed to take reasonable action. Where the duty to apply abrasives or chemicals to hazardous road conditions has been assumed or imposed by law, the transportation agency is held to a standard of ordinary care. The review of past cases showed that transportation agencies at various states have in some cases been held liable for failing to apply chemicals or sand in accordance with standard procedures in their maintenance manuals, but have in other cases been cleared when it was held that there was no evidence of actual notice to the agency of the existence of the ice on the facility, and consequently, insufficient time for constructive notice of the presence of such ice.

In sum, it would seem that transportation agencies have been given the duty of reasonable care on with respect to specific, hazardous snow or ice conditions, as distinguished from general conditions or natural accumulations of snow and ice which are generally consistent with immunity. 


\subsubsection{Other Areas of Concern in Risk Management}

\subsubsection{Pedestrian Safety}

The issue of risk management from the perspective of pedestrians was addressed by Anderson [1993], who examined published case law in order to present a better understanding of non-motor vehicle pedestrian accidents, and developed guidelines for transportation agencies to improve decision making as regards pedestrian safety. The author discussed recent court cases relating to accidents on pedestrian facilities, particularly sidewalks.

\subsubsection{Intelligent Transportation Systems (ITS)}

Recognizing that litigation was often cited as the major institutional constraint, Bagby and Gittings [1999] investigated the management of litigation risk for intelligent transportation systems. In the first part of their research, the authors focused on the analytical tools needed for highway risk management, while the second part was dedicated to the issue of tort, product liability, and privacy laws for ITS deployment. Other work regarding the management of risk in response to deployment of various ITS components such as Automated Vehicular Systems (AVS) and Electronic Toll Collection (ETC), was carried out by Bagby et al. [2000]. Also, in an earlier work, Roberts [1997] had sought to defray such future concerns associated with legal barriers to ITS implementation by asserting that under liability law, ITS is fundamentally similar to existing highway and vehicle technologies. The researcher however made an exception in the case of vehicle control: automated technologies gradually take away from the driver's command a certain number of functions, thereby shifting the burden of possible tort liability from the driver to the manufacturer of the vehicle control system.

\subsubsection{Environment}

McGuire [1995] recognized the importance of organizational coordination to effective planning and hazard mitigation particularly in environmentally sensitive areas such as the coast of North Carolina. Using three transportation projects in North Carolina as a case study, the researcher investigated the relationships between transportation improvements, coastal development and risk minimization, and determined that a major policy issue inhibiting effective planning in that area included inattention to the adverse impacts of transportation improvements and to hazard mitigation. 


\subsubsection{Hazardous Materials Routing}

Hengst et al. [1999] discussed the elements of risk involved in the transportation of hazardous materials in the Netherlands. Taking due cognizance of the high population density in that country and consequently the high premium paid to safety of highway routes, the researchers developed a risk management policy that includes the use of statistical tables to calculate risks associated with the transportation of hazardous materials.

\section{$\underline{2.5 \text { State Programs and Initiatives }}$}

A case study in highway tort liability risk management was discussed by Bair et al. [1980]. This involved the "Safety-First" initiatives launched by the Oakland County Road Commission in Michigan. These initiatives were part of an overall risk management program that was comprised of the following processes: (a) reorganization of the management decision process, (b) encouragement of all employees to participate in a road hazard identification process, (c) analyzing all identified hazards, traffic accidents (crashes), and legal claims, (d) documenting and determining priorities for project programming, (e) providing countermeasures for identified risks, and (f) evaluating the results and feeding this information back into the planning process. Gittings [1989] evaluated risk management practice at the state level with the objective of determining whether the most significant physical hazards had been properly identified and whether existing guidelines were being properly implemented. Three key recommendations arising from that study were to assign district offices the key role for risk management, creation of new positions of risk manager and tort coordinators in each district office, and the development of risk management systems and their incorporation into management performance evaluation review systems. A key aspect of risk management in the State of Alabama was reported to be the accident surveillance and roadway defect collision investigation program [Turner and Colson, 1988]. In that program, every accident was accompanied by a site review to determine whether roadway characteristics played any role in the incident, and to address any such deficiencies. According to the researchers, the implementation of this program had been highly successful in reducing court losses. Thackston and Black [1991] described an action plan for risk management in the Virginia Department of Transportation (VDOT). The first two phases of the project research involved identification of areas within VDOT that required improved risk management. The second phase involved investigation of ways to reduce the risk to human safety caused by transportation system defects, to minimize the risks of financial loss due to VDOT's tort liability, and to prepare for future "unavoidable" liability. The recommendations of the study included establishing additional cooperation between VDOT and existing state agencies to 
accomplish risk management objectives and developing training procedures and formal work response criteria for VDOT employees. Finally, the establishment of comprehensive systems for inventory, maintenance, and documentation was recommended to increase flow of information and response to highway defects.

To aid the selection of roadway improvement projects, Frohwein et al. [1999] developed a multi-criteria decision-making framework that incorporated three factors: crash-risk reduction, performance improvement, and project cost. The researchers stated that the decision tool they developed enabled comparisons between very diverse alternative projects on a common ground and provided information on the trade-offs associated with the choice of any course of action. The research was conducted to assist Virginia DOT in improving the way it carried out evaluation of potential roadway improvement projects. Demetsky and Yu [1992] developed a framework for evaluating existing risk management programs at state DOTs. Included in their framework were the goals and objectives of state DOT maintenance divisions, and a conceptual blueprint for risk management developed using the responses from a nationwide questionnaire survey of state DOTs. Also, based on the goals and objectives of various existing risk management programs, the researchers developed criteria and methods for risk management program evaluation. The researchers compared alternatives using single- and multi-objective optimization. With the aid of computer-based simulations and optimization techniques, optimal choices were made from alternative risk reduction actions.

The nationwide survey conducted by Demetsky and Yu [1993] assessed risk management procedures and objectives at state DOTs. That survey identified the various actions of a state and its employees that could constitute a liability. Also, the status of states' risk management programs (i.e., whether a state had established a formal risk management program to reduce liability for its actions and those of its employees) was assessed. Concerning the status of tort liability, it was found that regarding the level of immunity, there was significant variability among the thirty-eight (38) responding states. All states but one had lost their sovereign immunity, but some states had reinstated a partial immunity such as the employee-immunity or the design immunity. Some commonalities between states were also identified. For instance, in 1993, all responding states had the same monetary limit for an individual claimant: $\$ 250,000$ (equivalent to $\$ 350,000$ in 2001). Also, all but one responding state had the same limit for aggregate claims for one accident: \$1,000,000 in 1993 (equivalent to $\$ 1,430,000$ in 2001). The survey indicated that the type of negligence law prevailing at a state influenced the status tort liability at that state. Negligence laws are either comparative or contributory (Table 1). 
Table 1: Definitions of Various Categories of Negligence

\begin{tabular}{ll}
\hline \multicolumn{1}{c}{ LAW } & \multicolumn{1}{c}{ DESCRIPTION } \\
\hline Contributory Negligence & $\begin{array}{l}\text { The plaintiff is barred from recovering damages for the } \\
\text { accident for which he/she also was at fault. }\end{array}$ \\
\hline Comparative Negligence & $\begin{array}{l}\text { The driver is not barred from collecting damages, } \\
\text { because he/she was also at fault. }\end{array}$ \\
\hline Pure Comparative Negligence & $\begin{array}{l}\text { A DOT could be required to pay the full amount of } \\
\text { damages even if most fault is due to the plaintiff and } \\
\text { relatively little fault is due to the DOT. }\end{array}$ \\
\hline $\begin{array}{l}\text { Modified Comparative } \\
\text { Negligence }\end{array}$ & $\begin{array}{l}\text { A plaintiff must prove that the DOT is over 50\% at fault } \\
\text { in order to recover any damages from the DOT. }\end{array}$
\end{tabular}

Source: Demetsky and Yu [1993].

In the 1993 survey by Demetsky and Yu, Most states indicated that they had a comparative negligence law, and that the researchers believed that states with such laws were associated with higher levels of tort liability. Indiana generally has a "contributory negligence law”. The state also has a modified comparative negligence law if the plaintiff is a private company. In this latter case, the private company must be responsible for over $50 \%$ of the accident for the claim to be deleted. With contributory law, if the plaintiff is at fault, the entire claim is rejected without resorting to court. With comparative law, most claims reach court, and then the jury decides the case.

Concerning the status of risk management programs, Demetsky and Yu [1993] found that 21 out of 38 responding states had some form of risk management program and that three other states were in the process of developing one. The researchers determined that most risk management programs generally involved the following tasks: hazardous situation identification, reaction to notification, prioritization, documentation, time limits (response), claims handling, criteria for litigation, and information systems.

Methods of hazardous situation identification included litigation trends, traffic engineering experience, site investigation, observations by employees and police, etc. Thirty-one states indicated that for identifying hazardous locations, they use of at least the three following mechanisms: citizen complaints, accident reports, and routine inspections.

With regard to agency reaction to reported hazardous situations, the Demetsky and Yu study found that when a notice of a hazardous situation was issued, most state DOTs promptly take corrective measures to remedy the defect or to forward the notice to the appropriate division. However, specific procedures to address hazards differed from state to state. 
For priority determination for a number of hazardous situations, the 1993 survey found that most states use a categorical or numerical index to denote the degree of hazard. The degree of hazard had a different definition for each state, but it typically referred to a natural classification of the severity of consequences if no action was taken. For example, life threatening hazards were given priority over those that were not life threatening. A few states (Texas, Iowa and Colorado) used mathematical formulas to determine priorities, while about one-half of all responding states kept track of notices and actions taken to get a better defense in case of claim, and also had established a time limit for responding to reports of typical defects, and such time limit depends on the nature and location of the defect. Also, many states kept a record of all claims and classified claims for further use, while a few states used the information to establish risk management priorities.

The survey by Demetsky and Yu [1993] also found that states preferred to settle than to go to court if they estimated that the probability for them to lose the case was high. That finding seems to support the need for states to adopt a decision theoretic decision tree approach to risk management system evaluation. The probability at each stage of the tree could be obtained from historical data. It was also found that many states store highway tort liability information on centralized information systems, and process accident information in the form of reports in order to track hazardous locations and identify trends in tort litigation. As part of the present study, an Internet search was conducted, and state DOT websites were visited to document and assess the state of the practice of risk management. Also, a questionnaire survey was designed and sent to all 50 states in order to obtain current documentation on the state of risk management practice. The results of the current survey, which are presented in the next chapter, shows that current highway tort liability risk management practices have not changed much from those in 1993.

\section{$\underline{2.6}$ Tools of Implementation}

\subsubsection{Structure}

Gittings and Jacobs [1990] discussed the evolution of Pennsylvania DOT’s risk management process, which the authors considered to be in a relatively mature phase of development compared to most other states. The study described risk management initiatives and challenges encountered, and provided recommendations for overcoming obstacles to the development and implementation of risk management procedures for the state.

With the assumption that a liability reduction strategy would expose threats in a timely manner, Reed [1988] identified basic factors in any liability reduction scheme as follows: 
recognizing the degree of legal risk inherent in programs and actions; ensuring that available resources are used to achieve maximum risk reduction; preparing timely defense response for actual or threatened legal actions; and managing claims for resolution and economy. As knowledge of problems is obviously a major requirement, the author suggested that system inspection and monitoring should be carried out to aid timely notice, and discussed techniques for maximizing information management regarding the problem.

Tools of implementing highway risk management practice in Michigan's DOT were presented by Datta et al. [1991]. Such implementation tools consists of the following: the use of a risk management user guide by local government policy makers, a training program for local agency supervisory staff, and follow-up assistance in implementing risk management principles. The researchers also discussed the potential benefits of such a system.

\subsubsection{Database}

The critical importance of a risk management database has been stressed in several studies. Turner and Colson [1988] specifically identified the benefits of data to risk management and described several innovative accident data programs. According to the researchers, accident data are an excellent tool for reducing overall risk by identifying those sites that are of greatest risk to motorists and thus most deserving of safety treatment. Datta [1996] also addressed the importance of data not only on accident histories, but also on accident potential of roadway sections and locations. Defining risk management as "the identification, measurement and treatment of exposure to potential crashes and tort liability”, Datta discussed the uses of both objective and subjective parameters in the assessment of potential risk in a number of communities in Michigan, with a view to policy formulation for risk mitigation. Unlike most studies that focused on facility data, Choate [1999] discussed the importance of road user data, among others. He argued that the concept of an integrated traffic safety risk management information system could include existing databases for driver licenses, vehicle registrations, traffic records and fatality analysis.

\subsubsection{Training}

In 1990, the Education/Training Subcommittee of TRB Task Force on Torts performed a limited survey of the type and amount of risk management training administered to state highway agency employees [Turner, 1990]. The survey documented existing types of training, identified additional training packages, and made recommendations for future types and modes of training. The study also included a discussion of governmental and professional agency programs, and selected tort liability cases. 
Risk management at the Kentucky Transportation Commission has included a review and analysis of tort liability cases in the state, and the development of training material for highway personnel [Turner and Agent, 1992]. The training material was prepared to address the tort liability problems that were increasingly faced by that state's transportation agency. The workbook reviewed national cases and escalating losses from suits against highway agencies, and outlined solutions geared towards reduction of the frequency and magnitude of such losses.

\subsection{Chapter Summary}

The above review of literature on previous research and the state of the practice generally indicates that at the present time, many states have reached a relatively more advanced phase in the practice of highway tort liability risk management, compared to the State of Indiana. The review also shows that it is feasible to develop and implement a risk management program to address highway tort liability in the State of Indiana, and that such a program could be beneficial to the state in a variety of ways. The review also provided an insight into the various elements and tools that may be needed in designing and implementing a possible future risk management program for the state of Indiana.

The next chapter presents the results of a state of practice agency survey that was carried out to complement the literature review, and to shed more light on current practices on highway tort liability risk management. 


\section{CHAPTER 3: STATE OF PRACTICE AGENCY SURVEY FOR HIGHWAY TORT LIABILITY RISK MANAGEMENT}

In a bid to acquire information on the experiences, observations and evaluations of other states regarding highway-related tort liability and associated risk management, a questionnaire survey was designed and sent out to all 50 states. It was expected that such information would be beneficial in assessing where the current tort liability or risk management practices of other states stand in relation to those of INDOT. The survey instrument used for the survey is attached as Appendix $\mathrm{J}$ to this report. The first part of the questionnaire solicits information on the status of tort liability at the state while the second part focuses on any current practices of highway tort liability risk management. The following state transportation agencies responded to the survey:

- California DOT

- Hawaii DOT

- Idaho DOT

- Michigan State DOT

- Mississippi DOT

- Missouri DOT

- Nebraska Department of Roads

- Ohio DOT

- Oklahoma DOT

- South Dakota State DOT

- Tennessee DOT

- Vermont DOT

- Wisconsin State DOT

- District of Columbia Transportation Department

Subsequent sections of the present chapter present and discuss the survey responses and describe how highway tort liability risk management program in each state is addressed by that state's transportation agency or other agency to which such duties have been assigned. 


\subsection{Status of Tort Liability}

The current agency survey showed that of the 13 responding states, only three have full sovereign immunity against highway-related tort suits. Most of the responding states have reinstated partial immunity such as design immunity which results in liability only for construction or improvement to the highways, roads, bridges, or other public properties, and maintenance-related activities. Some states have waived sovereign immunity for dangerous conditions, weather conditions, or discretionary functions.

In a bid to control the size of tort liability costs, most states have established monetary limits for highway-related tort claims. The limits imposed for each individual claimant do not exceed $\$ 500,000$ for all responding states. Furthermore, for all states except Missouri, the limit for cumulative claims from each accident does not exceed $\$ 1,000,000$. The limit in Missouri for cumulative claims is $\$ 2,145,000$.

The survey found that one approach used by states to control tort liability costs has been to adopt a negligence law which can be either contributory or comparative. Table 1 in Chapter 2 defines both categories of negligence. Most of the responding states indicated that they currently adopt comparative negligence law. With this law, most of the claims reach the courts, where a case is decided by a jury and typically ends up with some payment to the claimant. The respondent from South Dakota stated that the state has adopted a contributory negligence law where the entire claim is rejected without going to court if the plaintiff is at fault.

\subsection{Status of Risk Management Programs}

It was found that 10 out of 13 responding states have explicit risk management programs within the DOT to address highway tort liability issues. Some states indicated that their risk management programs have a potential of reducing tort liability claim frequency and amounts, but up to this point it has not had much apparent success. Respondents also indicated that some staffs in their agencies were specifically assigned to management of highway tort liability risks. Many states have committees consisting of lawyers, engineers, and representatives from design, construction, and operations divisions who meet regularly to establish and evaluate risk management policy and to seek solutions to specific risk management problems. For instance, the respondent from Oklahoma stated that his state has attorneys to handle claims and litigation, in-house risk managers to investigate claims, and a risk manager (or investigator) to work with attorneys. Also, the respondent from Idaho DOT stated that his state has an Employee Safety \& Risk Manager (who reports to the 
Administrative Services Division) and a District EEO/Safety \& Training Coordinator (who investigates all tort claims, provides documentation for defense, and makes recommendations about remedial actions to district management). The respondent also stated that the Employee Safety \& Risk Manager is charged with the additional responsibility of liaising with legal staff to assess certain highway tort liability cases, publishes a report to management, and makes tort reduction recommendations every two months.

\subsubsection{Hazardous Situation Identification}

The questionnaire survey showed that 10 of the 13 responding states identify hazardous situations in three ways: citizen complaints, accident investigations, and special design and maintenance procedures. Five states also use central operations center and/or review of pass tort claims. To identify hazardous locations, some states carry out roadway monitoring, hazardous elimination program, field reviews, and annual high accident location review.

\subsubsection{Hazardous Situation Response}

The respondent from Tennessee DOT stated that when notified of a hazardous situation, the state DOT conducts in-depth review of data collected under the hazard elimination program, and then its traffic engineering unit conducts field reviews and develops possible solutions and recommendations. At the state of Wisconsin, the DOT analyzes various options and selects an appropriate treatment that is then implemented and its performance monitored over a period of time.

Like these states, Idaho DOT responds to a hazardous situation report by contacting the responsible organization, then discusses and prioritizes remedial measures. Some adjustments are made to revise recommended treatment for a potential hazardous location. The survey revealed that for most responding states, hazardous situation response depends on scope, cost and nature of the potential hazard. For example, the respondent from Vermont DOT indicated that relatively minor problems are handled by district maintenance forces, while the resolution of larger problems is generally made to wait for federal-aid project programming.

\subsubsection{Time Limits for Responses}

Of the 13 responding states, 8 stated that they specifically address the time limit within which an identified hazardous location should be remedied, stating that the response time limit depends on the nature of the risk, type of remedy selected, and type of defect. The Ohio DOT, for example, has established a time limit of 1-2 days for responding to relatively minor defects such as potholes, and 1 week or more for relatively major defects that require special equipment materials 
(e.g., guardrails for steep and high unprotected embankment). For the state of Mississippi, the respondent stated that the Tort Claims Board generally accepts constructive notice after 10 days.

\subsubsection{Priorities Determination}

Most of the responding states determine the priorities between competing potential hazardous locations by establishing ranking priorities. These ranking priorities are based upon the number of accidents, hazard exposure and experience (accident history). One respondent stated that situations involving maintenance are set to be the highest priority. However, areas with defects such as rutting generally require more extensive work, are slower to be repaired, and are therefore set to be lower priorities. It is therefore obvious that defects which are easy to remedy are given higher priority compared to those that are difficult to remedy, all other factors being the same. Some states use a subjective approach such as engineering judgment or management decision to set the level of priorities. Such judgment is often based on past experience and accumulated knowledge of the area and also of the type of defect. For instance, high consequence hazards that cause an immediate risk to human life or safety are dealt with instantaneously and low probability hazards are dealt with whenever time and resources permit. In addition, of the 13 states responding to this question, two states use mathematical formulas to evaluate crash severity for determining priorities.

\subsubsection{Settlement}

The respondents from seven states stated that $0-10 \%$ of the time, they settle cases by arbitration instead of going to court. However, in some states, the likelihood of going to court varies according to the type of claim. At Ohio for instance, the survey showed that motor accident cases go to court $0-10 \%$ of the time, while construction related cases go to court $60-70 \%$ of the time.

\subsubsection{Additional Strategies}

A majority of the responding states have training programs to teach employees about risk management practices. In California DOT, there are several 1-day and 2-day programs to instruct employees on ways to reduce the department's exposure to tort liability. The Office of Legal Counsel in the state of South Dakota DOT periodically provides risk management training and education to DOT employees. Respondents from other states indicated that risk management seminar programs, presentations and conferences, are conducted regularly. An email list-serve of program contacts is also used to disseminate information on safety topics. The California DOT uses retired former trial lawyers to assist in training key employees on how to be effective witnesses in highway tort liability court cases. 


\subsection{Risk Management Program Objectives}

From the survey, it is interesting to note that only three out of 13 states responding have clearly established objectives for highway tort risk management which are to review all tort claims, identify preventive actions, educate employees and endeavor to reduce tort claim incidents. Nevertheless, the respondents stated that there is currently very little documentation that explicitly describes such objectives. An example of such documentation is Oklahoma's Governmental Tort Claims Act.

\section{$\underline{\text { 3.4 Risk Management Program Evaluation }}$}

Of the 13 responding states, 6 states regularly evaluate the results and the performance of their risk management programs. Three states use the total number of all claims filed or paid and the total cost of all claims filed or paid as the criteria for evaluation, while one state specifically uses the number or rate of accidents for evaluation. The Wisconsin DOT uses other criteria of customer satisfaction and partnerships. Only one state stated explicitly that its program is not evaluated.

\subsubsection{Risk Management Effectiveness}

The survey showed that one-half of the states responding stated that their risk management program has helped significantly in reducing overall tort liability costs in their DOT. For example, as a result of numerous in-house training classes in California, employees are knowledgeable of the risks and of actions that they can take to reduce the tort liability costs. Also, the state of Michigan replied about the useful risk management program in that cases are better managed from the DOT's standpoint, appropriate witnesses are used for each case, and DOT is in a better position for settlement and trial strategies.

The respondent from the Idaho DOT indicated that the increase DOT tort claims is attributable to increased exposure of road users to incidents which is in turn due to increases in the volume of vehicular travel and also in highway maintenance work. However, the respondent aptly noted that without the current risk management program, tort claims would likely be higher than current levels.

\subsubsection{Funds for Future Claims}

Most responding states stated that they can determine the amount of funds needed to be set aside for paying all future claims that may be deemed unavoidable. The departments of finance and 
administration of such states determine these amounts primarily based upon number of employees, past historical basis of claims, actuarial studies and settlement figures. In some states, only a nominal amount is set aside for future claims. Settlements and judgments are generally paid through the annual appropriation bills. At the State of Vermont, for example, the state's self-insurance program charges premiums to individual departments and agencies based upon 5-year rolling average of claims paid. There are also funds which are used as expenses paid for tort claims. Ten (10) out of 13 responding states indicated that such funds are administered by their state DOT. The State of Idaho's Office of Insurance Management (OIM) provides coverage and manipulates claims for all state agencies. It also takes charge of providing claim payments, legal fees, and expenses. In the state of South Dakota, however, the Public Entity Pool for Liability Fund (PEPL) is maintained to pay defense costs and judgments for employees found to have tort liability.

\section{$\underline{3.5 \text { Chapter Summary }}$}

This chapter documents the state of practice of highway tort liability risk management at various states. Such information is useful in evaluating the current status of the INDOT program, and

in assessing the need for a risk management system for Indiana Department of Transportation and to assess where a current program stands with respect to similar programs in other states. The results of the survey showed that unlike Indiana, most states have an office or program explicitly set up to manage risks of highway tort liability. The next chapter provides a perspective of current highway tort liability claims in Indiana. This would constitute the initial building blocks for any possible future system to manage highway tort liability risks for the state. 


\section{CHAPTER 4: A PERSPECTIVE OF CURRENT HIGHWAY LIABILITY TORT CLAIMS IN INDIANA}

\subsection{Claims Management}

The previous chapter presented the results of an agency survey carried out as part of the present study. The survey showed that unlike Indiana, most states have established an office or program to manage risks of highway tort liability. Recognizing that there exists a potential for Indiana to start up an explicit highway risk management program using the state Attorney General's current practices of tort claim settlements and data management as a stating point, the present chapter presents the current state of the practice of tort liability settlement for cases involving INDOT. The chapter is based on information gathered from INDOT's Legal Division and the Indiana Attorney General's Office.

In the current situation at INDOT, each claim received by the department is forwarded to the Attorney General's Office for processing by that office's Investigation Division. Most of these claims are denied by the Attorney General's Office, as they are often not backed by sufficient evidence. A few claims are settled by the Attorney General's Office, thus avoiding the time and monetary costs of a trial. In certain cases, the Attorney General's Office sends claims to court rather than settle. Also, some claims that are denied by the Attorney General's Office are sent to court by the plaintiffs, but according to the Investigation Division, these cases are very few because people tend to shy away from possible high costs of court cases. The costs of claim settlement are borne by the Attorney General Office's and not by INDOT. Therefore, INDOT's budget is not affected by tort liability cases involving the use of its facilities.

Upon receipt of a claim from INDOT, the relevant details of the claim are entered in a database administered by the Attorney General's Office. This database contains data on all filed claims against various departments of the state. Therefore INDOT-related cases constitute only a small subset of this database. Currently, hardware and software problems make the use of this database quite cumbersome and this seriously impedes efficient management of claim data. Extraction of even simple information from the database requires elaborate tasks such as the writing

of software code. According to the Attorney General's Office, efforts are currently in progress to procure a new version of the database software so that data extraction efforts can be streamlined. 


\subsection{Claims Sources Associated with Highway Infrastructure}

Claims may result from various sources on a highway system. These may be broadly classified as vehicle, operator/freight/passenger, physical highway facilities, and external elements. It is expected that an effective highway tort liability risk management system would help monitor such aspects of the transportation environment with a view to reducing the incidence of tort-prone situations. Possible components of each of such elements are listed below.

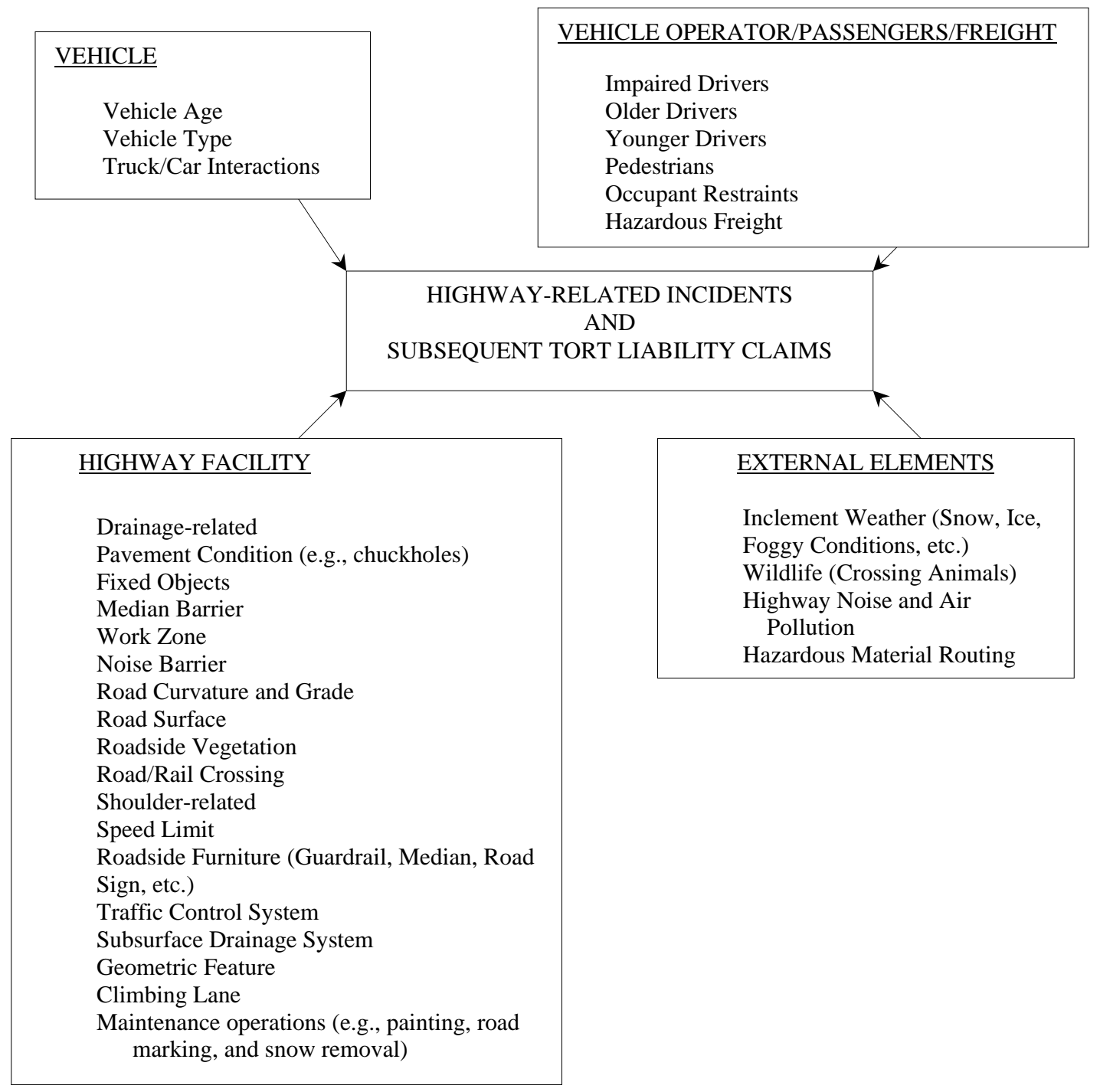

Figure 2: Sources of Highway Related Liability Tort Claims 
In 2001, the Attorney General's Office received over 1,600 claims from persons seeking damages for incidents related to the use of INDOT-managed facilities. From available literature as well as from data made available by the Indiana Attorney General's Office, the following facilities/actions were identified as the most common sources of highway related tort liability in Indiana at the present time:

- Roadway and bridge paint work

- Mowing operation

- Pavement surface defects, such as chuckholes

- Mailbox damage during snow removal operations

- Fixed objects near the roadway

- Traffic control devices

- Drainage facilities and associated problems

- Barrier structures

- Operations of state vehicles involved in highway maintenance/construction

- Work zone traffic control

- $\quad$ Shoulder-related defects

- Geometric feature defects

- Maintenance activity (other than road marking and mower claims)

- Construction activity

In the year 2001, 396 INDOT-related claims were paid. Of these, 239 claims were related to the four most frequently filed claims (referred to in this study as "common" claims) and had four categories: paint claims, mower claims, chuckhole claims and mailbox claims. Claim types other than these are referred to in this report as "other" claims. The total amount involved in settling common claims was approximately $\$ 80,000$, which is only $4 \%$ of the total $\$ 2$ million paid for all claims in the year 2001. Nevertheless, it is important to realize that processing, investigation, and other administrative duties associated with the common claims involved a significant amount of secondary cost incurred by the Attorney General's Office. Detailed data on “other” claim types were not available from the Attorney General's Office. The Investigation Division considers these other claims as mostly "unavoidable", but such characterization could be reviewed and revised after detailed future studies of such claims. The rest of the present chapter focuses on the distribution of the four categories of the common type of claims. 


\subsection{Trends in Tort Liability Cases}

\subsubsection{Data Collection for All Claims}

As part of the present study, efforts were made to collect as much data as possible from the INDOT Legal Division, the Indiana Attorney General's Office, and other sources. An Internet website that specializes on keeping records of court cases was accessed by paying a fee, for information on recent court cases involving highway related claims (www.westlaw.com). For each INDOT-related case reviewed with this website, data was gathered, such as the case reference, the type of court where the case was held, the name of the court where a primary judgment was given, if any, the cause and details involved in the claim, the date of closure, and the amount that was received by the plaintiff, if any. Of the cases identified, only 7 were highway-related. Other claims involved racial/sexual harassment or litigation between INDOT and its contractors, but such claims are outside the scope of the present study. Table 2 presents two examples of highway-related cases that were found from the Westlaw website.

Information of a general nature, such as the total annual number of filed claims, and the number of paid claims and claims that went to litigation, was provided by the Attorney General's Office. For each of the four common claim types (mower, paint, mailbox and chuckhole claims), information on paid claims included the county of the incident, the amount claimed and the amount paid (Appendices F, G, H and I).

The Investigation Division of the Attorney General's Office provided data for the years 1999, 2000 and 2001. A total of 1,657, 1,209 and 1,617 claims were filed in the years 1999, 2000 and 2001, respectively. Given the relatively little temporal span of the data, no conclusive trends in the number of cases within this time of interval could be established. Also, it is worth noting that some cases take a long time for final closure. The figures indicated do not include such "running” cases.

The total number of paid claims in 1999, 2000 and 2001 were 307, 308 and 396, respectively. Figure 3 indicates a significant increase in the total number of paid claims in the year 2001. The figure also illustrates the trend in the total number of litigations between 1999 and 2001. Fifty cases

(3\% of all cases) went to litigation in 1999 , while 45 cases $(3.7 \%)$ and 88 cases (5.4\%) went to litigation in 2000 and 2001, respectively. 
Table 2: Selected Cases Involving Highway-Related Claims

\begin{tabular}{|c|c|c|}
\hline CASE \# & 1 & 2 \\
\hline Court Type & Indiana Court of Appeals & Indiana Court of Appeals \\
\hline $\begin{array}{l}\text { Previous } \\
\text { Court }\end{array}$ & Circuit Court Clark County & Allen Superior Court \\
\hline Details & $\begin{array}{l}\text { Guardian for minor injured } \\
\text { in vehicular collision } \\
\text { brought action against state } \\
\text { for alleged negligence in } \\
\text { failing to install left turn } \\
\text { signal at dangerous } \\
\text { intersection. } \\
\text { The first judgment was in } \\
\text { favor of the State. Appeal } \\
\text { held that state had immunity } \\
\text { under discretionary acts } \\
\text { provision of Indiana Tort } \\
\text { Claims Act (ICTA). This } \\
\text { alleged act of negligence } \\
\text { was a discretionary } \\
\text { function. }\end{array}$ & $\begin{array}{l}\text { Pickup truck driver brought negligence action against } \\
\text { state arising out of injuries he sustained when his truck } \\
\text { struck snowplow operated by state employee. } \\
\text { First, truck driver had pleaded guilty (was drunk at time } \\
\text { of accident), but later (July } 23 \text { 1997) he sued the } \\
\text { snowplow driver and the state. The claim was barred by } \\
\text { contributory negligence. The snowplow driver obviously } \\
\text { made a mistake that led to the accident. He was dismissed } \\
\text { as a named defendant. The state lost, appealed. } \\
\text { The question of contributory negligence is generally a } \\
\text { question of fact for the jury. The established rule in } \\
\text { Indiana is that: “in order for an intoxicated person to be } \\
\text { deemed contributory negligent, not only must the } \\
\text { intoxication lead to negligent conduct, this conduct must } \\
\text { also be the proximate cause of the party’s injuries” }\end{array}$ \\
\hline Dates & $\begin{array}{l}\text { Closed: June } 272001 \\
\text { Facts: April } 221997\end{array}$ & $\begin{array}{l}\text { Closed: August } 92000 \\
\text { Facts: January } 271996\end{array}$ \\
\hline $\begin{array}{l}\text { Case } \\
\text { Outcome }\end{array}$ & Affirmed. State wins & State Loses \\
\hline $\begin{array}{l}\text { Settlement } \\
\text { Cost to state }\end{array}$ & None & $\$ 61,456$ \\
\hline
\end{tabular}

Source: [Westlaw, 2002]

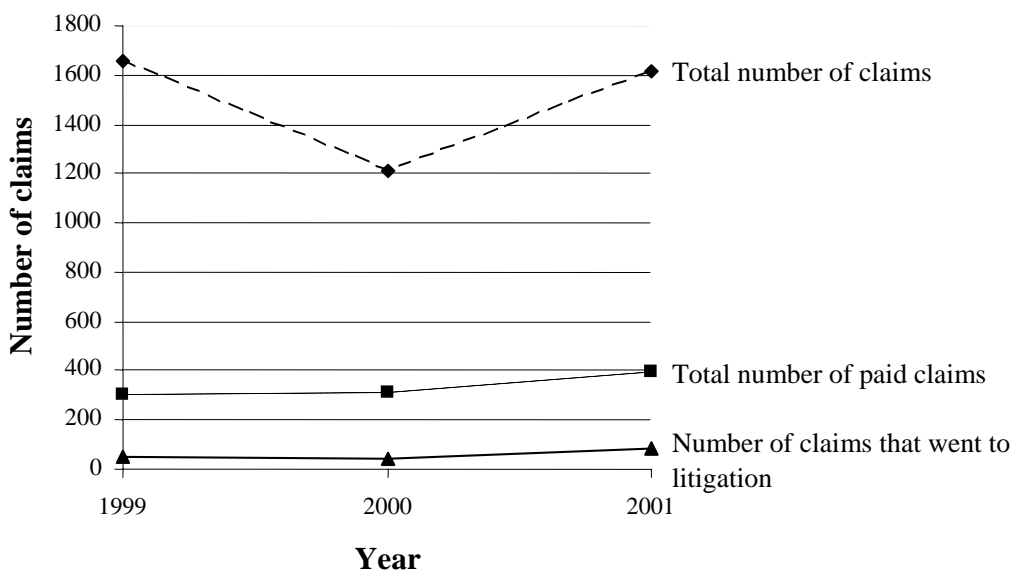

Figure 3: Highway Tort Liability Claim Trends in Indiana, 1999-2001 
Figure 4 shows the total number of claims per year and the number of claims involving the four common claim types.

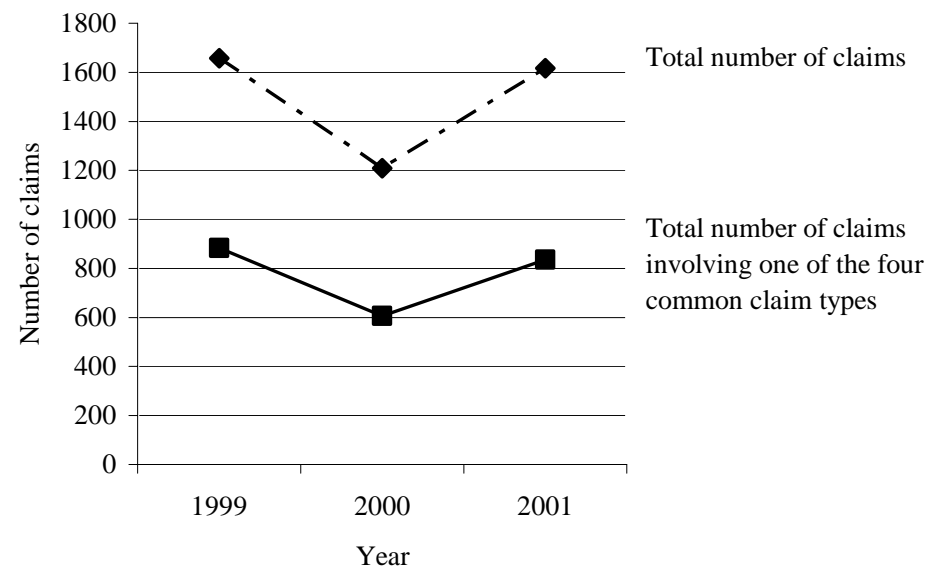

Figure 4: Trends in Frequency of Filed Claims (All Claim Types and Common Claims)

\subsubsection{Categories of Common Claims}

Details were available for paid claims for the four common claim types. These claims represent approximately 50\% of all INDOT's highway related claims received by the Attorney General’s Office.

- Mower Claims

INDOT's sub-district maintenance personnel are responsible for controlling vegetation growth along the highway right-of-way. In the course of mowing operations, it is typical for small objects such as rocks to be expelled from the mowing equipment onto the roadway, where they typically damage vehicles or sometimes strike road users. Claims brought against the state by victims of such incidents are classified as "mower claims". At the present time, INDOT uses chain devices not only to protect the motor blades, but also to minimize the incidence of rocks being expelled from the blades.

- $\quad$ Paint Claims

Pavement marking maintenance is another major source of highway tort liability claims in Indiana. During marking operations, errant vehicles run through the centerlines or lane lines, and reflective paint splatters and stains the sides of passing vehicles. Such claims are labeled as "paint claims". 
- Mailbox Claims

During the winter season, some roadside mailboxes get destroyed by snow removing equipment operated by INDOT employees. Mailbox claims represent claims associated with such incidents that are filed against the state. As the data shows, the cost of settling mailbox claims is rather low, but claims of this category are one of the most frequent.

- Chuckhole Claims

“Chuckhole,” a term used by the Attorney General's Office, refers mostly to pavement surface defects such as potholes. The Attorney General's Office receives several claims related to potholes and related road surface defects. The Investigation Division denies the claim if INDOT personnel were unaware of the defect at the time of the first reported incident. On the other hand, if INDOT had been informed about the defect but failed to undertake due repair actions on time (usually, a delay of 24 hours is the statutory deadline for INDOT to repair such defects), subsequent compensatory payment from the state is likely. Claims brought against the state by victims of such incidents are termed as “chuckhole claims".

According to the Attorney General's Investigation Division, the majority of claims, other than the four common claims, involves crashes with INDOT vehicles. Contrary to expectation, tort liability involving traffic signals or traffic signs is of relatively smaller scale. According to the Attorney General's Office, these cases are rare and are not sufficient to be considered for highway tort liability risk management in the short term. Cases involving defects in design or highway geometrics and hazardous material routing are also very few.

A large majority of cases in each of the four common claim types is denied by the Attorney General's Office. This is due to the large burden of proof that is incumbent on the claimant, by policy. Figure 5 presents the number of paid claims in the four common claim types compared to the total number of claims in those areas. 


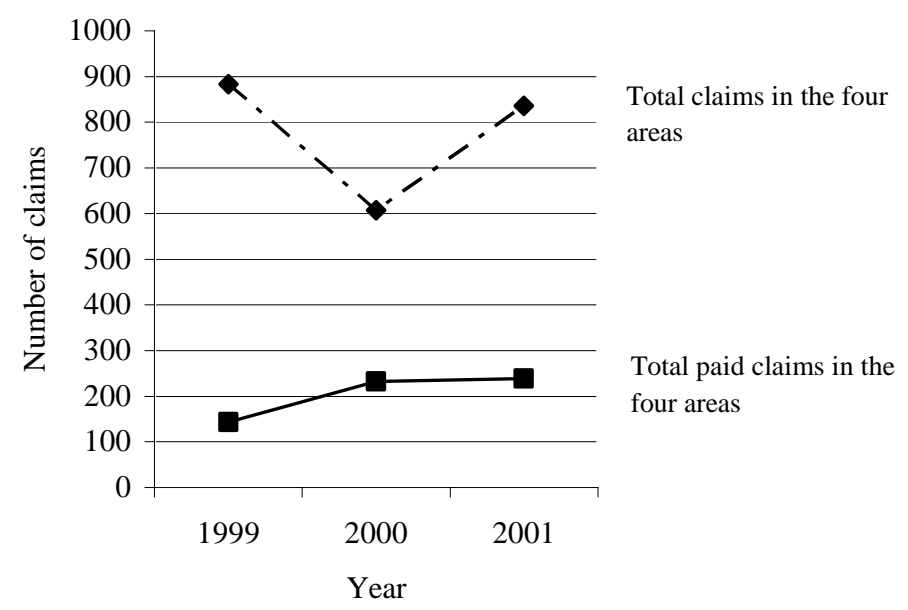

Figure 5: Temporal Distribution of Frequency of Total and Paid Common Claims

Table 3 shows estimated annual primary and secondary costs associated with common and other claims related to highway tort liability. These values were developed on the basis of recent data from the Attorney General’s office.

Table 3: Annual Primary and Secondary Costs for Common and Other Claims

\begin{tabular}{lccc}
\hline & Primary Costs & Secondary Costs & TOTAL \\
\hline Common Claims & $\$ 100,000$ & $\$ 100,000$ & $\$ 200,000$ \\
\hline Other Claims & $\$ 1,800,000$ & $\$ 900,000$ & $\$ 2,700,000$ \\
\hline TOTAL & $\$ 1,900,000$ & $\$ 1,000,000$ & $\$ 2,900,000$ \\
\hline
\end{tabular}

\subsubsection{Chuckhole Claims}

In the year 1999, a total of 406 chuckhole claims were filed, and only 6 were paid, while in the year 2000, 144 claims were filed of which only 7 were paid. In 2001, 57 of the 338 filed claims were paid. Figure 6 presents the trend in the number of paid claims compared to the total number of chuckhole claims. Annual payments made for chuckhole claims are shown in Figure 7. The figure indicates total amounts claimed for settled claims as well as total amounts that were finally paid for settled chuckhole claims. 


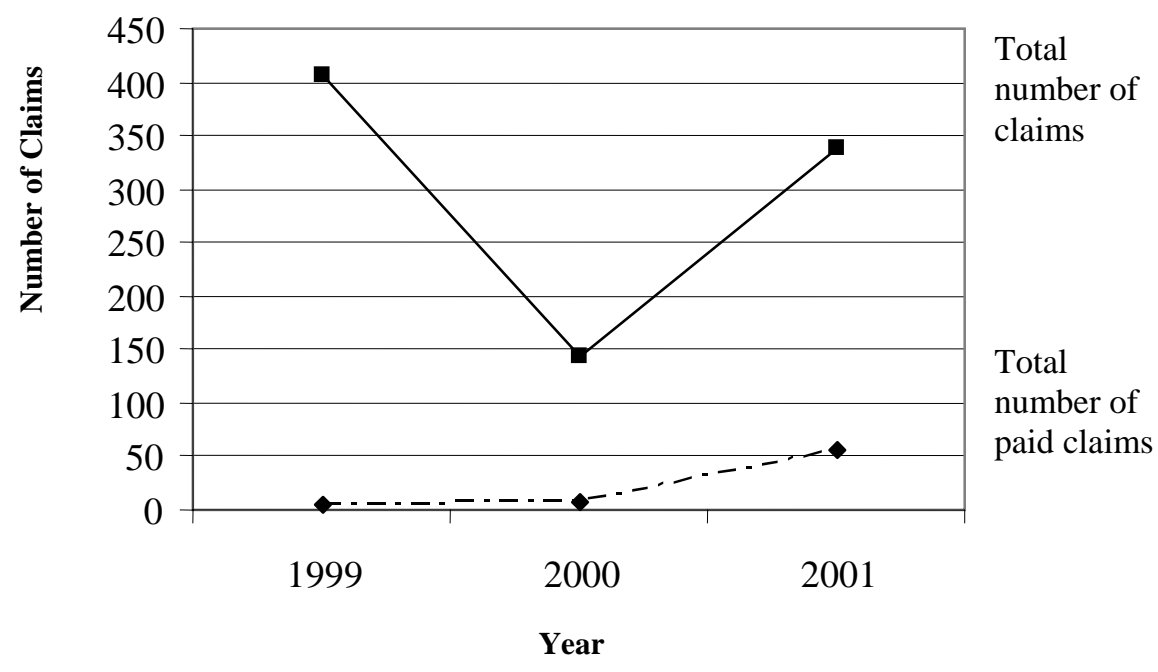

Figure 6: Temporal Distribution of Frequency of Filed and Paid Chuckhole Claims

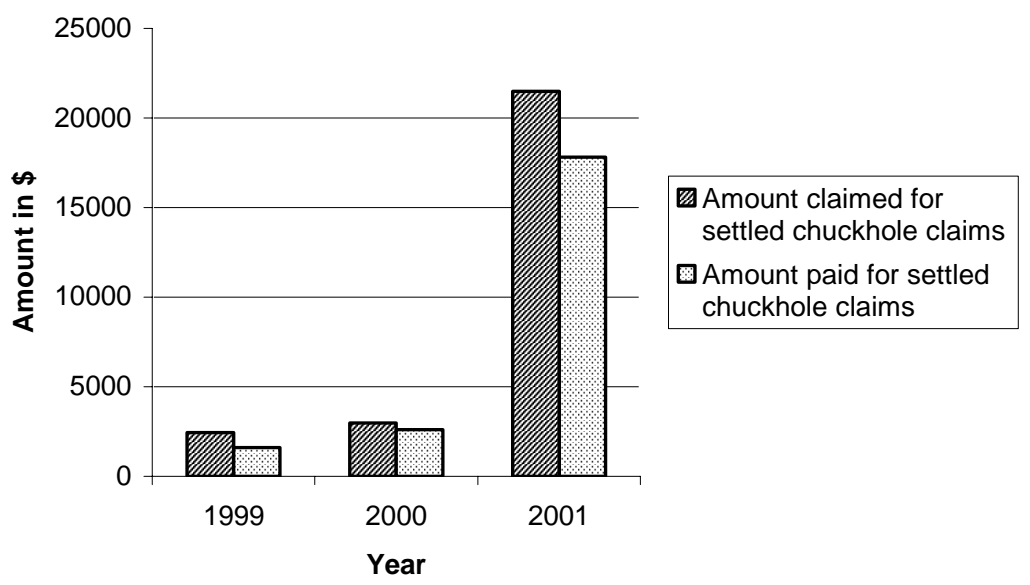

Figure 7: Amounts Claimed and Paid for Settled Chuckhole Claims 
The amount paid in 1999 for chuckholes was \$1,607. The amounts paid in 2000 and 2001 were $\$ 2,601$ and $\$ 17,811$, respectively. The amount paid in 2001 was much higher than those paid in previous years. A county-by-county analysis indicated that payments in Lake and St. Joseph counties represented $61.7 \%$ of the total statewide amount paid in 2001 for such claims. Lake County alone represented $46.3 \%$ of the total amount paid for chuckhole claims in 2001 . There is a need for the state to identify the reasons for such high levels of claim filings in those counties. It is expected that improved mechanisms of communication between road users and INDOT and further increased responsiveness of INDOT's maintenance crew to reported developments of chuckholes, would further reduce the frequency and total costs of chuckhole claims.

\subsubsection{Mailbox Claims}

In 1999, over 200 mailbox claims were filed, of which most were denied. As indicated earlier, the fact that so many claims were denied is because the Attorney General's Office refuses to pay if it lacks sufficient evidence that INDOT actually damaged a mailbox. Figure 8 presents the trend in the number of paid claims compared to the total number of mailbox claims.

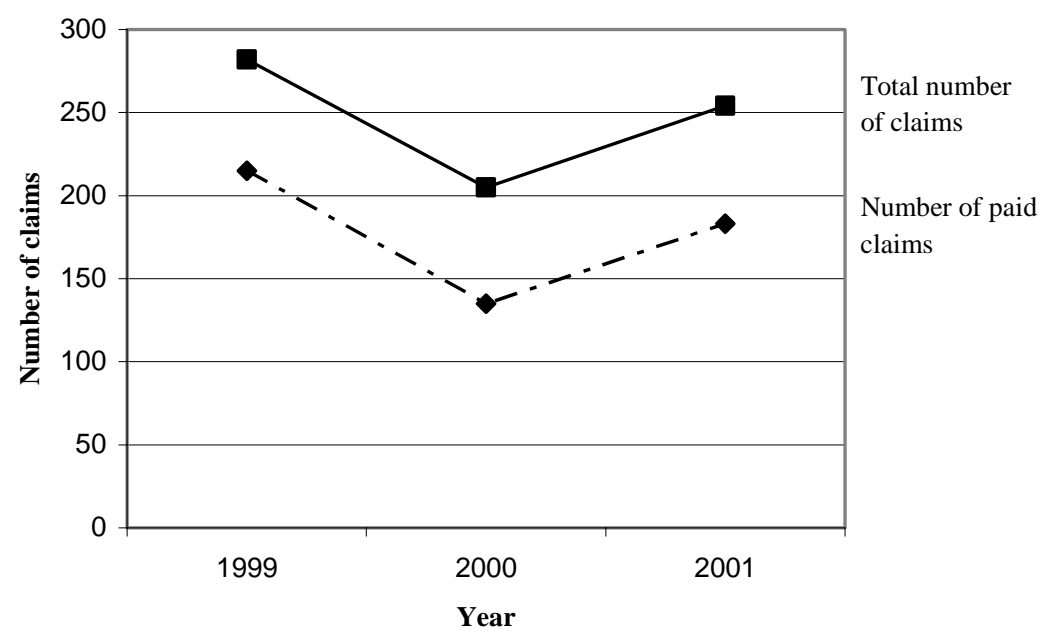

Figure 8: Temporal Distribution of Frequency of Filed and Settled Mailbox Claims

The cost associated with settling of such claims is shown in Figure 9. The "amount claimed for settled mailbox claims” represents the total amount claimed for claims that were eventually paid. 


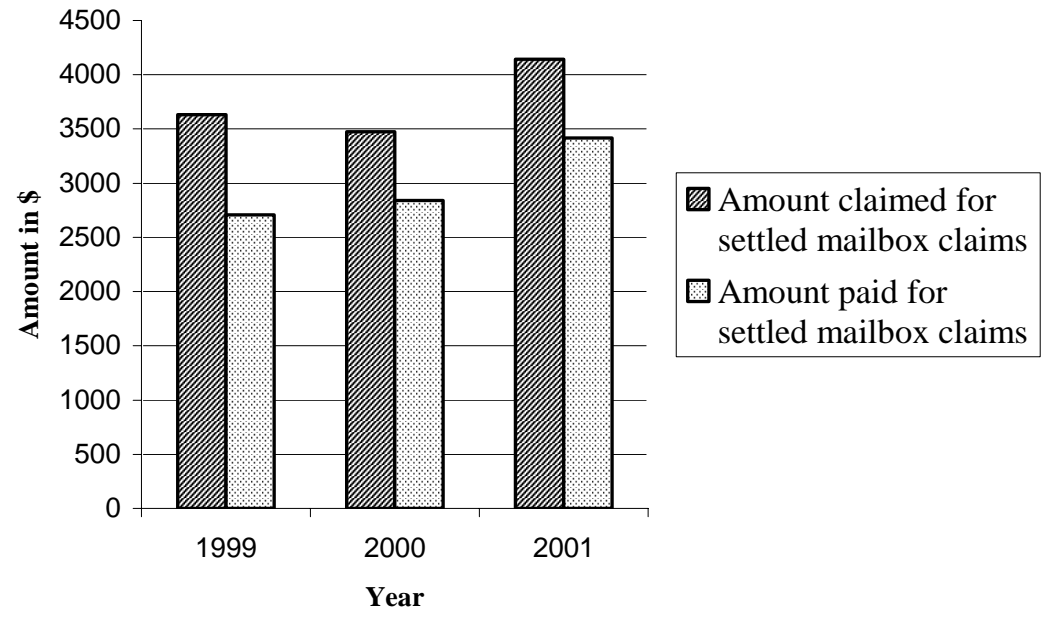

Figure 9: Amounts Claimed and Paid for Settled Mailbox Claims

The payments for mailbox claims were \$2,707, \$2,842 and \$3,415 in 1999, 2000 and 2001, respectively. The trends in the data show that the frequency of claims, as well as the amounts claimed and paid for mailbox claims increased between the years 1999 and 2001. According to the Attorney General's Office, the Investigation Division, at the present time, does not have adequate resources to distinguish real claims from those that are fraudulent.

It is obvious that INDOT employees who damage mailboxes during snow removal operations could help in the management of such claims by reporting such incidents to the local INDOT sub-districts in a prompt manner. Information such as the place and the time of the incident would allow the INDOT or the Attorney General's Office to check the authenticity of any subsequent complaints. 


\subsubsection{Mower Claims}

As Figure 10 indicates, there has been a steadily increasing trend in the number of filed and paid mower claims between 1999 and 2001.

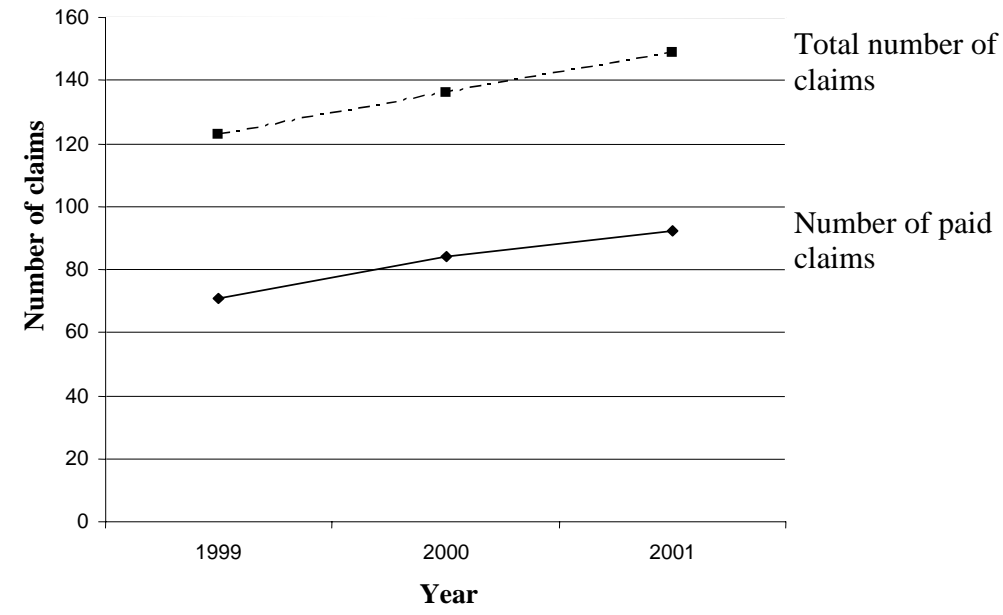

Figure 10: Temporal Distribution of Frequency of Filed and Settled Mower Claims

Trends in the cost of settling mower claims are presented in Figure 11. It is seen that with a total annual settlement cost of approximately \$30,000, costs for mower claims exceed those for other common claim categories. In 1999, \$29,273 was paid for mower claims while \$31,028 and \$33,529 were paid in 2000 and 2001, respectively.

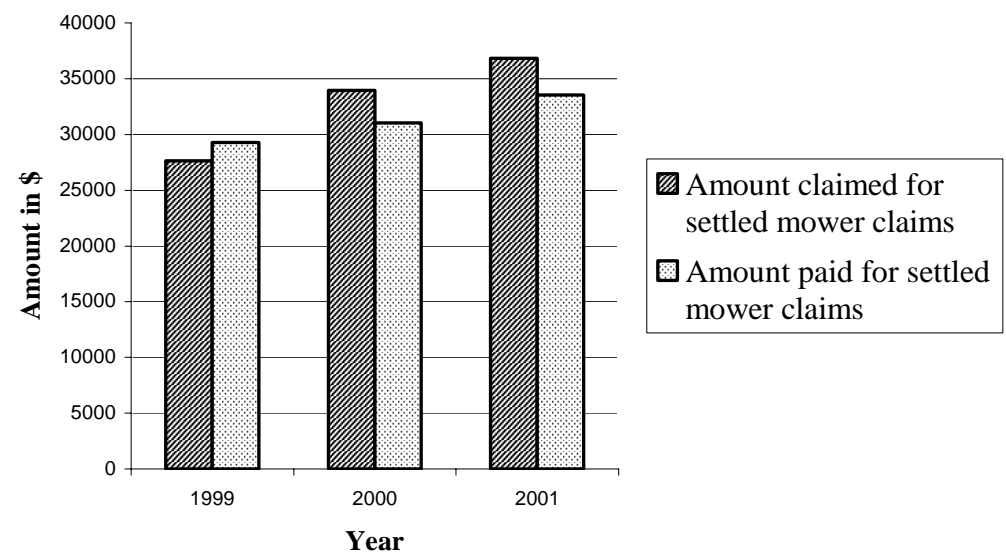

Figure 11: Amounts Claimed and Paid for Settled Mower Claims 
The cost of claims arising from mowing operations can possibly far exceed the expenses incurred for repairing vehicles damaged by an errant rock. For instance, in early 2002, a road user was severely injured by a rock flung from the blades of an INDOT mower. It is possible that the liability resulting from that incident will involve a large sum of money. According to the Investigation Division of the Attorney General's Office, the frequency of mower claims is hard to forecast, but could be reduced by continued use of metal chain net shields installed on INDOT's mowing machines. It is probably worth adding that the use of herbicides for vegetation control may not be considered an attractive alternative to mowing due to possible adverse environmental effects of the chemicals.

\subsubsection{Paint Claims:}

In the year 1999, 191 paint claims were filed, of which only 18 were paid, while in the year 2000, 184 claims were filed, of which 43 were paid. Then in the year 2001, 227 claims were filed, and of this number, 54 were paid. Figure 12 presents the trend in the number of paid paint claims compared to the total number of filed paint claims. The general trend is similar to those the other common claim types.

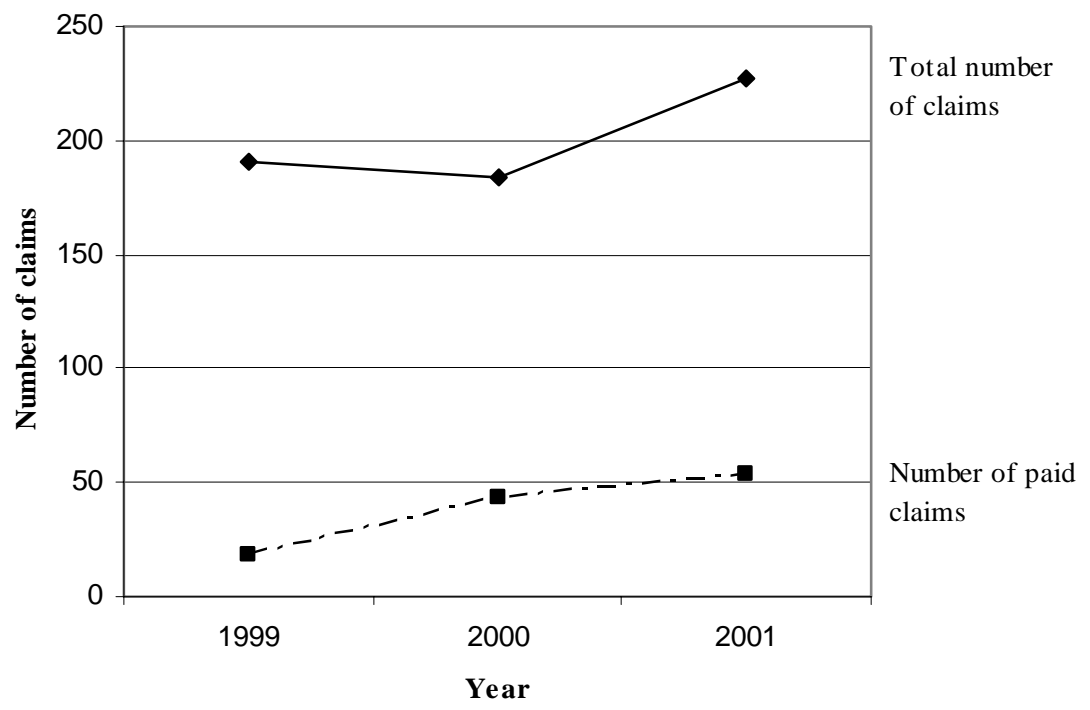

Figure 12: Temporal Distribution of Frequency of Filed and Settled Paint Claims 


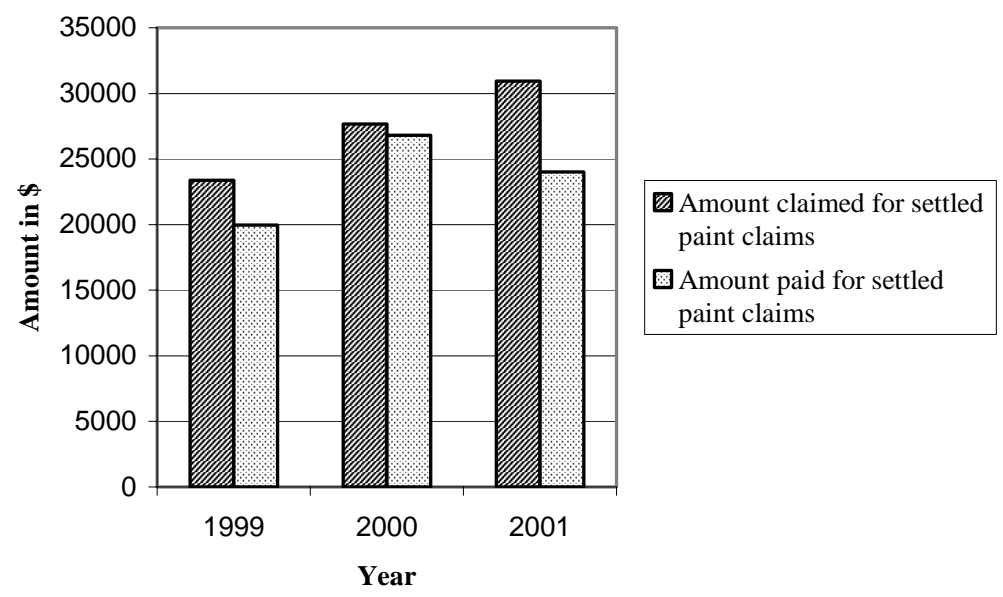

Figure 13: Amounts Claimed and Paid for Settled Paint Claims

Over the 1999 to 2001 period, there has been a general increase in the amounts claimed as well as the amounts paid for paint claims, as Figure 13 illustrates. It is seen that the total cost of settling paint claims remains high, with \$19,961 paid in 1999, \$26,807 in 2000 and \$24,031 in 2001.

\subsection{Estimating the Expected Annual Number of Paid Common Claims}

For planning purposes, it may be necessary to estimate the annual number of paid common claims that are expected every year in the state. To address this issue, the study developed a statistical model that relates the number of paid claims in each county to the amount of travel (in terms of vehicle-miles of travel) in that county. Models were developed for all four categories of common claims combined, as adequate models could not be developed separately for each category.

The response variable used was the average annual (over three years) number of paid claims at county level. The explanatory variables that were considered included the following:

- Population: In Indiana, population varies rather significantly among counties. It is expected that a county with a larger population would be associated with a higher number of claims, and subsequently, paid claims, all other factors being equal.

- Mileage of state highways: State highways comprise Interstates, US Roads, and State Roads. A county with a higher level of state highway mileage can be expected to experience a greater number of incidents, claims, and paid claims, all else being equal. This is because greater mileage is generally associated with greater exposure to risk. 
- Usage of state highway: A county with a higher total daily vehicle mile of travel (DVMT) may also experience more incidents, and consequently, a higher frequency of tort liability cases, all else being equal. It has been well established in past research that exposure to highway incident is more revealing when considered in terms of both traffic volume and facility extent (mileage), rather than just either one of these factors.

- Geographical region: This may be an influential factor, particularly when viewed in terms of geographical variation in weather conditions. Due to the passing of cold air over warmer lake water, the northern counties of Lake, Laporte, and Porter experience the highest levels of winter precipitation. Average annual snowfall ranges from 60 inches in northern Indiana to 10 inches in the south. Snowfall varies significantly from year to year depending on both temperature and frequency of winter storms. Greater levels of snowfall are expected to be associated with greater frequency of mailbox related claims, all else being equal.

- Rural/Urban nature of the county: As more mailboxes are located next to state highways in rural areas compared to urban areas, a rural county can be expected to experience higher frequency of mailbox claims.

Using data provided by the Attorney General's Office, a modeling database was developed. Final results showed that variables such as population, mileage of state highways, geographical region, nature of county and amount of snowfall were not significant at $95 \%$ confidence. The only variable found significant at the specified degree of confidence, was that which represents the amount of travel.

Figure 14 shows the distribution of the total observed number of common claims in each county for an average year (based on years 1999, 2000 and 2001) versus daily vehicles miles of travel (DVMT) expressed in millions. In this figure, Marion County is not included because the point representing data from that county seemed to be an outlier (the highly urbanized nature of that county makes it likely to have very few mowing and mailbox claims). Statistical regression analysis was carried out to fit an appropriate model to the given data. Various functional forms were investigated, such as square root forms, polynomial forms, logarithmic forms and exponential forms. It was found that the best functional form was as follows:

$$
N=\mathrm{a}+\mathrm{b} * \log _{\mathrm{e}}(D V M T)+\mathrm{c} * D V M T
$$

where $N=$ Average annual number of settled common claims in a given county DVMT = Daily Vehicle Miles Traveled in a given county. 
From the statistical analysis, the following parameter values for the above model were obtained: $\mathrm{a}=1.11214, \mathrm{~b}=0.58348, \mathrm{c}=0.34108$. The coefficient of determination $\left(\mathrm{R}^{2}\right)$ is 0.52 . Figure 14 shows the observed data and the fitted values for the regression line.

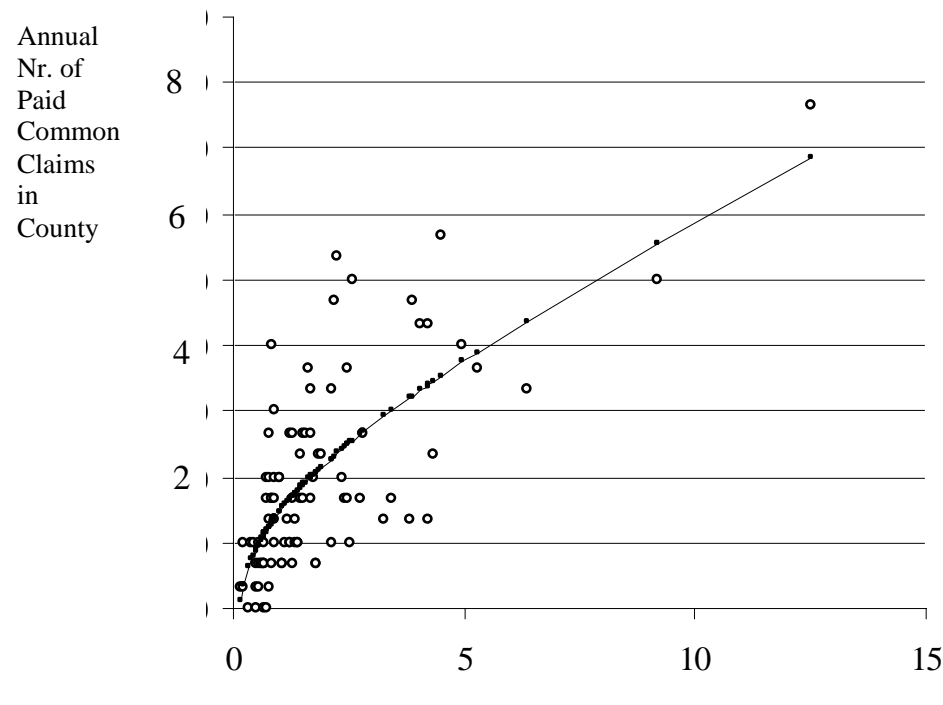

Daily Vehicle Miles of Travel (in millions) in County

Figure 14: Theoretical and Observed Annual Number of Paid Common Claims

\section{$\underline{4.5 \text { Chapter Summary }}$}

In the year 2001, the State of Indiana paid approximately \$2 million to settle claims brought against the state. This amount involves the "primary" costs, or the amounts paid by the Attorney General's Office for settlements and amounts granted to plaintiffs in court. For a more comprehensive assessment of the total cost of tort liability in Indiana, it is necessary to also consider the "secondary" costs, i.e., expenditure for claim investigation and filing.

This chapter documented the trends in the frequency and amounts for all claims, and specifically for each of four common categories of common types of claims. The data shows that while the total number of filed claims exhibits fluctuating trends, a generally increasing number of claims is being paid, and also an increasing percentage of cases is ending up in litigation. It was also found that the four categories of common claims represent approximately half the number of all claims received each year by INDOT. The direct cost of these claims (the cost associated with paid 
settlements) is low, but the time taken to process and handle these categories of claims is often costly. Table 4 summarizes the direct costs of such claims.

Table 4: Frequency and Amounts of Common Claims in Indiana in 2001.

\begin{tabular}{lcccc}
\hline Claim Type & Number of claims & $\begin{array}{c}\text { Number of paid } \\
\text { claims }\end{array}$ & $\begin{array}{c}\text { Percentage of } \\
\text { claims paid }\end{array}$ & Amount paid \\
\hline Paint Claims & 227 & 54 & $23.8 \%$ & $\$ 24,032$ \\
\hline Mower Claims & 92 & 57 & $62.9 \%$ & $\$ 33,529$ \\
\hline Chuckhole Claims & 334 & 57 & $17.1 \%$ & $\$ 17,811$ \\
\hline Mailbox Claims & 183 & 71 & $38.8 \%$ & $\$ 3,415$ \\
\hline TOTAL & 836 & 239 & $28.6 \%$ & $\$ 78,787$ \\
\hline
\end{tabular}

Statistical analyses were carried out to estimate the annual number of paid common claims, given the exposure to tort incident (expressed as the number of vehicle miles of travel). Each county was used as the unit of modeling.

In documenting the current situation of tort liability in Indiana with respect to the trends in frequency and amounts of tort claim filings and settlements, the chapter sets the stage for subsequent analysis of the feasibility of a highway tort liability risk management program for the State. On one hand, it may be hypothesized that the monetary amounts associated with highway-related tort claims are not enough to warrant the establishment of such a program. On the other hand, it may be argued that the establishment of such a program will be cost-effective as claim frequency and payment and secondary costs could be reduced significantly. As a compromise measure, it may be desirable to establish an evolutionary highway tort liability risk management program for the State with the initial task of building a highway-related tort claims database. In the light of the above discussions, the next chapter (Chapter 5) presents a framework that can be used to establish a risk management program for highway tort liability for the State, while Chapter 6 investigates the extent of resources needed for various levels of risk management on the basis of the developed framework. 


\section{CHAPTER 5: PROPOSED OPERATIONAL FRAMEWORK FOR A HIGHWAY TORT LIABILITY RISK MANAGEMENT SYSTEM IN INDIANA}

\subsection{The Framework}

As suggested in the previous chapter, it may be premature at the present time to establish a fully functioning office to manage risks associated with highway tort in the state. An appropriate approach would be to proceed in phases, starting with management of a comprehensive database. An immediate effort, however, should be made to strengthen the relationships between entities currently involved with the management of highway tort liability in Indiana. Improved coordination and communication between INDOT and the Attorney General's Office is the key element in both preemptive and palliative risk management. Pre-emptive risk management refers to the set of operational and institutional measures that help control the level of risk, i.e., reduce the probability of situations that would lead to tort liability. On the other hand, palliative risk management refers to the tools that can be applied to minimize the legal (and consequently, financial) impacts of current tort liability cases, and also to reduce the impacts of future tort liability through a systematic feedback to engineering design, construction, and maintenance organizations within INDOT. A proposed operational framework for a possible future risk management system for the State is illustrated in Figure 15.

As regards pre-emptive risk management, risk control measures fall under four broad categories: administrative procedures and legal action, information and training, enforcement, and engineering. Pre-emptive legal action involves aggressively maintaining appropriate laws that reduce liability exposure. This includes laws concerning immunity. It is expected that enhanced communication between INDOT and legislative authorities in Indiana would allow the latter to better understand the needs of the former. Information and training involves education of the general public by raising its awareness of accident-prone situations in the highway environment (such as current construction work-zone locations), the driver (such as the need for seat belt usage), and the vehicle (such as the need for road users to maintain their vehicles in good condition). Furthermore, there is a need to educate INDOT personnel about the tort liability issues involved in their day-to-day operations. Such training of personnel is an important part of successful risk management in many 
states. Enforcement refers to the assurance, through a variety of instruments that drivers operate their vehicles properly so as not to constitute a hazard to other vehicles on the roadway. Engineering refers to the elements of highway design (primarily geometric), construction, operations and maintenance involving such facilities as pavements, markings and signs, and signals. Liability for incidents within work-zones is generally the responsibility of the contractor involved in the work.

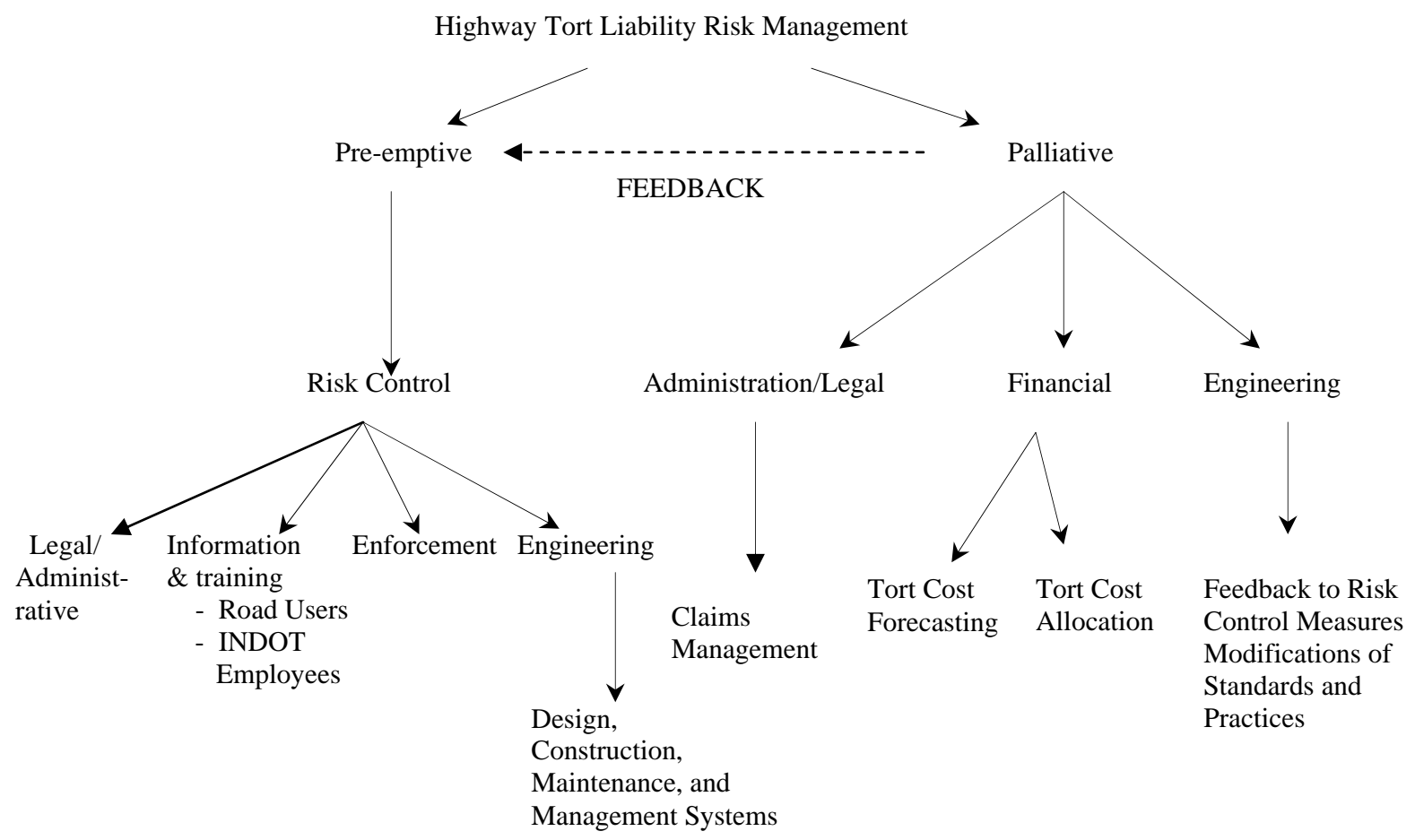

Figure 15: Proposed Operational Framework for a Highway Tort Liability Risk Management System in Indiana

Palliative risk management can occur at three different areas: legal/administrative, financial and engineering. The main purpose of palliative risk management is to provide feedback to ensure a better pre-emptive risk management. The legal aspect of palliative risk management involves a rigorous claims follow-up that is termed "claims management" in the present study. This includes collecting all data related to the claims and maintaining an accurate and up-to-date database with as much relevant information as possible. The expertise of a senior legal employee would also be necessary to assist the Attorney General's Office and INDOT's Legal Division in their efforts to 
study tort frequencies and costs. Eventually, it is important that the conclusions and findings of any analyses can be forwarded to the Safety Management Engineer of INDOT's Program Development Division and possibly, the Engineering Assessment Section of the Environment, Planning and Engineering Division.

The need for feedback between pre-emptive and palliative risk management cannot be overemphasized. Such a feedback constitutes the most vital aspect of the operational framework as it allows an evaluation of pre-emptive strategies. Tort claim frequencies and amounts could be analyzed jointly by the Attorney General's Office, and INDOT’s Legal, Operations Support, and Program Development Divisions. The Safety Management Engineer is expected to play a significant role in such efforts. Current practices such as periodic reporting of tort liability records and issues to INDOT by the Attorney General's Office should be encouraged.

\section{$\underline{5.2 \text { Aspects of Pre-Emptive Risk Management }}$}

\subsubsection{Legal/Administrative Aspects}

For effective pre-emptive risk management, it is essential that INDOT’s Legal Division and the Indiana Attorney General's Office work together to propose or support favorable laws aimed at reducing or minimizing the State's liability to tort. The consequences of actions taken by INDOT directly affect the budgetary allocation for investigation and settlement of highway tort liability cases by the state's Attorney General's Office. Lewis et al. [1994] stated that a program that encourages the creation and support of laws that reduce liability exposure is a very important element of a risk management system for highway tort liability. It is desirable for an agency to keep the legislature informed on a regular basis about the increasing amounts paid for tort liability, and the implication in the long run. In some states where the state's immunity has been waived, there is still a limited immunity in some discretionary functions. This is apparently the case for Indiana as in the other states. For example, according to the NCHRP Synthesis 206, legislation was enacted in Iowa that amended the State Tort Claims Act to specifically exempt the state from one part of its liability and effectively bar suits raised against the state for action involving negligence in the design and operation of highways. The report further states that in the South Carolina Code \$15-78-60, some exceptions to the waiver of immunity can be found. As of 1994, highway design was still under total immunity, but maintenance activities were not protected by the law [Lewis et al., 1994].

Besides the immunity aspects that the legal division must protect, there are some other actions that can be implemented to reduce tort liability exposure. Recognizing that defacement, 
removal or destruction of traffic control devices could cause death, serious injury or property damage for which the state could be held liable, certain states are taking strong measures against vandalism to such devices. The State of Wisconsin, for instance, has strict policies regarding vandalism on traffic control devices, such as [Lewis, 1994].

The number of filed tort claims is influenced by the time of response. According to Indiana's Office of the Attorney General, a plaintiff has 270 days to notify his or her intent to file a claim. A claim at INDOT is transmitted to the Attorney General's Office which should respond within 90 days either to accept or to deny the claim in its entirety. The response time limit and the time allowed for plaintiff to file a claim vary from state to state. The claim filing deadline is longer in Indiana compared to many other states. In California, for example, most of claims under $\$ 1,000$ must be filed in a period of 6 months. INDOT’s Legal Division and the Indiana Attorney General's Office could help lower the frequency of tort claims by advocating for a reduction in the length of time within which a claim should be filed.

\subsubsection{Information and Training}

\subsubsection{Road Users}

The flow of information between INDOT and road users should be in both directions. INDOT must continue to inform road users on highway-related risks and how such risks can best be avoided. Emerging Intelligent Transportation Systems (ITS) technologies show much promise in achieving this objective in the future. At the present time, information dissemination tools such as the print and electronic media, including INDOT's internet website, could be used effectively. Some states such as California have an interactive section on their website concerning lawsuits, and provide detailed online forms explaining claim filing procedures. A good information system would not only reduce the number of untenable claims but would also help boost INDOT's public relations through enhanced transparency in its operations.

Regarding the other direction of information flow, it is imperative that INDOT continues to live up to its stated key mission of customer service. Consistent with this mission, INDOT should continue to address the needs of its customers (i.e., road users and the general public) with a constant

focus on better service, paying close attention to their customer needs, improving INDOT accessibility to customers, enhancing customer satisfaction with INDOT, and providing timely and professional response to all customers. INDOT should continue to take all citizen complaints and warnings with due seriousness, and act upon such complaints with diligence. It has been found that 
regular users of any given road section are typically the best source for information regarding early detection of defects, and such sources are considered valuable for risk management. An example of a tool for effective communication between INDOT and road users is found in a recent research project that developed an interactive website for the Tippecanoe County [Tarko and DeSalle, 2002], which enables road users to report defects quickly, conveniently, and inexpensively via electronic means. It is recommended that the findings of that research be considered for possible implementation throughout the state.

\subsubsection{INDOT Employees}

Available literature on highway tort liability risk management greatly emphasizes the importance of employee training. An important purpose of training is typically to encourage interaction between staff from different units, such as engineering and legal divisions. Training programs have been established in states such as Michigan, Ohio and Texas for supervisors, engineers and managers. Lewis et al. [1994] state that the objectives of a risk management training program for agency employees would enable such employees to achieve the following objectives:

- Understand legal duties of agency personnel,

- Comprehend the changing legal climate where highway agencies are increasingly vulnerable to tort liability litigation and judgments,

- Identify potential liability situations,

- Recognize appropriate actions to mitigate liability,

- Work effectively with legal staff and others in the defense of the agency,

- Participate in legal processes, such as depositions and giving testimony at trial,

- Support risk management program objectives.

\subsubsection{Enforcement}

Past research has shown that causes of road incidents (and consequently, possible tort claims) fall into any one of the following broad categories (or a combination thereof): the highway and its environment, the driver, and the vehicle. In order that road users are kept safe from possible incidents due to their mistakes or problems with their vehicles, or problems/mistakes of other drivers/vehicles on the road, it is essential that existing highway usage regulations and policies be enforced as much as possible. It is important to ensure that drivers keep their vehicles in good condition, and that only fit drivers use the highway. This can be achieved through continued appropriate penalties for violations such as drunk driving, operating non roadworthy vehicles, failing to obey road signs, overspeeding, etc. Legislation aimed at improvements in vehicle design, occupant 
protection (seat belts, headrests, air bags or special seats for children) and vehicle maintenance, should be encouraged. Furthermore, through regular education via print and electronic media, road users should be encouraged to maintain safety-related vehicle components.

\subsubsection{Engineering}

\subsubsection{Design}

According to the Attorney General's Office, INDOT receives only a few claims related to design. The Attorney General's Office does not consider design-related claims to be a major problem in highway tort liability in Indiana. Nevertheless, it is important that INDOT pays close attention to procedures established in its design and other manuals, particularly to terms as "should", "must" or "would", as such terms are associated with legal implications, and because several lawsuits have been lost by transportation agencies in other states due to poor understanding of these terms [Gowen, 1990]. Current safety-related considerations (directly or indirectly), in engineering design, such as the use of safety factors in bridge design, is consistent with pre-emptive risk management.

\subsubsection{Construction}

Construction zones foster situations that readily lend themselves to highway incidents and consequently, tort liability. Several current research projects are addressing this issue. For example, in an effort to reduce work-zone incidents, INDOT recently initiated a study for improving construction work-zone safety [Garcia et al., 2002]. The objectives of the project are (a) to determine if it is appropriate to consider temporary roads and bridges during construction activity, and (b) to evaluate if improved signing or active warning devices have an influence on work-zone safety. Such measures are important in reducing the possibility of highway work-zone crashes and attendant lawsuits. It should be noted, however, that the responsibility for traffic maintenance in work-zones generally lies with the contractors.

\subsubsection{Maintenance}

Road sections needing maintenance as well as maintenance work-zone issues are considered critical as far as highway safety is concerned. This problem persists at most highway agencies in the United States, and many costly claims have been brought to court because of surface defects and work zone problems. It is important that INDOT strives to seek solutions to improve safety at maintenance work-zones. The State is not liable for incidents associated with certain types of 
highway maintenance done by contract. Even where the State is liable, certain restrictions exist. For example, the Attorney General's Office does not consider the state liable for pothole defects unless INDOT had received notice of the "discovery" but failed to act within a stipulated time period. Nevertheless, various in-house maintenance operations done by force account, such as snow removal or pavement marking, can lead to tort against the State. In Chapter 6, recommendations are made that could reduce the tort exposure arising from certain aspects of highway maintenance.

\subsubsection{Management Systems}

Reduction of tort exposure is an important element of pre-emptive risk management: design and maintenance decisions based on budgetary or other economic constraints are generally seen as discretionary in nature. However, as demonstrated in a past case, a transportation agency that argues that its failure to remedy a defective design due to funding priorities can be held liable if it presents no evidence on planning, ordering of priorities, or limitations on available funding. In this regard, the current development of safety and congestion management systems for INDOT and the on-going refinement of the already developed pavement and maintenance management systems, will serve to provide such evidence on planning and programming of investments, and will subsequently reduce the exposure of the state to tort

\subsubsection{Other Operations}

The operation of freeway patrol systems (Hoosier Helpers) that clear incidents inherently reduces the risk of secondary incidents, and are therefore important elements of pre-emptive risk management in Indiana.

\section{$\underline{5.3 \text { Aspects of Palliative Risk Management }}$}

Palliative risk management is an important part of any risk management system. It takes place at three different levels: legal, financial and engineering. The main purpose of palliative risk management is to use current tort data in order to better understand the risks and eventually avoid them in future.

\subsubsection{Legal/Administrative}

The legal and administrative aspect of palliative risk management necessarily involves a rigorous claims follow-up. This includes collecting all data related to claims and maintaining a 
reliable and comprehensive database. At present, INDOT plays the role of a link between the general public and the Attorney General's Office. Complaints arrive at INDOT where they are registered by the Legal Division. The claims are then transmitted to the Investigation Division of the Attorney General's Office where the case is either denied in its entirety or settled through an agreement with the plaintiff. As the present data trends indicate, the proportion of cases is brought to court is relative small (5.4\% in 2001), but is steadily increasing over the years. The Attorney General's Office regularly provides INDOT with reports giving various recommendations regarding tort liability. It is important that periodic meetings be held between the Attorney General's Office and INDOT's Legal, Program Development, and Environment, Planning and Engineering Divisions, in order to avoid any misunderstandings and to improve communication and information flow.

\subsubsection{Financial}

\subsubsection{Tort Cost Forecasting}

It is important for INDOT as well as the Attorney General's Office to be able to estimate the amount of money that will be needed in future to settle highway-related tort claims. This would help these agencies to balance risk by comparing expected tort cost with possible additional expenditures to reduce risk. The expected tort cost for each category of incidents can be identified in terms of settlement amounts and their probabilities. Expenditures will include costs associated with additional personnel for managing risk and related activities. It is expected that adoption of a decision theoretic approach (subsequently discussed in Chapter 7) would enable the estimation of the resource expenditures that would balance tort costs. To make decisions in this regard, risk personnel at the proposed risk management office need to acquire insights into the magnitude of the problem of highway tort liability. It is important that data concerning claims be classified and made available to responsible staff at relevant divisions. At the present time, INDOT could put in greater efforts in processing and analyzing tort costs. A database can help in keeping track of claim trends and costs that can lead to significant savings in personnel time and settlement amounts.

There are several issues related to the development of a tort claims dataset. First, present available data only give indications about past risks that took place under a different environment. The problem is that a case takes a long time to be processed. Several years may lapse between accident occurrence and case closure, especially when there are multiple successive judgments at different courts. A good risk management should not only document and analyze closed cases, but should also track all active, pending cases and potential claims. In this way, there is a trade-off that 
takes place between using past accurate data and current estimated data. It is also preferred to have a comprehensive and all-encompassing dataset, to avoid the effect of randomness. Since many incidents are rare events in a given geographical spot, it is recommended to collect data on cases from the entire state over selected time periods. The database should also link each case to the function(s) in the relevant agency unit to provide a clear and accessible feedback to those who manage risks.

\subsubsection{Tort Cost Allocation}

It may be desirable to allocate the historical costs of tort liability to the type of road facilities associated with the claim. A distribution of claim frequency and amounts by facility type can identify areas of needed improvement. In this regard, tort cost allocation studies have been conducted in several states including Pennsylvania, Kentucky and Michigan, and an example of such allocation is presented in Figure 16.

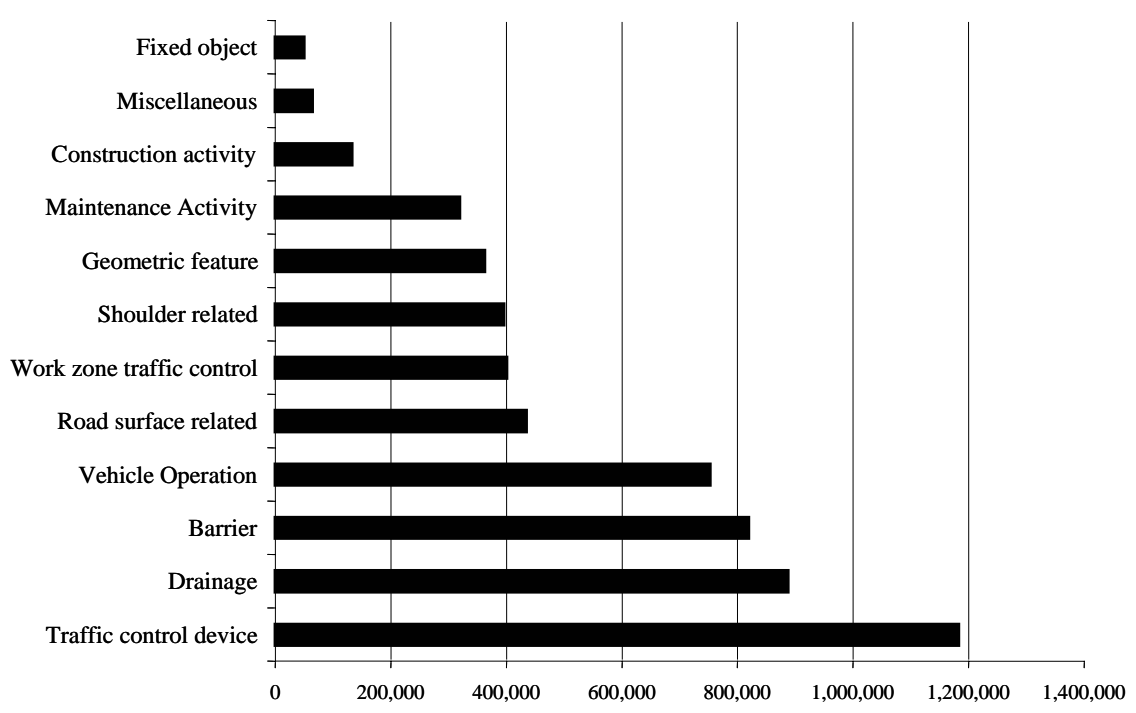

Figure 16: Distribution of Highway Tort Claim Expenditure at Kentucky, 1981-1989

Delays inherent to claims processing and variability in claims parameters usually lead to failure in estimation of dollar exposure. According to the NCHRP Synthesis 206, these attempts have 
been "at best unreliable and at worst worthless in terms of financial planning" [Lewis et al., 1994]. Nevertheless, some agencies strive to be prepared by setting aside money for future claims.

In Virginia, the Tort Claims Act states that "risk management division and Attorney General shall cooperatively develop an actuarially sound program for identifying, evaluating, and setting reserves for the payment of claims cognizable under the act” [Virginia Tort Claims Act, Va. Code, § 18.1-195.1 through 195.8]. In California, each annual budget contains an item in the DOT program to pay for settlements and judgments (\$37 million in 1994). If this amount is not sufficient, some payments are made the following year. From time to time, it can be found necessary to increase such funds. In the long term, such analysis can help to determine general trends that can be useful for tort liability managers. Usually, it takes years after the loss of sovereign immunity for a state to be able to estimate the appropriate amount of funds to be set aside. Indiana lost its sovereign immunity in 1978.

Notwithstanding the variation in tort liability costs, it is possible that the annual amount needed for such a "risk fund" can be estimated with a significant degree of reliability. In some cases, it is important to be able to evaluate and forecast the cost of an individual claim. This requires much expertise and experience including extensive legal knowledge. For any given case, the personnel in charge of this work should be able to determine the probability that the claimant wins and the amount of money the State would have to pay if the claimant should win, giving due consideration to all requisite legal issues and all circumstances concerning the incident. For this reason, such responsibility should be borne by senior personnel in the legal division, or at least by someone closely supervised by senior personnel in the legal division. It is important that there are some fixed tort forecasting guidelines developed by such personnel to avoid possible excessive variability in their predictions.

The use of a decision theoretic approach could help establish various probabilities associated with each claim filing/acceptance/rejection/litigation situations as well as expected amounts associated with each possibility. This way, it may be possible to estimate the amounts needed to be set aside to cover tort payments. The next chapter addresses this issue.

\subsubsection{Insurance Issues}

Tort cost allocation and management involves the resolution of two important questions: where the money is spent, and where the money comes from, for establishing a mechanism that would make money available for future tort payments. Regarding the latter question, there are two possibilities open to highway agencies seeking to establish a risk management program: 
- Obtain insurance with a commercial carrier,

- Elect and develop a program of self-insurance.

Many states no longer carry commercial liability insurance for common tort liability arising from the management of their highway systems. States usually self-insure through a fund administered by an agency of the state government. Thus, costs associated with tort liability exposure (payments to claimants and support costs) are borne directly by states that adopt such schemes.

At the present time, INDOT's Attorney General's Office adopts an insurance system similar to self-insurance by using general funds to pay for settlements arising from the State's highway tort liability cases. This strategy may not be useful for smaller entities such as local governments.

\subsection{Commercial Insurance}

Advantages of commercial insurance are that the cost of insurance is known in advance and that potentially large and unpredictable claims are better covered by a large commercial carrier than by small governmental entities. Commercial insurance can also save the cost of setting up a costly tort liability management office for agencies that are too small to afford it. On the other hand, commercial insurance is associated with high costs. In recent years, many public entities have encountered very large and rapid premium increases, making the practicality of commercial insurance doubtful. In addition, objectives of insurance companies are often based on the short term (period of contract) and may not be consistent with those of transportation agencies. For instance, insurance companies may be tempted to settle some cases in order to avoid the costs of going to court, even though the transportation agency may not be liable. Also, insurance companies typically do not provide adequate feedback to the agencies, thus depriving them of the building blocks needed for establishing highway tort liability management programs [Lewis et al., 1994].

\subsection{Self-Insurance}

Many states and large governmental units choose self-insurance. The exposure to risk is so important that tort payment will tend to average out each year. Various alternative insurance options can be considered:

- Excess Insurance: In this concept, the state is self insured up to a certain amount beyond which a commercial insurance will cover costs. This results in a reduction of the cost of the insurance. However, this may lead agencies to unjustified settlements.

- Self-Insurance Pools: This involves the pooling of several agencies to form a bigger entity in order to centralize their tort liability management efforts. 
Different laws exist in various states for the establishment of a separate fund for claim settlements. In Pennsylvania, a portion of the fees derived from motor vehicle licenses is set aside in a fund for such payments [Lewis et al., 1994].

\subsubsection{Engineering}

After development of a comprehensive risk management database, risk-reducing engineering decisions will be easier to justify. For instance, if a defect in road geometry is found to cause highway incidents and leads to increased tort claims, redesigning that section would be considered palliative risk management of an engineering nature. After such defects are addressed, it is important that they should not be repeated in future design. Therefore, palliative engineering risk management should be followed by pre-emptive engineering risk management.

\section{$\underline{5.4 \text { Chapter Summary }}$}

The initial effort towards a risk management program should focus on strengthening links existing between the Attorney General's Office and INDOT. The developed framework for risk management practice in Indiana addresses two different aspects: pre-emptive ("before-the-fact”) and palliative ("after-the-fact”). In pre-emptive risk management, actions have to be taken to minimize occurrence of tort liability incidents. This can be done using legal and administrative procedures (such as promoting laws that reduce the state's exposure to highway tort liability, and reducing claim filing deadline periods), improving communication within INDOT divisions (through regular risk management seminars, for instance), and also between INDOT and road users (through the use of the media). Pre-emptive highway tort risk management can also be enhanced by tougher law enforcement (through policies and regulations, driver education, and higher penalties). Furthermore, continuation of INDOT innovations in design and materials and construction and maintenance work zone improvements can help reduce the frequency of highway incidents that could lead to tort liability, and the development of management systems that present evidence on planning, ordering of priorities, or limitations on available funding, can help place INDOT in a better position during tort cases.

Palliative risk management involves actions that are taken after an accident takes place, in order to minimize its consequences, and eventually provide a feedback to pre-emptive risk management. Legally and administratively, this can be achieved by enhancing the current database 
being operated by INDOT's Legal Division, for purposes of reliable forecasting of future tort claims. Also, shortcomings in engineering designs, maintenance and operational procedures that have resulted in tort cases should be addressed promptly, to reduce the possibility of future tort liability lawsuits.

On the basis of the proposed operational framework for risk management discussed in this chapter, the next chapter proceeds to identify the resources and organizational setup that would be necessary for the effective implementation of such a framework. 


\section{CHAPTER 6: RESOURCES AND ORGANIZATIONAL SETUP FOR A HIGHWAY TORT LIABILITY RISK MANAGEMENT PROGRAM IN INDIANA}

\subsection{Introduction}

Evaluating the cost-effectiveness of a highway tort liability risk management program requires an assessment of the expected expenditure on claim settlements on one hand, and the resource costs associated with risk management on the other hand. In Chapter 4, trends in tort claim payments were reviewed and analyzed. Chapter 5 presented the operational framework for a risk management program and therefore provided the basis for the current chapter which identifies the resources needed for risk management, including a list of various positions and associated duties. Tort liability claims can be split into two categories: claims that are common but whose settlement amounts are typically low, and claims that are rare but whose settlement amounts may be very high. A description of the various positions of highway tort liability risk management staff, as well as the logistic resources, needed is provided in the present chapter. Also, entities involved in risk management at other states are presented in Appendix D. Appendix E lists the tasks and personnel responsible for risk management in the state of Virginia. Finally, the present chapter makes specific recommendations to address some common types of claims.

The highway tort liability risk management office could be located at INDOT's Legal Division or at the Attorney General's Office. The development of the risk management office could be incremental and evolutionary in nature. For purposes of the present study, it is assumed that levels of risk management are reflected not only by the extent to which operational functions are being addressed, but also by the expenditure involved in setting up a risk management office. Such expenditure is reflected in the number of personnel that are either hired for or re-assigned to risk management. 


\subsection{Personnel}

Full-time, well-trained and experienced employees are vital for effective administration of any risk management program. A fully functioning office to manage highway related risks will require three primary staff positions: a risk manager, a claims analyst, and a database specialist.

\subsubsection{The Risk Manager}

As in many other states, the risk manager would lead the State's highway tort liability risk management program. This person will supervise the entire program by coordinating with the Attorney General's Office, various divisions in INDOT's Central Office, and districts and subdistricts, among other entities. The duties of the risk manager may include the following [Lewis et al., 1994]:

- Developing tort management policy directives and guidelines for implementation by top management,

- Monitoring and revising tort liability management procedures based on continuing analysis of tort actions,

- Providing support to legislation that strengthens the agency's tort liability posture,

- Providing information and guidance to INDOT districts and divisions regarding the implications of recent tort activities and legal actions,

- Analyzing and evaluating office programs, policies, and procedures involving handling of claims and lawsuits,

- Maintaining lists of expert witnesses who may help defend the agency in tort cases,

- Coordinating with the Attorney General's Office for refining settlement strategies for major tort liability actions,

- Acting as a link between INDOT’s Legal Division and the Attorney General's office.

- Initiating special studies associated with tort liability and risk management, when needed,

- Follow-up of the development of tort liability documentation and database and use of these for liability defense and loss-prevention analysis,

- Developing and enforcing procedures ensuring that all complaints or criticisms of highway facilities and procedures are promptly answered by the appropriate functional unit (with most of the actual work being done at the district level), 
- Working with the operating units on the development and evaluation of manuals, standards, and guidelines that may affect tort liability. Recommendation of changes to publications based on tort actions,

- Acquiring information useful to tort liability management in the state,

- Originating letters in response to correspondence and inquiries from attorneys, general public, aggrieved citizens, and plaintiffs (in coordination with the public information office),

- Coordinating the development and presentation of training programs and seminars on tort liability and risk management for central office, district, and field personnel (in coordination with the training office),

- Supervising employees in the risk management section.

\subsubsection{The Claims Analyst}

The claims analyst may be perceived as an associate of or assistant to the risk manager. The tasks performed by a claims manager may include the following [NCHRP Synthesis 206, 1994]:

- Receiving and processing claims and notices of intent to file claims,

- Initiating investigations of factual information behind lawsuits, claims, and potential claims,

- Providing names of recommended witnesses requested by attorneys handling claims,

- Maintaining documentation on the status and disposition of claims,

- Identifying and monitoring of tort liability trends,

- Participating in seminars and training provided to the agency personnel and attendees from local agencies. Stimulation of the legal staff to explain state statutes and court decisions in tort liability litigation as it affects highway operations and policy-making decisions,

- Originating letters in reply to outside inquiries regarding claims procedures,

- Acquiring information useful to defending tort liability cases,

- Coordinating with the database specialist,

- Negotiating settlement of routine claims and participation in settlement negotiations for major claims.

\subsubsection{The Database Specialist}

At the present time, the Indiana Attorney General's Office possesses a large database in which claim data pertaining to INDOT and other state agencies are managed. Management of claim 
data using the current database appears to be a rather difficult task as evidenced by the significant amount of efforts associated with simple data management tasks such as data retrieval. It may be desirable for any future risk management office to develop a dedicated highway tort claims database to facilitate management of highway-related tort liability data. A database specialist could be hired for this task. Such a database could be tied in to existing INDOT databases on crash records, roadway inventory, geometric characteristics, etc.

\subsubsection{Other Risk Management Positions}

\subsubsection{Investigators}

In some transportation agencies, claims investigators work under the risk manager. In other agencies, investigators work in the district or in the legal office. In Michigan for instance, the investigators work for attorneys rather than the DOT, with the objective of making their work less visible. Responsibilities of investigators include photographing crash sites, gathering evidence, and performing other technician level duties associated with the investigation of claims and preparation of cases for trial [Lewis, 1994].

\subsubsection{Inspectors}

Transportation agencies use safety inspectors to identify problems and check on field forces and contractors. This position is separate from a project inspector, who is assigned to oversee specific construction or maintenance contract operations. In Ohio for instance, the DOT has a "safety and health inspector” position, while in Oklahoma DOT, division risk managers essentially perform field reviews and report to the division (district) engineer. It has been stated that training and experience are determinants to the effectiveness of such personnel [Lewis, 1994].

\subsubsection{Risk Management Committee}

A risk management committee, typically chaired by the Risk Manager, is formed within a transportation agency typically focuses safety enhancement, risk mitigation methods, and analysis of situations and conditions that may engender tort liability [Lewis, 1994], with the basic responsibility of developing a coordinated agency-wide program to manage tort risks. Members are typically appointed from each relevant administrative functional area, such as legal, enforcement, design, construction, traffic, and maintenance. Lewis [1994] recommends that a state agency may ask the governor's highway safety representative to participate on such a committee, and states that for

smaller jurisdictions, such committees are an effective means to obtain broad support for a small 
staff; additional people sought as members include representatives from the general counsel, public relations, law enforcement, and elected officials.

\subsubsection{Experts}

According to Lewis [1994], witnesses, under the normal rules of evidence, can state only what they have seen or know firsthand: they may testify as to facts, but may not give opinions or conclusions. Courts use lay witnesses to establish facts in a case and to testify on their personal knowledge of such facts. As such, highway agency personnel may serve as fact witnesses to answer questions concerning matters such as work they performed or conditions they observed at the site.

On the other hand, expert witnesses are used to assist the jury in understanding and interpreting areas of specialty in which lay persons are not skilled. An expert is one who, by reason of education, experience, or both, possesses special skills or knowledge in some science, business, or profession that is not common to the average person [Lewis, 1994]. Such witnesses can offer their opinions and conclusions based on facts. Transportation agency personnel may be called as expert witnesses in highway tort cases depending on their knowledge of the case circumstances or their position.

\subsubsection{Full-Time In-House Experts}

According to Lewis [1994], a few highway departments have created positions for full-time, in-house people who serve as expert witnesses in tort liability cases involving their agencies. For instance, California DOT has two such positions with support staff, one each for two large districts having large numbers of claims. An approach used by other states such as New York involves the appointment central office personnel, but such extraneous duties often interferes with their designated responsibilities, and they are not always available for litigation work as may be desired [Lewis, 1994].

According to Lewis [1994], agency personnel who provide legal consultation and serve as an agency's experts typically have many years of accumulated experience and a broad background in the operations of the agency. A degree in engineering (ordinarily, civil engineering) and a professional engineering license are normally considered essential, but an advanced degree may further enhance the expert's credentials. In the highway agencies of many states, senior engineers who understand the agency's functions, the legislation under which it operates, and the legal process typically serve as the agency's experts. It is worth noting that persons with the best technical ability are not necessarily the best candidates because some of them lack effective communications skills, which are also critical in tort cases [Lewis, 1994]. 


\subsubsection{External Experts}

In certain cases where the function of the expert is to assess the appropriateness of the agency's action, an independent expert may have more credibility in the eyes of the jury. Opinions of a department employee, regardless of qualifications, may be seen as self-serving by the jury. In resolving whether action was in accord with accepted engineering practice or if a situation was safe, the opinions of outside experts may be perceived as being more impartial and carrying more weight. As such, "external" engineers are considered more suited to assume an unbiased posture and examine issues in a broader context. Another advantage of "external" experts lies in the breadth of their knowledge: such experts generally have broader experience, enabling them to speak with more authority on the state-of-the-art and the practices of other agencies, while many agency engineers have spent their entire careers with the agency. Furthermore, when highly technical issues are involved, an outside expert may have more in-depth experience, credentials, and professional recognition than the departments' senior engineers whose work experience may be more general and administrative in nature.

\subsection{Levels of Highway Tort Liability Risk Management}

It is assumed that a base condition of highway tort liability risk management refers to the current situation where no staff is explicitly assigned to highway risk management. Table 5 shows the various levels of risk management and the corresponding staff strength.

Table 5: Level of Risk Management and Corresponding Staff Strength

\begin{tabular}{cl}
\hline Level of Risk Management & Risk Management Staff Strength \\
\hline Base Condition & No staff for highway tort liability risk management \\
\hline Level 1 & Database Specialist \\
& (see Section 6.2.3 for associated duties) \\
\hline Level 2 & Database Specialist and Claims Analyst \\
& (see Sections 6.2.3 and 6.2.2 for associated duties) \\
\hline Level 3 & Database Specialist, Claims Analyst, and Risk Manager \\
& (see Sections 6.2.3, 6.2.2, and 6.2.1 for associated duties) \\
\hline
\end{tabular}




\subsection{Risk Management System Organization}

The feedback aspect of an effective risk management system is represented by the reporting of lessons learned from after-the-fact experiences which are reported back to risk prevention strategy elements such as engineering, enforcement and information dissemination. After-the-fact aspects of the risk management program, also referred to as palliative measures, would include reception and logging of suit notices, claim investigations, legal proceedings, and records compilation and analysis. It is expected that the Attorney General's Office would continue to handle the legal aspects of the risk management system.

\subsubsection{Effective Agency-User Communication for Risk Management}

An effective risk management program hinges on efficient information flow regarding the location and nature of hazardous situations. Road users can serve as an excellent source of timely information and can build a strong relationship with INDOT. Remarks and warnings from road users have been found to be a good source of information for risk management systems. This information can be obtained through a website, telephone, mail, or e-mail. An illustration of this concept is a web-based tool developed as part of a JTRP study [Tarko and DeSalle, 2002]. Using the tool, road users who encounter or notice dangerous road situations would be able to report it to the risk management office using any of the identified means of communication. The risk management office should investigate concerns brought by citizens with due diligence. Also, the office should have strong organizational links with the law enforcement agencies as well as the highway maintenance agencies. Gittings [1987] states that the relationship between highway maintenance personnel and state/local police has a major impact on tort liability prevention. He further states that the timely sharing of information between a DOT and the police on serious injury or fatality incidents associated with dangerous highway conditions is an important aspect of effective risk management loss control. This cooperation is essential, as data collected without delay at accident sites would result in a better quality and accuracy of those data. These data are typically critical in the resolution of court cases, particularly where the State's position could be viewed more favorably due to prompt reaction on its part. INDOT and the Attorney General's Office should hold regular meetings to ensure that an effective communication between them. Their unique roles should be clearly defined and understood by all personnel involved in highway tort liability risk management. 


\subsubsection{Estimated Costs of Establishing and Operating an Office for Highway Tort Risk Management}

Initially, a highway tort liability risk management program could be started by assigning one person for management of such risks, as a Level 1 effort in risk management. This staff, who may be based at INDOT's Legal Division or at the Attorney General's Office, would work directly with the Investigation Division of the Attorney General's Office to build a comprehensive highway tort liability risk management database. This staff would also interact with INDOT's other divisions, particularly the Program Development, Operations Support, and Construction Divisions to coordinate activities relevant to tort issues. Eventually, the second and third professionals (claims analyst and risk manager) can be added as the role of risk management evolves. While Levels 1 and 2 are interim levels with shared secretarial assistance, Level 3 will be a reasonably well staffed unit with full-time secretarial assistance. The estimated annual cost can be from $\$ 70,000$ for Level 1 , to $\$ 350,000$ for Level 3. This includes salaries, fringe benefits, office furniture and equipment, communications, and supplies. It should be noted that Levels 2 and 3 should be considered only after the database is developed and if it is established that further work on claims analysis and subsequent risk management actions are justified.

\subsection{Suggested Site Improvements for Reducing the Frequency of Common Claims}

The duties of a risk management office would be to liaise with the design, operations and construction divisions to develop practices that reduce the incidence of tort situations. In Chapter 4, four types of common claims were studied in detail: chuckhole claims, mailbox claims, mower claims and paint claims. The frequency of common claims could be reduced by continued use of effective practices, or site specific modification of existing practices. A few of such recommendations are explained below.

\section{Chuckhole Claims:}

The Attorney General's Office denies all claims for which INDOT did not have a previous warning. This means that the first person who complains about a pothole will not receive any compensation. Then, if INDOT fails to repair the potholes and fails to signal it to road users, the Attorney General's Office will have to pay if another accident occurs. According to the Attorney General's Office, INDOT is generally very efficient in responding to such requests. To help reduce the frequency of this category of tort claims, INDOT should continue to seek ways to quickly identify and react to road surface defects. 


\section{Mailbox Claims:}

INDOT employees should be continually reassured that damaging a mailbox during snow plowing operations does not necessarily constitute a grave act of negligence, but should be reported as soon as it happens. This way it would be possible for the Attorney General's Office to easily investigate the legitimacy of filed mailbox claims. Recorded information such as the place and the time of the incident would facilitate such investigations.

\subsection{Chapter Summary}

Establishment of an incremental highway tort liability risk management program should be preceded by a clear definition of each stage of the system, with an identification of the roles expected to be played by each member of the highway tort liability risk management team. This chapter identifies the various positions involved in a typical risk management setup and discusses the functions of each position. The chapter defines four levels of risk management including a base case, and explores the impact of implementing various levels of risk management. Each level of risk management is surrogated by the number of staff hired, each for the positions of database specialist, claims manager, and risk manager. With the implicit assumption that an increasing risk management efforts (such as personnel strength) translates to higher effectiveness of risk management up to a certain point, the next chapter builds on the present chapter and evaluates the cost effectiveness of various levels of risk management effort. Also, the present chapter makes a few suggestions on how to reduce the frequency of incidents that are typically associated with filing of common claims. On the basis of the discussion from this chapter as well as the results from previous chapters, the next chapter utilizes a decision-theoretic approach to investigate the cost-effectiveness of alternative levels of highway tort liability risk management for the state of Indiana. 


\section{CHAPTER 7: COST EFFECTIVENESS EVALUATION OF HIGHWAY TORT LIABILITY RISK MANAGEMENT AT INDOT USING A DECISION THEORETIC APPROACH}

\section{$\underline{7.1 \text { Introduction }}$}

The present chapter provides a decision theoretic approach to establishing and evaluating the cost-effectiveness of a risk management program for INDOT. In this approach, the expected values of tort amounts at various levels of risk management are estimated by identifying possible paths of various claims and assigning complementary probabilities for events associated with these paths. Thus, the benefits, costs, and cost-effectiveness of establishing various levels of risk management can ultimately be estimated.

\section{$\underline{7.2 \text { Assumptions }}$}

Based on recent data, it can be estimated that yearly primary costs of common claims represent only $\$ 100,000$ of the annual $\$ 1,900,000$ paid by the Attorney General's Office for INDOT's claims. Secondary costs associated with all claims of all state agencies (including INDOT) reach approximately \$2.3 million annually. INDOT related claims represent the largest share of tort costs borne by the Attorney General's Office, and can be estimated to be between $\$ 600,000$ and $\$ 1,200,000$ per year. Even though the number of common claims constitutes approximately one-half of all claims, they rarely end up in litigation. It can, therefore, be assumed that the secondary costs associated with common claims are considerably less than those for other claims. A reasonable estimate of annual secondary costs associated with highway related common claims can be as low as $\$ 100,000$. Estimates of annual average primary and secondary costs were provided in Table 3. It is felt that these values could be sufficiently reduced by risk management strategies such as monitoring tort claims and maintaining a comprehensive data-base. 


\section{$\underline{\text { 7.3 Basic Principles }}$}

The present study focuses primarily on incidents that take place on the highway and for which INDOT is subsequently responsible. The study refers to such incidents as "highway facility incidents”. The occurrence of highway incidents has been found to follow stochastic processes that are governed to a large extent by known probabilistic distributions such as the Poisson and Negative Binomial [Pasupathy and Ivan, 2000; Konduri, 2002].

Occurrence of a highway facility incident may or may not result in vehicular or personal injury. Even if it does, one of two things would happen: a) compensation is sought by the victim from the transportation agency responsible for operating/maintaining the facility, or b) the victim decides not to file claim for compensation. In cases where the victim files for compensation, the amount sought is highly variable, depending on the nature and severity of the incident, and other factors. Furthermore, claim filing may or may not result in compensation, depending on the circumstances of the case. Given such highly probabilistic nature of highway facility incidents and subsequent tort claims, it may be a challenge to provide an accurate forecast of tort claim frequency and amounts. In the past, various actuarial techniques have been developed by insurance companies to predict future claims using probability theory and stochastic modeling. According to some researchers, the delays inherent in claims processing and variability in claims parameters usually lead to failure in efforts to estimate risk levels, and these attempts have been "at best unreliable and at worst worthless" in terms of financial planning [Lewis et al., 1994]. Consequently, such models may not provide an accurate reflection of future yearly claims. They can be effectively used, however, to develop a decision support system for planning and programming purposes.

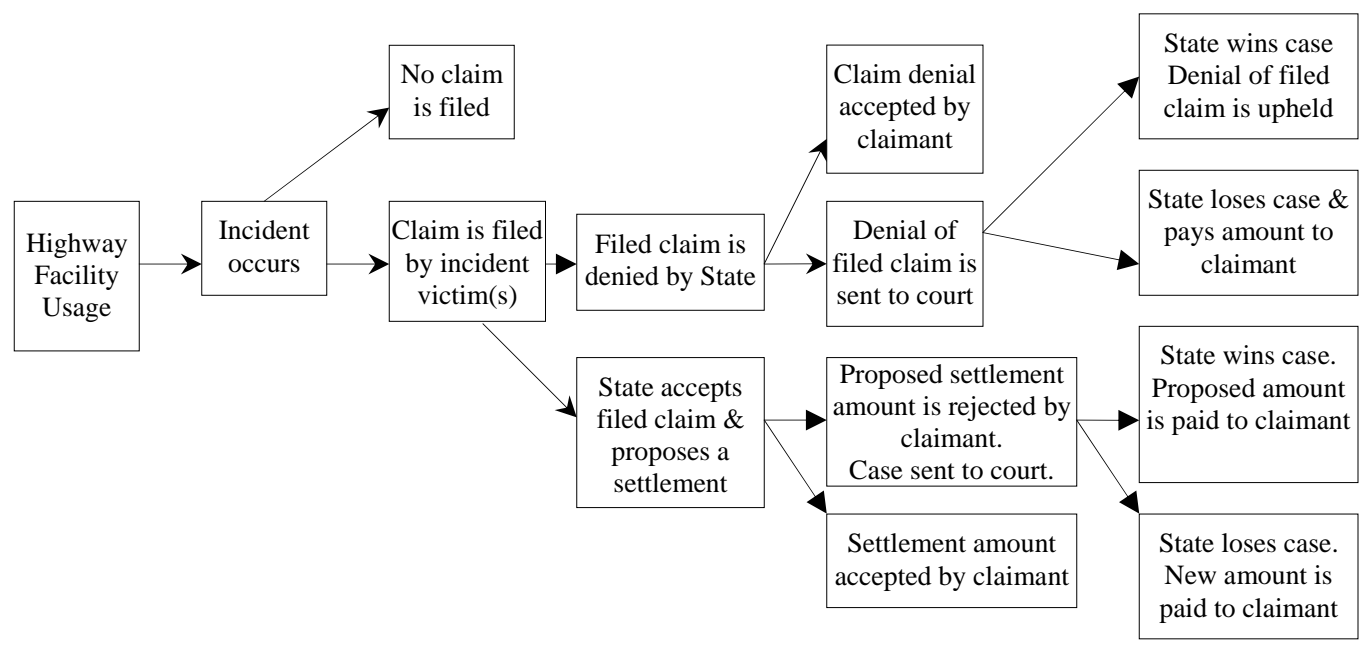

Figure 17: Claim Sequence 


\subsection{Description of Claim Sequence}

From published literature, and based on data made available by the Indiana Attorney General's Office (State), a list of typical generic claims can be drawn up as shown in Section 4.2. When a claim arrives at INDOT it is transmitted to the Attorney General's Office where it is denied or not denied. Usually, when a case is not denied, a settlement is proposed to avoid a court procedure. Figure 18 shows a tree that represents the different paths that a claim can follow during its life. The tree is claim category specific. It means that there are as many trees as there are claim categories within a claim type. Probabilities are indicated along the branches of the tree.

The different branches of the tree presented in Figure 18 are described in the following sub-sections:

- Incident Occurrence

- Claim Filing,

- Denial/Settlement of Filed Claims

- Claimant’s Acceptance or Rejection of Claim Denial/Settlement

- $\quad$ Outcome of Court Cases

\subsection{Determination of Probability Values at Each Stage of Claim Life}

For each stage of the claim path, probabilities can be determined on the basis of historical data. Also, legal experts at the Attorney General's Office have experience in dealing with tort cases and their opinions can serve as prior values for probabilities. Information from personnel in INDOT's Legal Division can also be of use in this effort. Questionnaires or surveys can serve as the medium for gathering information from the experts and employees of INDOT and the Investigation Division of the Attorney General's Office.

A desirable method to develop probability values at each stage would be to use aggregated historical data. However, the accuracy will depend on the amount of data available. Various estimates can be made, including the number of tort claims per year by type and category, the geographic location of incidents, the proportion of incidents leading to a claim, the average amount paid for each category of claims, and so on. More details should be maintained for costly claims that are not common. Only with an extensive database can trends, cycles and patterns be revealed for development of probability trees. 


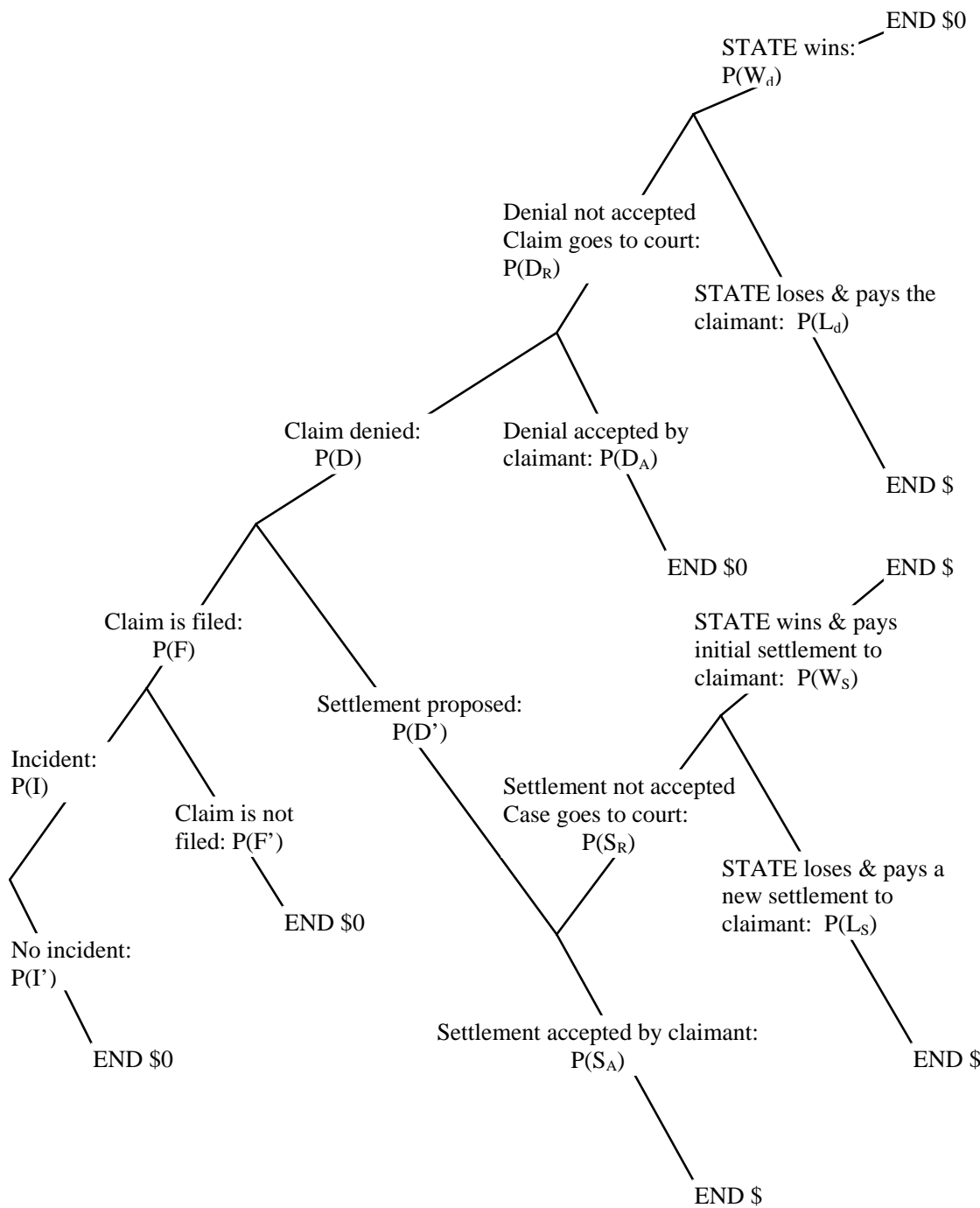

\begin{tabular}{l|lll|l} 
Stage 1 & Stage 2 & Stage 3 & Stage 4 & Stage 5
\end{tabular}

Figure 18: Claim Probability Tree for a Given Claim Type and Category, and a Given Level of Risk Management 
The decision tree approach uses the concept of statistical expectation and probability as follows:

For a claim type $k$ and category $i$, for which cost is typically $x_{k, i}$,

$$
E\left(x_{k, i}\right)=x_{k, i} \times p\left(x_{k, i}\right)
$$

where

$E\left(x_{k, i}\right)=$ expected cost of the claim of type $k$ and category $i$,

$p\left(x_{k, i}\right)=$ probability that the claim type $k$ and category $i$ is paid.

In other words, the expected cost of each category within a claim type is simply calculated as the probability that the claim is paid (either by mutual agreement or as a result of a court case), multiplied by the average amount incurred in settling this category of claim. For example, INDOT related claims can be considered to have two types, common and other. Within each claim type, there can be several categories. For example, the common claim type has four categories: paint, mower, chuckhole, and mailbox claims.

The sum of the expected costs of all claim categories gives the expected cost of a particular type of claim for a given period of time:

$$
E\left(x_{k}\right)=\sum_{\text {all }} E\left(x_{k, i}\right)
$$

where

$E\left(x_{k, i}\right)=$ expected cost of the claim of type $k$ and category $i$,

$E\left(x_{k}\right) \quad=$ expected cost of claim type $k$.

Then the expected cost of all claims is obtained by summing the expected costs of all claim types:

$$
E(x)=\sum_{k} E\left(x_{k}\right) A_{k}
$$

where

$E(x) \quad=$ expected cost of all claims,

$E\left(x_{k}\right) \quad=$ expected cost of claim type $k$,

$A_{k} \quad=$ Average number of claims of type $k$ per year.

The decision tree approach involves the development of probability trees that model the entire life path of tort claims, from incident occurrence to final claim settlement or claim denial. The probabilities at each branch of the tree can be developed using data on tort histories. In case such 
data are not available, subjective judgment of personnel involved in tort cases can be used as prior values. Sections 7.5.1 to 7.5.4 present methods of how the probabilities could be calculated on the basis of historical data.

\subsubsection{Probability of Incident Occurrence and Claim Filing}

As an alternative to the use of statistical models, to estimate the expected number of claims, probability values can be calculated as shown below:

$$
\begin{aligned}
& P(I)=\frac{\text { Number of incidents }_{\Sigma_{i} \text { mileage }_{i} * \text { yearly traffic volume }_{i}}}{P(I)} \quad=\text { incidents per year per vehicle mile of travel, } \\
& P\left(I^{\prime}\right) \quad=\text { Probability of no incident }=1-P(I), \\
& i \quad=\text { highway section. }
\end{aligned}
$$

For each claim category certain factors are irrelevant. For instance, the probability of a mailbox incident is clearly to be independent of traffic volume. Therefore, for mailbox incidents, $P(I)$ = Incidents per year per mile. For each category of claim, $\mathrm{P}(\mathrm{I})$ and $\mathrm{P}(\mathrm{I}$ ') occupy Stage 1 of the probability tree in Figure 18.

After an accident occurs, it may or may not be filed. Claim filing may be described as the formal act of registering or notifying the state of fatality, injury or damage upon a highway user, and the consequent intention of the user (or person(s) acting on his/her behalf) to seek compensation for such fatality, injury or damage. The seeker of such compensation is described as a "claimant" or "plaintiff."

For each claim category, the probability that a claim is filed is simply the ratio of filed claims for that category to the total number of incidents of that claim category.

$$
\begin{aligned}
& P(F)=\frac{\text { Number of claims filed in a category }}{\text { Total number of incidents in this category }} \\
& P\left(F^{\prime}\right)=1-P(F)
\end{aligned}
$$


For each claim category, $P(F)$ and $P\left(F^{\prime}\right)$ occupy Stage 2 of the probability tree in Figure 18. If an incident occurs but a claim is not filed, then the life of the claim comes to an end. In reality it may not be possible to make an estimate of the number of incidents, but the total number of filed claims can be determined. Therefore, it may be desirable to estimate the probability of a claim filed in terms of vehicle miles of travel or miles of road length. For claim categories related to vehicle miles of travel, the probability of filing a claim can be estimated as shown below:

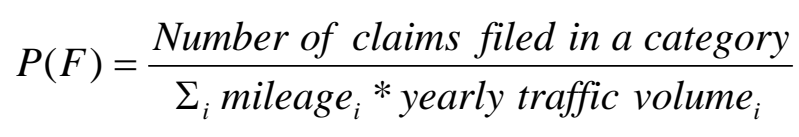

\subsubsection{Probability of Denial/Settlement of Filed Claims}

When the Attorney General's Office receives a claim, it is typically investigated by that department's Investigation Division. Depending on the results of the investigation, the claim is either denied (the state refuses to pay the amount associated with the claim) or a settlement is proposed. In a settlement, the state acquiesces and pays the claim amount because a) the claim appears well founded, or b) the claim may not appear well grounded, but its denial may likely lead to subsequent expensive court procedures and therefore be much more costly than a settlement. For each claim category, the probability that a filed claim is denied is the ratio of denied claims of that category to total number of filed claims of that category.

$$
P(D)=\frac{\text { Number of denied claims in given category }}{\text { Total number of filed claims in given category }}
$$

The probability that a settlement will be proposed is given by $P\left(D^{\prime}\right)$, where $P\left(D^{\prime}\right)=1-P(D)$. For each claim type, P(D) and P(D') occupy Stage 3 of the probability tree in Figure 18.

\subsubsection{Probability of Claimant's Acceptance or Rejection of Claim Denial/Settlement}

If the Attorney General's Office denies a claim, the claimant may accept such denial, in which case the life of the claim comes to an end. However, if the claimant does not accept denial of his claim, the case then proceeds to court. The probability that denial of a claim of a given type will be accepted by the claimant is:

$$
P\left(D_{A}\right)=\frac{\text { Number of denials that are accepted }}{\text { Total number of denials in given category }}
$$


The probability that denial of a given claim category will be rejected by the claimant (hence leading to subsequent court action) is: $P\left(D_{R}\right)=1-P\left(D_{A}\right)$

If the Attorney General's Office agrees to settle a claim on its terms, the claimant may or may not accept the settlement. If the claimant accepts the proposed settlement, then the life of the claim comes to an end, and a specific amount of money is disbursed to the claimant. However, if the claimant rejects the proposed settlement (often because he/she perceives the proposed settlement amount too little in comparison to the fatality, injury or damage), the case then heads to court. The probability that a proposed claim settlement is accepted by the claimant is:

$$
P\left(S_{A}\right)=\frac{\text { Number of proposed settlements that are accepted in a given category }}{\text { Total number of proposed settlements in a given category }}
$$

and the probability that the proposed settlement in a given claim category is rejected by the claimant is: $P\left(S_{R}\right)=1-P\left(S_{A}\right)$. For each claim category, $P\left(D_{R}\right), P\left(D_{A}\right), P\left(S_{R}\right)$, and $P\left(S_{A}\right)$ occupy Stage 4 of the probability tree in Figure 18.

\subsubsection{Probability of Outcome of Court Cases}

\subsubsection{Claim-Denial Court Cases}

If a claim is denied, it heads to court. If the Attorney General's office loses the case, it pays a specific amount to the claimant, and the life of the claim ends. The amount of money paid varies from one category of claim to the other. For instance, a typical mailbox claim is expected to cost \$43.10, while other categories of claims can be more costly. However, if the Attorney General's Office wins the case, its decision to deny the claim is upheld, and the life of the claim ends without any payment to the claimant. The probability that the Attorney General's Office wins a claim-denial case is given by:

$$
P\left(W_{d}\right)=\frac{\text { Number of "claim }- \text { denial" cases won in given category }}{\text { Total number of "claim }- \text { denial" cases in given category }}
$$

The probability that the state loses a claim-denial case is given by: $P\left(L_{d}\right)=1-P\left(W_{d}\right)$

For each category of claim, $P\left(L_{d}\right)$ and $P\left(W_{d}\right)$ are associated with Stage 5 of the probability tree in Figure 18. 


\subsubsection{Settlement-Denial Court Cases}

If a claim is not denied but the proposed settlement is rejected by the claimant, the case proceeds to court. If the state wins the case, the claimant is made to accept the initial settlement amount, and the case ends. However, if the state loses the case, it is made to pay the claimant a sum of money that is perceived by the court to be commensurate with the severity of the incident.

The probability that the state wins a settlement rejection case is:

$$
P\left(W_{s}\right)=\frac{\text { Number of "settlement }- \text { denial" cases won in given category }}{\text { Total number of "settlement }- \text { denial" cases in given category }}
$$

The probability that the state loses a claim-denial case is given by: $P\left(L_{s}\right)=1-P\left(W_{s}\right)$. For each category of claim, $P\left(L_{s}\right)$ and $P\left(W_{s}\right)$ are associated with Stage 5 of the probability tree in Figure 18.

\subsection{Evaluation of Cost-effectiveness of Various Levels of Risk Management}

After a comprehensive incident occurrence and tort claims database is developed, or after collation of survey responses from risk management experts, appropriate probability values can be assigned for each stage of the decision tree. These values can then be periodically updated using a Bayesian approach as new data is obtained. The probability values are necessary to establish appropriate strategies for risk management and to assess the cost-effectiveness of these strategies. The benefit of a particular level of risk management program can be evaluated in terms of its impact on reducing the number of filed claims, associated probabilities along the decision tree, and the monetary amounts of settlements. In order to have a detailed evaluation of a risk management program, the following information for each category of claims will be necessary along with estimates of monetary settlement figures.

- $A_{k, i}=$ Average number of claims per year in category $i$ and type $k$,

- $P(D)=$ Probability that a claim will be denied by state,

- $P\left(D_{R}\right)=$ Probability that the denial of a claim is rejected,

- $P\left(S_{R}\right)=$ Probability that a settlement is rejected,

- $P\left(L_{d}\right)=$ Probability that state loses a case in court that had been previously denied,

- $P\left(L_{s}\right)=$ Probability that state loses a case previously proposed for settlement. 
For the purpose of cost-effectiveness evaluation using the decision theoretic approach, attempts were made to develop probability trees for each level of risk management program and each type and category of claim. However, currently available data at INDOT was not adequate to enable demonstration of the overall decision theoretic framework. As such, an abbreviated decision tree can be considered for illustrating the approach. Using the abbreviated decision tree, and the costs and benefits associated with each level of risk management, the required reductions in probability of claims or number of claims for breakeven between costs and benefits were determined. The framework used for such breakeven analysis is illustrated as Figure 19.

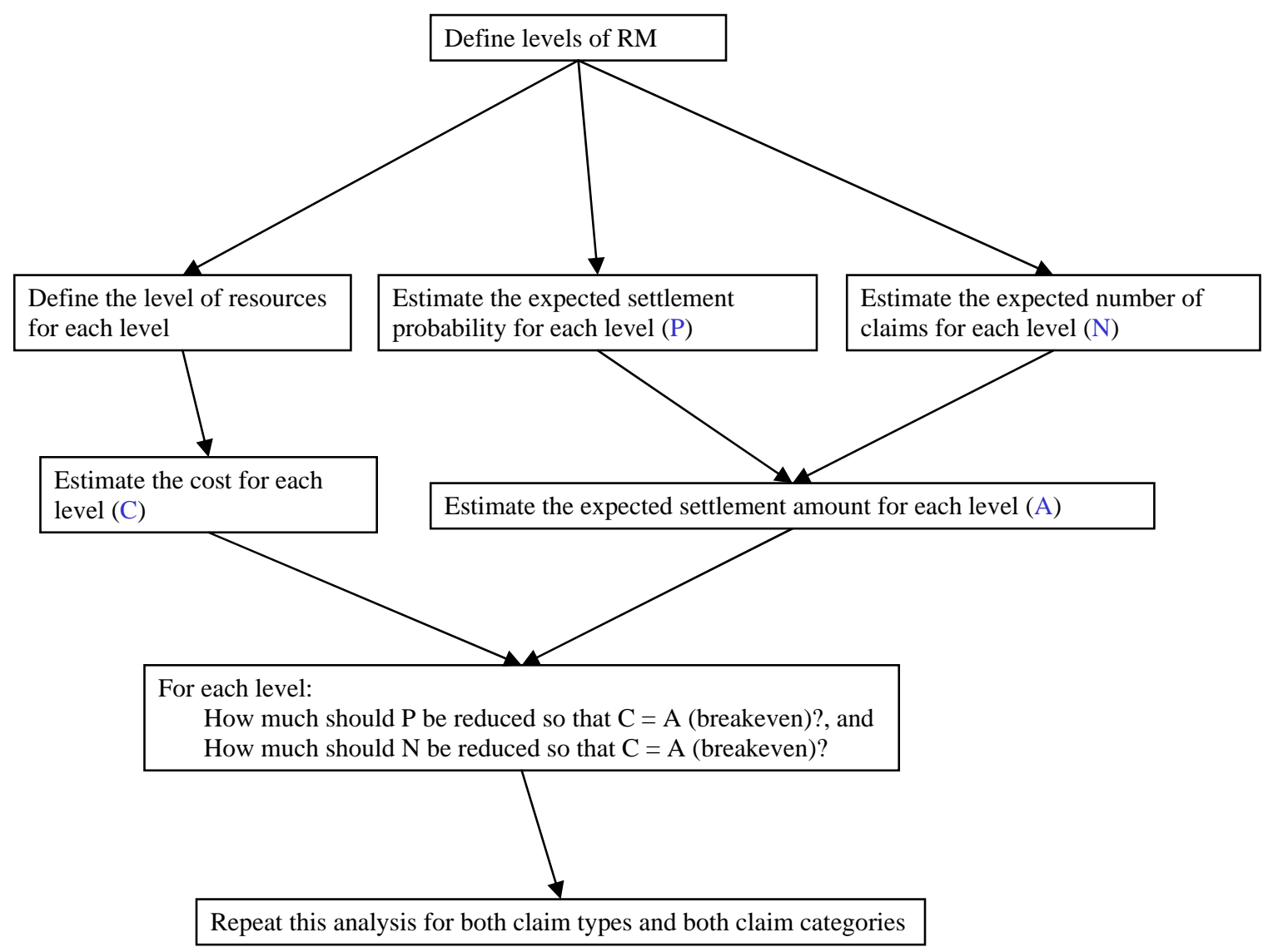

Figure 19: Breakeven Analysis on the Basis of the Abbreviated Decision-Theoretic Approach 
The total expected cost of settlement per year is the sum of the expected costs of settlement for the two claim types. For each claim type, the expected cost of settlement is simply a product of the average number of filed claims for that type $\left(A_{k}\right)$, the probability of monetary settlement of cases involving that claim type $\left(\mathrm{p}_{\mathrm{k}}\right)$, and average amount involved in monetary settlement of that type of claim $\left(\mathrm{S}_{\mathrm{k}}\right)$, as shown in Equation (1).

$$
E C=\sum_{\text {ClaimType }(k=1)}^{2}\left(p_{k} \times S_{k} \times A_{k}\right) \text {. }
$$

Under current base condition, where INDOT related tort liability is managed by the Attorney General's Office with no explicit risk management program at INDOT, the annual average primary cost is approximately $\$ 1.9$ million and the associated secondary cost is $\$ 1,000,000$ per year. Table 6 presents estimated values for the variables in Equation (1) for expected cost (EC), based on annual average primary tort cost of $\$ 1.9$ million. The values for common claims were computed from the recent 1999-2001 data from the Attorney General's Office, discussed in Chapter 4. For other claims, the settlement value used was based on the data from 2001. This number compared well with the data from at least one other state (Turner, 1992)

Table 6: Average Values of Variables Associated with Claim Cost Estimation (\$2001)

\begin{tabular}{lcc}
\hline & \multicolumn{2}{c}{ Claim Type } \\
\cline { 2 - 3 } & Common Claims & Other Claims \\
\hline $\begin{array}{l}\text { Average Annual Number of } \\
\text { Filed Claims (A) }\end{array}$ & 770 & 750 \\
\hline $\begin{array}{l}\text { Probability of Monetary } \\
\text { Settlement (p) }\end{array}$ & 0.29 & 0.2 \\
\hline $\begin{array}{l}\text { Average Primary Cost Incurred } \\
\left.\text { per Settlement ( } \mathrm{S}_{\mathrm{p}, \mathrm{k}}\right)\end{array}$ & $\$ 330$ & $\$ 12,000$ \\
\hline $\begin{array}{l}\text { Average Secondary Cost } \\
\text { Incurred per Settlement }\end{array}$ & & \\
\hline
\end{tabular}

*1 Note: From Table 3 ratio of primary and secondary costs is 2:1 for common claims

*2 Note: From Table 3 ratio of primary and secondary costs is 11/2:1 for other claims 


\subsubsection{Reductions in Settlement Probability and Frequency of Filed Claims}

Additional resource costs for various levels of a risk management program were estimated on the basis of Equation (1). This was done by considering that additional resource costs could be justified only if appropriate savings in tort liability costs could be achieved in terms of percent reduction in the probability of settlement and a reduction in the number of filed claims. This was done for each of the following cases of claim type and cost consideration combinations:

- Common claims, on the basis of primary cost only,

- Common claims, on the basis of both primary and secondary costs,

- "Other" claims, on the basis of primary cost only,

- "Other" claims, on the basis of both primary and secondary costs,

The results are shown in Table 7. Sample calculations are presented in the following sections.

Table 7: Percent Reductions in Probability of Settlement and Reductions in Number of Filed Claims for Various Claim Type, Cost Consideration, and Risk Management Level Combinations

\begin{tabular}{|c|c|c|c|c|}
\hline \multirow[b]{2}{*}{$\begin{array}{l}\text { Claim Type and Cost } \\
\text { Consideration }\end{array}$} & \multirow{2}{*}{$\begin{array}{c}\text { Level of } \\
\text { Risk } \\
\text { Management }\end{array}$} & \multirow[b]{2}{*}{$\begin{array}{c}\text { Additional } \\
\text { Resource Costs }\end{array}$} & \multicolumn{2}{|c|}{ Reduction from Base Case } \\
\hline & & & $\begin{array}{l}\text { Probability of } \\
\text { Settlement (\%) }\end{array}$ & $\begin{array}{c}\text { Number of Filed } \\
\text { Claims }\end{array}$ \\
\hline \multirow{4}{*}{$\begin{array}{l}\text { Common Claims only, } \\
\text { Primary Cost }\end{array}$} & Base & - & - & - \\
\hline & 1 & $\$ 70,000$ & $27.55 \%$ & 731 \\
\hline & 2 & $\$ 175,000$ & $68.87 \%$ & 770 \\
\hline & 3 & $\$ 350,000$ & $100.00 \%$ & 770 \\
\hline \multirow{4}{*}{$\begin{array}{l}\text { Common Claims only, } \\
\text { Primary and Secondary } \\
\text { Costs }\end{array}$} & Base & - & - & - \\
\hline & 1 & $\$ 70,000$ & $13.77 \%$ & 366 \\
\hline & 2 & $\$ 175,000$ & $34.44 \%$ & 770 \\
\hline & 3 & $\$ 350,000$ & $68.87 \%$ & 770 \\
\hline \multirow{4}{*}{$\begin{array}{c}\text { “Other” Claims only, } \\
\text { Primary Cost }\end{array}$} & Base & - & - & - \\
\hline & 1 & $\$ 70,000$ & $0.78 \%$ & 29 \\
\hline & 2 & $\$ 175,000$ & $1.94 \%$ & 73 \\
\hline & 3 & $\$ 350,000$ & $3.89 \%$ & 146 \\
\hline \multirow{4}{*}{$\begin{array}{c}\text { “Other” Claims only, } \\
\text { Primary and Secondary } \\
\text { Costs }\end{array}$} & Base & - & - & - \\
\hline & 1 & $\$ 70,000$ & $0.52 \%$ & 19 \\
\hline & 2 & $\$ 175,000$ & $1.30 \%$ & 49 \\
\hline & 3 & $\$ 350,000$ & $2.59 \%$ & 97 \\
\hline
\end{tabular}




\subsubsection{Sample Calculation for Percent Reduction in Probability of Settlement}

We determine the percentage reduction in probability of settlement necessary, while all other values remain the same, in order to break even. Consider common claims on the basis of primary cost only, and risk management Level 1:

Additional resource costs for Level 1 of risk management $=\$ 70,000$

Equation (1) is solved using the base case values from Table 6.

Additional resource costs $\quad=\Delta p \times A \times S$

$$
\begin{aligned}
& \$ 70,000=\Delta p \times 770 \times \$ 330 \\
& \Delta p=0.2755
\end{aligned}
$$

Thus, Level 1 of risk management can be justified on the basis of primary cost only, if it can reduce the probability of settlement by approximately $28 \%$.

\subsubsection{Sample Calculation for Reduction in Number of Filed Claims}

The reduction in number of filed claims is established while all other values remain the same in order to break even. Consider common claims on the basis of primary cost only, and risk management Level 1:

Additional resource costs for Level 1 of risk management $=\$ 70,000$

Equation (1) is solved using the base case values from Table 6.

Additional resource costs $=p \times \Delta A \times S$

$$
\begin{aligned}
& \$ 70,000=0.29 \times \Delta A \times \$ 330 \\
& \Delta A=731 \text { claims }
\end{aligned}
$$

Therefore, at least 731 filed claims must be reduced in order to justify Level 1 risk management program, if one considers only the primary cost of common claims.

\subsubsection{General Discussion}

In order for the Level 1 risk management program (with an estimated resource cost of $\$ 70,000$ ) to break even on the basis of primary cost savings, for example, the probability of settlement for only common claims has to be reduced by about $27.55 \%$ as presented in Table 7 , assuming all other values in Table 6 remain the same. However, if one assumes that a better database and record keeping can also reduce secondary costs, only about $13.77 \%$ decrease in probability of settlement would offset the cost of Level 1 program. Table 7 also indicates that the trend is increased with increasing levels of risk management. 
In reality, a risk management program can potentially lower not only the probability of settlement, but also the number of filed claims. For Level 1 risk management, the number of common claims filed must be reduced by 731, considering only primary cost savings. On the other hand, if only "other" claims are considered, they must be reduced by 29 to justify Level 1 risk management on the basis of primary cost savings. If secondary costs representing expenses associated with investigation and prosecution are included in total costs, only 366 of common claims and 19 of other claims have to be decreased in number of filed claims, as shown in Table 7 . The reductions necessary for higher levels of risk management are also given in Table 7.

In order to determine the best level of risk management, the reasonableness of the reductions necessary in probability of settlement and number of filed claims should be considered. For example, if the goal is to focus on common claims, any level higher than the first level may not be realistic, as the higher levels require a very large reduction in the probability of settlement or the elimination of practically all common claims. However, if both types of claims can be expected to be affected by risk management, an investment in higher levels of risk management programs can be justified.

\section{$\underline{7.7 \text { Chapter Summary }}$}

A systematic approach can be followed to assess various levels of a risk management program using a decision theoretic framework. The approach can be useful not only in evaluating the cost-effectiveness of a program, but also to develop appropriate management strategies that can affect the number of claims, various probabilities associated with a claim sequence, as well as the monetary values of settlements. On the basis of recent experience with INDOT related tort cases and their settlements, it appears that an explicit risk management program can be economically justified. 


\section{CHAPTER 8: SUMMARY AND CONCLUSIONS}

In constructing, maintaining, and operating the state’s highway transportation infrastructure, the Indiana Department of Transportation is inevitably exposed to the risk of occurrence of various incidents that can result in death or injury of road users, or property and environmental damage. With the amendment of Indiana's Legal Code in 1972, the state was largely stripped of its immunity from liability in state court proceedings for damages resulting from exercise of its proprietary or governmental functions. In wake of this event, the number of highway-related tort claims received at and settled by the Attorney General's Office has shown a marked increase over the years, a trend that is not inconsistent with that of other states. Increases in costs associated with tort claims against state and local transportation agencies have generally translated in reduction in available funds for other vital state functions, a trend that is considered particularly ominous when viewed in the context of current budgetary constraints.

A review of available literature on the state of practice has shown that the management of highway tort liability risks can lead to their reduction, with subsequent benefits to all parties directly or indirectly involved with the usage or administration of the highway facility. Many states have begun the development of various programs to manage the risks associated with highway tort, and to handle tort claims, and several have touted the benefits of such programs in reducing highway tort liability risks. As part of the present study, literature on previous research was reviewed and a questionnaire survey was carried out to document the state of the risk management practice in other states. The results of such information search revealed that compared to Indiana, most states have reached a relatively advanced stage in the practice of highway tort liability risk management and have set up offices or programs explicitly to manage risks associated with highway tort liability. The review and survey also showed that it is feasible to develop and implement a risk management program to address highway tort liability in the State of Indiana. Furthermore, the literature review and questionnaire survey provided an insight into the various elements and tools needed for the design and implementation of such a program. The State of Indiana is in a position to draw on the experience and knowledge garnered by other states as it considers the establishment of an office to manage highway tort liability risks.

This study documents the current situation of tort liability management in Indiana, with specific focus on the trends involving categories of common claims. The study also provides a basis 
for decision making regarding the establishment of a risk management program for the State, and argued for strengthening links existing between the Attorney General's Office and INDOT, and an incremental and evolutionary approach towards the establishment of a risk management office to manage highway tort liability in the state. The study takes due cognizance of the fact that the Attorney General's Office, and not the Indiana Department of Transportation, is responsible for the payment to settle any tort claims against the state including those claims arising from the use of transportation infrastructure.

The study identifies elements of pre-emptive risk management where actions of a legal, administrative, engineering and enforcement nature have to be taken to reduce the incidence of tort liability incidents, and a palliative risk management which involves actions taken to lessen the impacts of tort liability incidents after they have occurred. Reduction of tort exposure is an important element of pre-emptive risk management: design and maintenance decisions based on budgetary or other economic constraints are generally seen as discretionary in nature, and therefore the INDOT is generally not liable to tort in cases related to such areas. However, as demonstrated in a past case, a transportation agency that argues that its failure to remedy a defective design due to funding priorities can be held liable if it presents no evidence on planning, ordering of priorities, or limitations on available funding. In this regard, the current development of safety and congestion management systems for INDOT and the on-going refinement of the already developed pavement and maintenance management systems, will serve to provide such evidence on planning and programming of investments, and will subsequently reduce the exposure of the state to tort. Furthermore, it should be noted that in the current situation, risk management is implicitly involved in various aspects of INDOT's design and operations. For instance, the use of safety factors in highway engineering design is consistent with risk management practice. Also, the operation of freeway patrol systems (Hoosier Helpers) that clear incidents inherently reduces the risk of secondary incidents

The study defines four levels of highway tort liability risk management effort including a base case, and explores the impact of implementing each level. An implicit assumption is that each level of risk management can be adequately surrogated by the number of staff hired, each for the positions of database specialist, claims manager, and risk manager. Considering Level 1 risk management program (herein specified as INDOT's hiring of only a database specialist), it can be assumed that at a minimum, the development of a database would reduce the probability of monetary settlement. To break even at this level (on the basis of primary cost savings) the probability of settlement for only common claims generally has to be reduced by about $28 \%$, assuming all other factors remain constant. With the assumption that a better database and record keeping can also 
reduce secondary costs, only about $14 \%$ decrease in probability of settlement would offset the cost of Level 1 program. A program for managing highway tort liability risks in Indiana can potentially lower not only the probability of settlement, but also the number of filed claims.

Consequently, it seems reasonable to expect that the stepwise implementation of a risk management program for INDOT outlined in the present study can be well justified. The incremental and evolutionary would ensure the cost-effectiveness of a systematic highway tort liability risk management program, and such a program would help the Indiana Department of Transportation to improve the performance of its facilities as well as reliability of service, while strategically reducing risks to facility users, and also to non-users and agency workers. Reduced expenditure for payments to settle tort liability cases could translate to increased availability of funding for other sectors of the state economy. Summing up, it is envisaged that the development of a fully operational risk management system for highway tort liability would ultimately provide the following benefits:

- Coordination and tracking of all highway related claims and litigation against the state,

- Processing of all highway related claims and managing a tort liability loss-mitigation program, and directing the resources of the department to minimize the adverse effects of litigation on the department and the public,

- Promotion of a cost-effective risk management effort statewide, development of control mechanisms through training and counseling, and fostering awareness by all employees of the risk potential associated with their actions,

- Improvement of highway safety by identifying incidents types and locations associated with high tort costs and/or frequencies,

- $\quad$ Reduction of the state's exposure and loss due to highway related tort liability. 


\section{LIST OF REFERENCES}

Anderson, R.W. [1985]. "Booby Trapped: Potholes”, Transafety Reporter, Volume 3, Issue 4, Washington, D.C.

Anderson, R.W. [1986. “On the Road: Highway Design Inadequacies for Trucks”, Transafety Reporter, Volume 4, Issue 7, Springfield, VA.

Anderson, R.W. [1990]. “Tort Liability and Risk Management”, Transafety Reporter, Volume 8, Issue 8, Burke, Virginia.

Anderson, R.W. [1992]. “On the Road: A Need for Risk Management in Road Agencies”, Transafety Reporter, Volume 10, Issue 2, Burke, VA.

Anderson, R.W. [1993]. "On the Road: Managing the Risk and Recognizing the Liability When Pedestrians are Involved”, Transafety Reporter, Volume 11, Issue 7, Burke, VA.

Bagby, J.W., and Gittings, G.L. [1999]. "Litigation Risk Management for Intelligent Transportation Systems: Part 2.”, ITS Quarterly, Volume 3, Issue 7, Washington, D.C

Bagby, J.W., John, W., and Gittings, G.L. [2000]. "Litigation Risk Management for Deployment of AHS and ETC”, Part 3, ITS Quarterly, Volume 7, Issue 1, Washington, D.C.

Bair, B.O., Fornini, W.J., Grubba, J.L. [1980]. "Highway Risk Management: A Case Study”, Transportation Research Record 742, Transportation Research Board, National Research Council, Washington, D.C.

Choate, P. [1999]. "Development of a Conceptual Integrated Traffic Safety Problem Identification Database", California Department of Motor Vehicles Research and Development Branch, Sacramento, CA.

Cooley, A.G. [1996]. "Risk Management Principles of Transportation Facility Design Engineering”, Journal of Transportation Engineering, Volume 122, Issue 3, American Society of Civil Engineers, New York, NY.

Datta, T.K. [1996]. “Accidents and Risk Management”, Proceedings of ITE 1996 International Conference, Moving Forward in a Scaled-back World: Challenges and Opportunities for the Transportation Professional. Dana Point, CA.

Datta, T.K., Krycinski, T.R., Taylor, W.C. [1991]. "Highway Risk Management System: A Michigan Program”, ITE Journal, Volume 61, Issue 10, Washington, D.C.

Demetsky, M.J., and Yu, K. [1992]. “A Framework for Evaluation of Risk Management Programs in State Departments of Transportation. Risk Management Systems Volume III”, Transportation 
Research Record 1345, Transportation Research Board, National Research Council, Washington, D.C.

Demetsky, M.J., and Yu, K. [1993]. “Assessment of Risk Management Procedures and Objectives in State Departments of Transportation”, Transportation Research Record 1401, Transportation Research Board, National Research Council, Washington, D.C.

Edson, C.T. [1980]. “Risk Management”, Transportation Research Record 781, Transportation Research Board, National Research Council, Washington, D.C.

Frohwein, H.I., Lambert, J.H., Schiff, L.A. [1999]. "Multi-criteria Framework to Aid Comparison of Roadway Improvement Projects”, The Journal of Transportation Engineering, Volume 125, Issue 3, American Society of Civil Engineers, Reston, VA.

Garcia, C., Huebschman, R., Abraham, D., and Bullock, D. [2002]. "Innovative Approaches for Improving Safety in Construction Work Zones" Proceedings of the 10th International Symposium in Construction Innovation and Global Competitiveness of CIB W-65., September 11-13,2002, Vol 2, 1063-1076, Cincinnati, OH.

Gittings G.L. [1987]. “Tort Liability and Risk Management”. Journal of Transportation Engineering volume 113, Issue 1., American Socitey of Civil Engineers, Reston, VA.

Gittings, G.L. [1989]. “Attacking Tort Liability through an Improved Risk Management Process: A State Perspective”, Transportation Quarterly, Volume 43, Issue 3, Eno Foundation, Westport, CN.

Gittings, G.L., and Jacobs, D.J. [1990]. "Evolution of Risk Management in a State Highway Agency”, Transportation Research Circular 361, Transportation Research Board, National Research Council, Washington, D.C.

Gowen B. C. [1990]. "Manuals for Traffic Engineers: an Engineering Tool or Legal Weapon? The California Experience”. Transportation Research Circular. Number 361.

Hengst G. [1999]. "Risk Management for the Transport of Hazardous Substances: The Dutch Approach”. Second World Congress on Safety of transportation: Imbalance Between Growth and Safety? Delft, the Netherlands.

Hoel, L.A., Demetsky, M.J., Reagan, D. [1991]. "Risk Management Systems Volume 2: Identification and Evaluation of Risk Elements for Highway Systems in Tort Liability”, University of Virginia, Department of Civil Engineering, Report Number MAUTC-UVA04-0991, Charlottesville, VA.

Konduri S. and Sinha, K.C. [2003]. "Models for Prediction of Freeway Incidents", JTRP Final Report, FHWA/IN/JTRP-2003/23, Purdue University, West Lafayette, IN.

Lewis R.M. [1994]. “Managing Highway Tort Liability. A Synthesis of Highway Practice”, NCHRP Synthesis 206., Transportation Research Board, National Research Council, Washington, D.C.

McGuire, P.J. [1995]. "Organizational Coordination, Transportation Planning, and Hazard Mitigation: A View from the North Carolina Coast”. Transportation Research Record 1449, Transportation Research Board, National Research Council, Washington, D.C. 
Mehndiratta, S.R., Brand, D., Parody, T.E. [2000]. "How Transportation Planners and Decision Makers Address Risk and Uncertainty”, Transportation Research Record 1706, Transportation Research Board, National Research Council, Washington, D.C.

Pasupathy, R.K., Ivan, J.N. [2000]. "Single and Multi-vehicle Crash Prediction Models for TwoLane Roadways”, Final Report, New England Universities Transportation Center, Report Number NEUTC UCNR9-8, Cambridge, MA.

Purdue University Exponent. [2002]. Petty Suits Take Toll on State Budget, September 25 Edition, West Lafayette, IN.

Reed, G.L. [1988]. “Improve Inspections and Reviews to Reduce Liability”, ITE Journal, Volume 58, Issue 1, Washington, D.C.

Roberts S.N. [1993]. “Advanced Traffic management Systems Tort Liability Issues”. Prepared for the Federal Highway Administration, Washington, D.C.

Roberts, S.N. [1997]. "Liability and ITS, Traffic Technology International”, Special Issue, UK and International Press, Surrey, England, U.K.

Smith J.L., Lawrence A. Durant, Norman N. Hill and Charles Raymond Lewis II. [2000]. "Transportation Tort Law. A Look Forward". TRB. Committee on Tort Liability and Risk Management, Washington, D.C.

Tarko A. and DeSalle. [2002]. "Internet Supported Evaluation of Highway Safety”, JTRP Final Report, FHWA/IN/JTRP-2002/9, Purdue University.

Thackston, A.C., and Black, J.C. [1991]. “An Action Plan for Risk Management in the Virginia Department of Transportation: Final Report”, Report No. VTRC 91-R14, Virginia Department of Transportation, Richmond, Virginia.

Thomas, L.W. [2003]. "Tort Liability of Highway Agencies”, Selected Studies in Transportation Law Volume 4, National Cooperative Highway Research Program, Transportation Research Board, Washington, D.C.

Turner, D.S. [1990]. "Education/Training Subcommittee, TRB Task Force on Tort Liability: Final Report”, Transportation Research Circular 361, Transportation Research Board, National Research Council, Washington, D.C.

Turner, D.S., and Agent, K.R. [1992]. "Roadway Related Tort Liability and Risk Management”, Report Number KTC-92-2, Kentucky Transportation Center, Lexington, Kentucky.

Turner D.S. and Colson, C.W. [1988]. “Two Approaches To The Tort Liability Issue”. Quarterly.

Westlaw [2002]. Proceedings of Court Cases in Indiana, February - May 2002, www.westlaw.com, Eagan, MN. 


\section{APPENDIX A}

\section{A Newspaper Article on Tort Liability Expenditure in Indiana}

'Petty' suits take toll on state budget, by Yuri Victor, City Editor

When raccoons rip open backpacks in state parks, taxpayers foot the bill.

Since 1997, the state has paid at least $\$ 30$ million on thousands of claims involving state agencies, ranging from civil rights settlements to prison inmates' lost belongings. But if Attorney General Stephen Carter has his way, many of these claims would be dismissed. Carter rejected more than 1,400 claims last year and again this year. "If they have a legitimate claim, we should pay it," Carter said. "If not, we are going to aggressively defend it."

Some of the claims are frivolous, he said. They involve harm for which the state is not liable, including inmates stealing from one another and car-deer accidents. Other claims have become so common — such as mailboxes damaged by snowplows or property damaged by debris thrown from mowers - the state has drafted form-letter responses. The state awarded the highest claim to a family wrongly separated by a welfare caseworker, while the lowest claim went to an armed robber whose collarbone was broken during a prison search.

The potential for lawsuits seem limitless:

- When a student at the Indiana School for the Deaf was sexually assaulted, taxpayers paid.

-When a state-owned vehicle skidded into a truck, damaging a trailer and riding mower, taxpayers paid.

- When a trooper forgot to remove stop sticks from the interstate, stranding five drivers, taxpayers paid.

The Indiana Department of Transportation had the most claims. Since January 2001, they've had 600 cases, totaling \$3.22 million in taxpayer's money. State Police were next highest in the tally, with \$1.04 million paid on 90 claims - most involving traffic accidents. The Department of Correction ranked third. Of the $\$ 673,249$ paid on 19 claims, $\$ 100,000$ went to the family of an inmate who committed suicide. Another $\$ 90,000$ went to an inmate who was raped and $\$ 15,000$ to an inmate who was stabbed. The state also paid to replace items broken or lost by guards. The lists of replaced items included television sets, snacks and pornographic magazines.

As the state continues to face budget problems the payments take on greater significance.

But state agencies have little incentive to protect the public purse because settlements aren't deducted from their budgets. The money is cut from the general funds. Carter questions that system. "Managers should have incentives to hold down litigation costs," he said. "I think we need more accountability."

The attorney general's office must spend money to investigate and defend the state against these claims. The total comes out to about $\$ 2.3$ million annually.

The Associated Press contributed to this story.

(Source: The Exponent, Purdue University, September 25, 2002) 


\section{APPENDIX B}

\section{Goals and Objectives of a Risk Management Program}

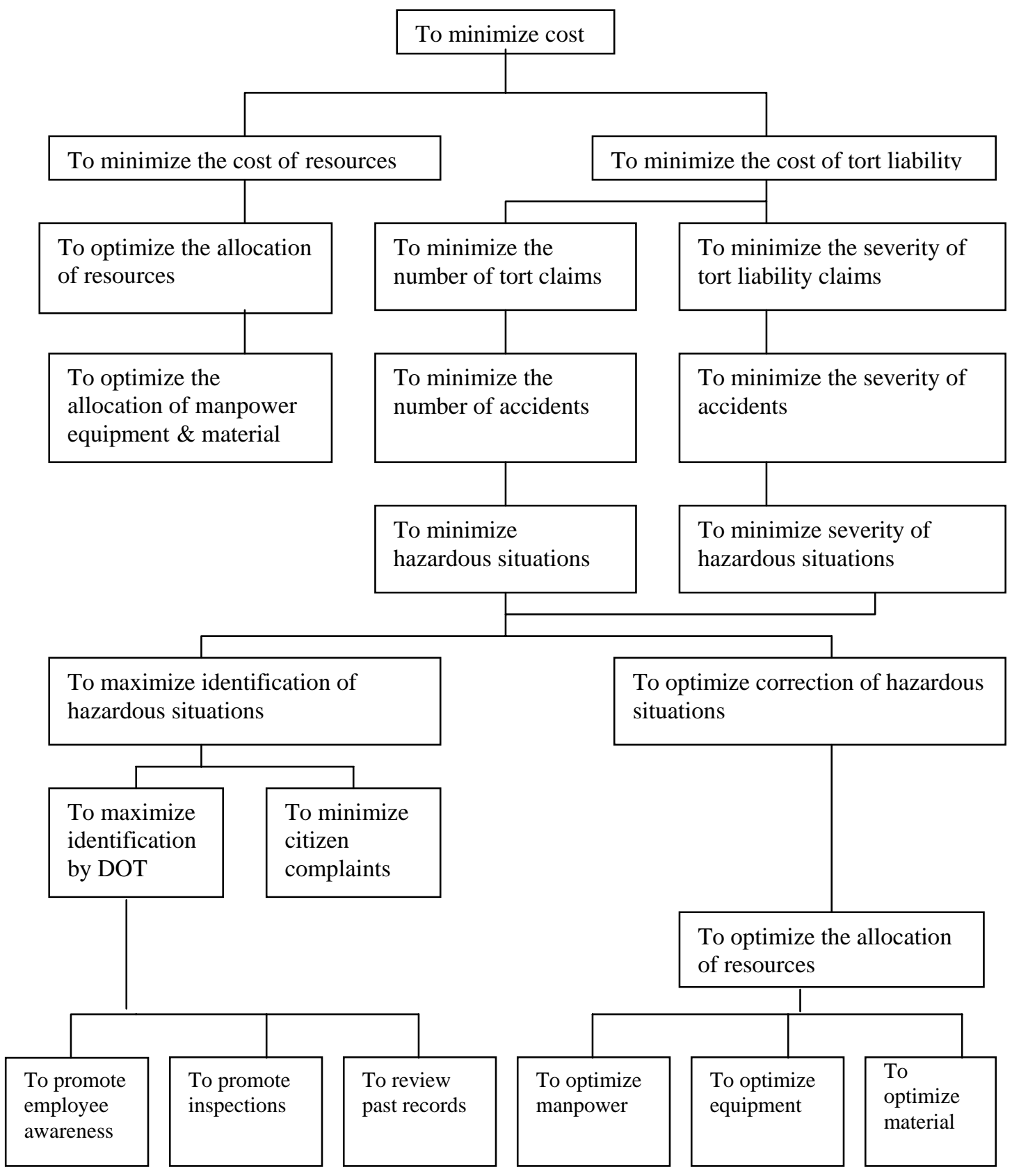

Source: [Demetsky and Yu, 1993] 


\section{APPENDIX C}

\section{General and Specific Objectives of Risk Management Systems}

\begin{tabular}{|c|c|c|c|}
\hline $\begin{array}{l}\text { Agency }_{\rightarrow} \\
\text { Objective } \\
\downarrow\end{array}$ & Virginia DOT & NCHRP Synthesis 202 & $\begin{array}{c}\text { Alabama } \\
\text { Highway } \\
\text { Department }\end{array}$ \\
\hline $\begin{array}{l}\text { Reduce the } \\
\text { number of } \\
\text { accidents on } \\
\text { the road }\end{array}$ & $\begin{array}{l}\text { Improvement of highway safety by } \\
\text { identifying, analyzing, prioritizing, } \\
\text { and recommending alternatives to } \\
\text { change the roadway environment in } \\
\text { a manner that will reduce motor } \\
\text { vehicle accidents. }\end{array}$ & $\begin{array}{l}\text { Reduction of the number and } \\
\text { severity of crashes. }\end{array}$ & $\begin{array}{l}\text { Minimizing the } \\
\text { number of lawsuits } \\
\text { being filed. }\end{array}$ \\
\hline $\begin{array}{l}\text { Reduce the } \\
\text { impact of tort } \\
\text { liability on } \\
\text { the agency }\end{array}$ & $\begin{array}{l}\text { - Reduction of the department's } \\
\text { exposure and loss due to liability, } \\
\text { - Coordination and tracking of all } \\
\text { claims and litigation against the } \\
\text { department, } \\
\text { - Processing of all claims and } \\
\text { managing a tort liability loss- } \\
\text { mitigation program, } \\
\text { - Serving as the tort claim } \\
\text { representative for the department } \\
\text { and coordinating of investigative } \\
\text { service with the attorney general's } \\
\text { office, } \\
\text { - Administration of an employee } \\
\text { safety program, promotion of a cost- } \\
\text { effective risk management effort } \\
\text { statewide, development of control } \\
\text { mechanisms through training and } \\
\text { counseling, and fostering an } \\
\text { awareness by all employees of the } \\
\text { risk potential associated with their } \\
\text { actions. }\end{array}$ & $\begin{array}{l}\text { - Reduction of claims, } \\
\text { - Handling or disposing of minor } \\
\text { claims, } \\
\text { - Enhancement of the defensive } \\
\text { posture of the agency, } \\
\text { - Vigorous defense of the agency } \\
\text { in claims carried through the } \\
\text { litigation process. }\end{array}$ & $\begin{array}{l}\text { Reducing the risk of } \\
\text { financial loss due to } \\
\text { the tort liability of the } \\
\text { agency. }\end{array}$ \\
\hline $\begin{array}{l}\text { Be prepared } \\
\text { for the } \\
\text { unavoidable } \\
\text { claims. }\end{array}$ & Preparing for unavoidable liability. & $\begin{array}{l}\text { Implementation of loss- } \\
\text { prevention measures. }\end{array}$ & $\begin{array}{l}\text { Minimizing the } \\
\text { financial damages } \\
\text { from lawsuits lost }\end{array}$ \\
\hline Reference & [Demetsky and Yu, 1993] & [Lewis et al., 1994] & $\begin{array}{l}\text { [Turner and } \\
\text { Colson,1988] }\end{array}$ \\
\hline
\end{tabular}




\section{APPENDIX D}

\section{Entities Responsible for Risk Management in Selected States}

\begin{tabular}{|c|c|}
\hline State & Person/Office Responsible for Risk Management \\
\hline Alaska & Director of Risk Management \\
\hline Arizona & Office of Risk Management \\
\hline Colorado & Division of Risk Management \\
\hline Hawaii & Assistant Chief of Construction and Maintenance \\
\hline Idaho & $\begin{array}{l}\text { Maintenance supervisor, Traffic Supervisor, as well as Safety } \\
\text { Program Coordinator }\end{array}$ \\
\hline Iowa & Safety Review Engineer as well as Litigation Engineer \\
\hline Louisiana & Department of Transportation and Development \\
\hline Michigan & $\begin{array}{l}\text { Supervisor of Litigation Coordination and Risk Management Section } \\
\text { as well as Risk Management Engineer }\end{array}$ \\
\hline Minnesota & Tort Claims Engineer \\
\hline Missouri & Risk Manager \\
\hline Oklahoma & Division Manager of Operations Review and Evaluation Division \\
\hline Pennsylvania & Risk Management Engineer \\
\hline Washington & Office of Risk Management \\
\hline Wisconsin & Risk manager \\
\hline
\end{tabular}

Source: Demetsky and Yu [1993] 


\section{APPENDIX E}

Tasks and Personnel for Virginia DOT’s Risk Management System

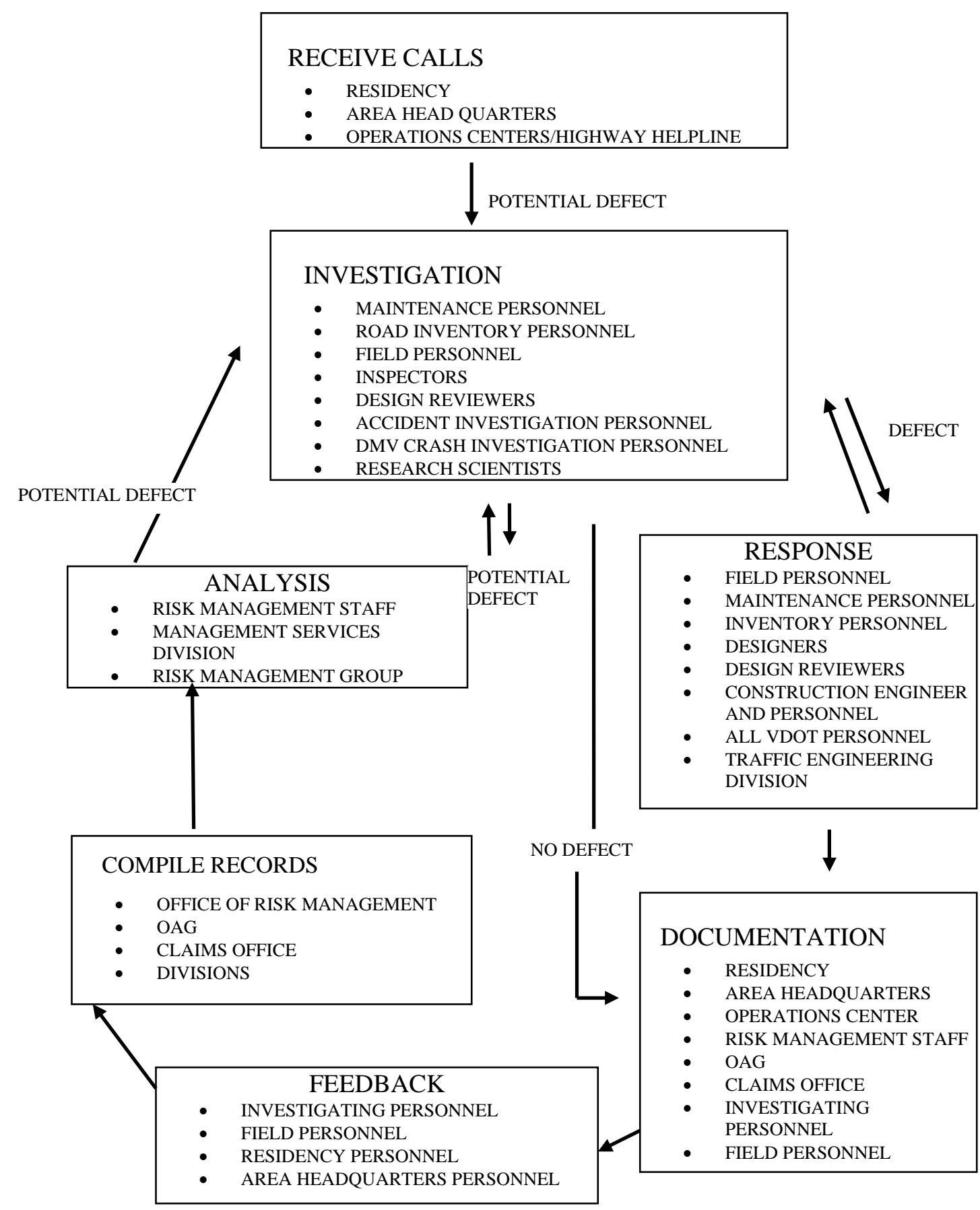

Source: Demetsky and Yu「19921 


\section{APPENDIX F}

Amounts Claimed and Paid for Settled Chuckhole Claims

\begin{tabular}{|c|c|c|c|c|c|c|c|c|}
\hline \multicolumn{9}{|c|}{ CHUCKHOLE } \\
\hline \multicolumn{3}{|c|}{1999} & \multicolumn{3}{|c|}{2000} & \multicolumn{3}{|c|}{2001} \\
\hline COUNTY & CLAIMED & PAID & COUNTY & CLAIMED & PAID & COUNTY & CLAIMED & PAID \\
\hline Marion & 274.7 & 274.76 & Floyd & 436.22 & 436.22 & Tippecanoe & 128.7 & 128.7 \\
\hline Gibson & 55 & 55 & Jay & 166.5 & 166.5 & St. Joseph & 21.15 & 21.15 \\
\hline Clark & 618.7 & 309.35 & Pike & 1182.7 & 815.21 & Floyd & 328.44 & 328.44 \\
\hline Marion & 149.95 & 149.95 & Clay & 303.93 & 303.93 & St. Joseph & 186.63 & 186.63 \\
\hline Knox & 902.35 & 402.35 & Dearborn & 421.43 & 421.43 & Laporte & 156.85 & 156.85 \\
\hline Dearborn & 429.76 & 415.73 & Vigo & 84.87 & 84.87 & Tippecanoe & 228.7 & 228.7 \\
\hline $\begin{array}{l}\text { TOTAL in } \\
\$\end{array}$ & 2430.46 & 1607.14 & Vanderburgh & 373.53 & 373.53 & Lake & 52.43 & 52.93 \\
\hline & & & TOTAL in \$ & 2969.18 & 2601.69 & St. Joseph & 100 & 100 \\
\hline & & & & & & & 300.33 & 205.01 \\
\hline & & & & & & St. Joseph & 338.15 & 338.15 \\
\hline & & & & & & Putnam & 351.74 & 288.02 \\
\hline & & & & & & Lake & 491.86 & 316.48 \\
\hline & & & & & & Lake & 107.5 & 107.5 \\
\hline & & & & & & Lake & 133.65 & 133.65 \\
\hline & & & & & & Tippecanoe & 1463.92 & 765.35 \\
\hline & & & & & & St.Joseph & 483.96 & 301.04 \\
\hline & & & & & & Lake & 250 & 250 \\
\hline & & & & & & Floyd & 159.5 & 159.5 \\
\hline & & & & & & Lake & 327.5 & 327.5 \\
\hline & & & & & & Lake & 431.62 & 208.95 \\
\hline & & & & & & Clarck & 265.65 & 265.65 \\
\hline & & & & & & Franklin & 93.23 & 93.23 \\
\hline & & & & & & Lake & 421.51 & 450.86 \\
\hline & & & & & & Lake & 677.02 & 677.02 \\
\hline & & & & & & Marshall & 101.5 & 101.5 \\
\hline & & & & & & Lake & 216 & 207.51 \\
\hline & & & & & & Lake & 557.56 & 557.56 \\
\hline & & & & & & St.Joseph & 559.6 & 250 \\
\hline & & & & & & Lake & 317.01 & 317.01 \\
\hline & & & & & & Lake & 67.32 & 67.32 \\
\hline & & & & & & St.Joseph & 766.1 & 766.1 \\
\hline & & & & & & Clay & 1000 & 950 \\
\hline & & & & & & Lake & 459.79 & 459.79 \\
\hline & & & & & & Starke & 539.85 & 539.85 \\
\hline & & & & & & Lake & 1289.85 & 1289.85 \\
\hline & & & & & & St.Joseph & 154.77 & 154.77 \\
\hline & & & & & & Lake & 218.55 & 218.55 \\
\hline & & & & & & Lake & 485.99 & 485.99 \\
\hline
\end{tabular}


APPENDIX F (continued):

Amounts Claimed and Paid for Settled Chuckhole Claims

\begin{tabular}{|c|c|c|c|c|c|c|c|c|}
\hline \multicolumn{9}{|c|}{ CHUCKHOLE } \\
\hline \multicolumn{3}{|c|}{1999} & \multicolumn{3}{|c|}{2000} & \multicolumn{3}{|c|}{2001} \\
\hline COUNTY & CLAIMED & PAID & COUNTY & CLAIMED & PAID & COUNTY & CLAIMED & PAID \\
\hline & & & & & & Lake & 366.7 & 366.7 \\
\hline & & & & & & Blackford & 280.9 & 280.9 \\
\hline & & & & & & Lake & 363.3 & 363.3 \\
\hline & & & & & & Blackford & 440 & 440 \\
\hline & & & & & & Lake & 187.7 & 187.7 \\
\hline & & & & & & Montgomery & 135.64 & 135.64 \\
\hline & & & & & & Tippecanoe & 2337.1 & 837.64 \\
\hline & & & & & & lake & 620.5 & 460.27 \\
\hline & & & & & & Floyd & 219.16 & 219.16 \\
\hline & & & & & & Lake & 1080 & 738.69 \\
\hline & & & & & & St.Joseph & 146 & 146 \\
\hline & & & & & & St.Joseph & 206.65 & 206.65 \\
\hline & & & & & & Tippecanoe & 239.92 & 239.94 \\
\hline & & & & & & Allen & 66 & 66 \\
\hline & & & & & & Marshall & 131.02 & 131.02 \\
\hline & & & & & & Warrick & 60.09 & 60.09 \\
\hline & & & & & & St.Joseph & 83.63 & 83.63 \\
\hline & & & & & & St.Joseph & 140.96 & 140.96 \\
\hline & & & & & & St.Joseph & 157.67 & 250.38 \\
\hline & & & & & & TOTAL in $\$$ & 21496.87 & 17811.78 \\
\hline
\end{tabular}


APPENDIX G

Amounts Claimed and Paid for Settled Mailbox Claims

\begin{tabular}{|c|c|c|c|c|c|c|c|c|}
\hline \multicolumn{9}{|c|}{ MAILBOX } \\
\hline \multicolumn{3}{|c|}{1999} & \multicolumn{3}{|c|}{2000} & \multicolumn{3}{|c|}{2001} \\
\hline COUNTY & CLAIMED & PAID & COUNTY & CLAIMED & PAID & COUNTY & CLAIMED & PAID \\
\hline Adams & 44.46 & 44.46 & Elkhart & 61.91 & 50 & Franklin & 62.9 & 62.9 \\
\hline Tipton & 213.75 & 50 & Porter & 67 & 50 & Lagrange & 97.58 & 75 \\
\hline Scott & 50.67 & 50.67 & Porter & 54.82 & 50 & Jackson & 50 & 11.54 \\
\hline Wabash & 275 & 50 & Montgomery & 88.88 & 50 & Clinton & 50 & 23.68 \\
\hline Fulton & 40 & 39.8 & Delaware & 52.38 & 52.38 & Carroll & 43.3 & 43.3 \\
\hline Clarck & 63.56 & 63.56 & Blackford & 60.49 & 55.99 & Bartholomew & 30.7 & 30.7 \\
\hline Jennings & 35.42 & 35.42 & Elkhart & 65.14 & 45.14 & Laporte & 75 & 50 \\
\hline Wells & 48.87 & 48.87 & Floyd & 39.87 & 39.87 & Madison & 17.44 & 15.2 \\
\hline Allen & 41.99 & 41.99 & Allen & 41.5 & 15.75 & Monroe & 45.66 & 45.66 \\
\hline Adams & 15.57 & 15.57 & Noble & 52.42 & 47.42 & St. Joseph & 41.99 & 41.99 \\
\hline Fayette & 52.4 & 52.4 & Madison & 118.5 & 65.83 & Pike & 150 & 43.81 \\
\hline Switzerland & 5 & 5 & Marshall & 40 & 40 & Fayette & 225 & 69.95 \\
\hline Kosciusko & 110 & 50 & Porter & 53.9 & 53.9 & Whitley & 58.79 & 58.79 \\
\hline Madison & 20.99 & 20.99 & Starke & 55 & 50 & Greene & 22.02 & 51 \\
\hline Hendricks & 42.89 & 32.89 & Harrison & 45 & 45 & Whitley & 18.72 & 18.72 \\
\hline St. Joseph & 41.98 & 41.98 & Noble & 48.53 & 48.53 & Washington & 6.63 & 6.63 \\
\hline Wabash & 145 & 50 & Huntington & 29.53 & 29.53 & Madison & 76.24 & 19.5 \\
\hline Newton & 34.94 & 34.94 & Porter & 44.88 & 44.88 & Marshall & 51.44 & 51.44 \\
\hline Cass & 50 & 45.95 & Kosciusko & 50 & 50 & Carroll & 56.82 & 56.82 \\
\hline Jackson & 52.4 & 50 & Jay & 50.98 & 50 & St. Joseph & 69.95 & 69.95 \\
\hline Huntington & 82.57 & 50 & Marshall & 66.99 & 49.89 & Delaware & 48.91 & 48.91 \\
\hline Rush & 52.57 & 50 & Laporte & 52.49 & 50 & Porter & 52.39 & 52.39 \\
\hline Owen & 57.18 & 50 & Delaware & 15 & 15 & Kosciusko & 30 & 21.21 \\
\hline Porter & 7 & 7 & Warrick & 75 & 50 & Madison & 52.49 & 52.49 \\
\hline Monroe & 58.78 & 50 & Jackson & 6.96 & 6.96 & Bartholomew & 100 & 100 \\
\hline Madison & 35.95 & 35.95 & Ripley & 30 & 30 & Miami & 14.27 & 14.27 \\
\hline Howard & 43.03 & 43.03 & Wells & 9 & 9 & Laporte & 85 & 52.36 \\
\hline Hamilton & 46.41 & 46.41 & Porter & 58.98 & 50 & Monroe & 18.89 & 18.89 \\
\hline Porter & 22.98 & 22.98 & Madison & 48.89 & 48.89 & Kosciusko & 62.99 & 62.99 \\
\hline Jefferson & 64.56 & 50 & Allen & 70 & 50 & Hendricks & 31.37 & 31.37 \\
\hline Wabash & 63.66 & 38.66 & Huntington & 100 & 50 & Huntington & 75 & 63.93 \\
\hline Ripley & 59.8 & 26.21 & Fulton & 43.14 & 43.14 & Tipton & 62.89 & 62.89 \\
\hline Jay & 51.27 & 50 & Blackford & 7.97 & 7.97 & Noble & 49.99 & 49.99 \\
\hline Huntington & 15.2 & 15.2 & Gibson & 22.86 & 22.86 & Monroe & 63.7 & 54.9 \\
\hline Hamilton & 56.71 & 50 & Hancock & 25.18 & 25.18 & Allen & 100 & 49.89 \\
\hline Hamilton & 76.61 & 50 & Whitley & 28.75 & 28.75 & St. Joseph & 50 & 50 \\
\hline Porter & 28.86 & 28.86 & Dubois & 80.7 & 50 & Switzerland & 25 & 25 \\
\hline
\end{tabular}




\section{APPENDIX G (continued)}

\section{Amounts Claimed and Paid for Settled Mailbox Claims}

\begin{tabular}{|c|c|c|c|c|c|c|c|c|}
\hline \multicolumn{9}{|c|}{ MAILBOX } \\
\hline \multicolumn{3}{|c|}{1999} & \multicolumn{3}{|c|}{2000} & \multicolumn{3}{|c|}{2001} \\
\hline COUNTY & CLAIMED & PAID & COUNTY & CLAIMED & PAID & COUNTY & CLAIMED & PAID \\
\hline Delaware & 46.99 & 46.99 & Hendricks & 117.9 & 50 & Grant & 52.4 & 52.4 \\
\hline Jay & 51.08 & 50 & Kosciusko & 47.24 & 47.24 & Laporte & 59 & 59 \\
\hline Lagrange & 47.24 & 47.24 & Laporte & 8.39 & 8.39 & Dearborn & 19.97 & 19.97 \\
\hline Sullivan & 22.89 & 7.89 & Whitley & 41.99 & 41.99 & Elkhart & 54.29 & 54.29 \\
\hline Laporte & 60.52 & 50 & Porter & 16.49 & 60 & ?? & 45 & 45.1 \\
\hline Jay & 53.74 & 50 & Steuben & 12.59 & 12.59 & Monroe & 25.91 & 25.91 \\
\hline Jefferson & 100 & 50 & Elkhart & 94.62 & 50 & Perry & 100 & 75 \\
\hline Monroe & 91.76 & 50 & Tipton & 85 & 50 & Porter & 140 & 71.98 \\
\hline Laporte & 54.2 & 50 & Decatur & 102.16 & 50 & Bartholomew & 49.9 & 49.9 \\
\hline Huntington & 24.5 & 24.5 & Carroll & 58.78 & 50 & Tipton & 12.91 & 7.97 \\
\hline Lawrence & 54.24 & 50 & Hamilton & 87.4 & 87.4 & Kosciusko & 24.4 & 20.97 \\
\hline Gibson & 56.49 & 50 & Fulton & 21.39 & 21.39 & Dearborn & 32 & 32 \\
\hline Putnam & 51 & 50 & Hamilton & 41.64 & 41.64 & Huntington & 23.1 & 23.1 \\
\hline Jefferson & 52.49 & 50 & Porter & 75 & 50 & Boone & 58.93 & 58.93 \\
\hline Hancock & 67.4 & 50 & Bartholomew & 49.64 & 29.64 & Noble & 58.21 & 58.21 \\
\hline Jefferson & 73 & 50 & Fulton & 55 & 52.49 & Grant & 70 & 50 \\
\hline Laporte & 92.62 & 50 & Vigo & 49.89 & 49.89 & Putnam & 30 & 30 \\
\hline Hancock & 17.04 & 17.04 & Tipton & 52.48 & 50 & Morgan & 100.71 & 50 \\
\hline Greene & 62.11 & 44.22 & Tipton & 55.92 & 55.92 & Orange & 15.72 & 15.72 \\
\hline Newton & 9.12 & 9.12 & Bartholomew & 20 & 15.48 & Howard & 48 & 24.08 \\
\hline Jefferson & 37.74 & 37.74 & Laporte & 4.19 & 4.19 & Whitley & 39.99 & 41.98 \\
\hline Wells & 62.99 & 50 & Kosciusko & 33.06 & 33.06 & Fulton & 47.15 & 47.15 \\
\hline Johnson & 44.75 & 20.97 & Elkhart & 4.66 & 4.66 & Whitley & 44.69 & 44.69 \\
\hline Steuben & 32.76 & 32.76 & Clinton & 57.5 & 50 & Johnson & 52.49 & 52.49 \\
\hline Laporte & 40 & 20 & Carroll & 29.1 & 29.1 & Kosciusko & 102.89 & 102.89 \\
\hline Boone & 52.49 & 52.49 & Elkhart & 13.58 & 13.58 & Dekalb & 50 & 45 \\
\hline Huntington & 46.18 & 46.18 & Whitley & 70 & 50 & Dearborn & 91.6 & 66.6 \\
\hline Hamilton & ?? 41.98 & 41.98 & Laporte & 41.93 & 41.93 & Allen & 65 & 65 \\
\hline Porter & 19.97 & 19.97 & Clay & 41.93 & 41.93 & Noble & 52.49 & 52.49 \\
\hline Montgomery & ?? 50 & 50 & Johnson & 79 & 50 & Huntington & 44 & 44 \\
\hline TOTAL in $\$$ & 3633.34 & 2707.88 & Vigo & 52.88 & 52.88 & Monroe & 216.43 & 216.43 \\
\hline & & & Randolph & 25 & 25 & Rush & 56.69 & 56.69 \\
\hline & & & Allen & 67.75 & 50 & Hamilton & 45 & 45 \\
\hline & & & TOTAL in \$ & 3476.74 & 2842.25 & Elkhart & 41.95 & 52.45 \\
\hline & & & & & & TOTAL in $\$$ & 4143.89 & 3415.45 \\
\hline
\end{tabular}




\section{APPENDIX H}

\section{Amounts Claimed and Paid for Settled Mower Claims}

\begin{tabular}{|c|c|c|c|c|c|c|c|c|}
\hline \multicolumn{9}{|c|}{ MOWER CLAIMS } \\
\hline \multicolumn{3}{|c|}{1999} & \multicolumn{3}{|c|}{2000} & \multicolumn{3}{|c|}{2001} \\
\hline COUNTY & CLAIMED & PAID & COUNTY & CLAIMED & PAID & COUNTY & CLAIMED & PAID \\
\hline Monroe & 689.24 & 931.1 & Vanderburgh & 220 & 202.57 & Henry & 341.66 & 341.66 \\
\hline Tipton & 386.73 & 386.73 & Ripley & 381.44 & 381.44 & Vanderburgh & 628.25 & 628.25 \\
\hline Clark & 400.68 & 400.68 & Marion & 864.64 & 864.64 & Allen & 276.9 & 86.25 \\
\hline Tippecanoe & 1321.37 & 1321.37 & Warrick & 1900.62 & 1900.62 & Dekalb & 277.21 & 277.21 \\
\hline Tippecanoe & 114.64 & 114.64 & Jefferson & 701.08 & 701.08 & Madison & 939.78 & 939.78 \\
\hline Harrison & 361.06 & 361.06 & Hamilton & 540.49 & 529.74 & Dekalb & 1144 & 648 \\
\hline Vanderburgh & 1334.25 & 1334.25 & Montgomery & 717.8 & 717.8 & Montgomery & 576.82 & 576.82 \\
\hline Howard & 1134.1 & 1134.1 & Scott & 306 & 306 & Madison & 328 & 328 \\
\hline Jennings & 201.25 & 201.25 & Clark & 4500 & 3755 & Lawrence & 247 & 247 \\
\hline Steuben & 225 & 225 & Elkhart & 827.59 & 821.95 & Clark & 617.08 & 617.08 \\
\hline Warrick & 431 & 431 & Lagrange & 171.34 & 171.34 & Jefferson & 1002.25 & 1002.25 \\
\hline Vanderburgh & 203.68 & 1835.98 & Posey & 623 & 623 & Bartholomew & 442.2 & 442.2 \\
\hline Hamilton & 333.4 & 333.4 & Vermillion & 302.52 & 302.52 & Grant & 308.18 & 308.18 \\
\hline Wayne & 529.97 & 529.97 & Lawrence & 248.03 & 248.03 & Dekalb & 1358.63 & 1358.63 \\
\hline Floyd & 385.9 & 385.9 & Monroe & 379.55 & 379.55 & Porter & 2127.51 & 2127.51 \\
\hline Lake & 233.89 & 233.89 & Greene & 551.82 & 551.82 & Hendricks & 798.85 & 798.85 \\
\hline Spencer & 1777.81 & 1502.78 & & 929 & 929 & Scott & 285 & 285 \\
\hline Lagrange & 500 & 445.75 & Spencer & 1376.25 & 1376.25 & Jefferson & 1237.27 & 1237.27 \\
\hline Monroe & 390.75 & 390.75 & Wabash & 126.36 & 126.36 & Porter & 138.03 & 138.03 \\
\hline Clinton & 52.45 & 52.45 & Spencer & 1866.58 & 1502.36 & Miami & 1036.21 & 1036.21 \\
\hline Allen & 294.9 & 284.9 & Tippecanoe & 530.43 & 322.93 & Madison & 286.4 & 286.4 \\
\hline Monroe & 588.71 & 582.27 & Porter & 326.51 & 326.51 & Floyd & 658.54 & 658.54 \\
\hline Jefferson & 332.42 & 332.42 & Benton & 536 & 478 & Boone & 1350.35 & 1350.35 \\
\hline White & 275 & 264.93 & Knox & 300 & 298.82 & Bartholomew & 175 & 175 \\
\hline Putnam & 364.54 & 364.54 & Knox & 423.57 & 423.57 & Noble & 962.35 & 962.35 \\
\hline Spencer & 258.85 & 258.85 & Carroll & 124.93 & 124.93 & Warren & 350.82 & 350.82 \\
\hline Wayne & 182.4 & 182.4 & Jefferson & 1710.58 & 1710.58 & Gibson & 313.28 & 313.28 \\
\hline Franklin & 287.89 & 287.89 & Laporte & 401.62 & 280.46 & Jay & 1276.83 & 1276.83 \\
\hline Crawford & 208 & 208 & Vigo & 45 & 45 & Spencer & 973.87 & 973.87 \\
\hline Steuben & 350 & 350 & Laporte & 2171.35 & 1717.63 & Wells & 164.57 & 164.57 \\
\hline Tipton & 359.45 & 383.01 & Boone & 334.66 & 334.66 & Morgan & 456.94 & 456.94 \\
\hline Lawrence & 189.42 & 189.42 & Grant & 49.94 & 49.94 & Clark & 770.04 & 731.9 \\
\hline Jefferson & 341.47 & 341.47 & Lagrange & 393.57 & 393.57 & Jay & 1478.49 & 1252.47 \\
\hline Hendricks & 585.57 & 585.57 & Owen & 309.85 & 309.85 & Allen & 755.44 & 450 \\
\hline Elkhart & 169.98 & 169.98 & Sullivan & 86.44 & 86.44 & Brown & 681.9 & 681.9 \\
\hline Whitley & 214.03 & 214.03 & Dearborn & 700 & 699.39 & Decatur & 1369.44 & 486.3 \\
\hline Kosciusko & 231 & 231 & Grant & 1229.11 & 1229.11 & & 499.5 & 499.5 \\
\hline Vanderburgh & 640 & 620.9 & Ripley & 996 & 1128 & Bartholomew & 256.23 & 256.23 \\
\hline Randolph & 500 & 500.3 & Tippecanoe & 317.44 & 317.44 & Adams & 1039.33 & 1039.33 \\
\hline
\end{tabular}




\section{APPENDIX H (continued)}

\section{Amounts Claimed and Paid for Settled Mower Claims}

\begin{tabular}{|c|c|c|c|c|c|c|c|c|}
\hline \multicolumn{9}{|c|}{ MOWER CLAIMS } \\
\hline \multicolumn{3}{|c|}{1999} & \multicolumn{3}{|c|}{2000} & \multicolumn{3}{|c|}{2001} \\
\hline COUNTY & CLAIMED & PAID & COUNTY & CLAIMED & PAID & COUNTY & CLAIMED & PAID \\
\hline Morgan & 67.34 & 67.34 & Elkhart & 100 & 100 & Hamilton & 503.22 & 503.22 \\
\hline Dubois & 303.86 & 303.86 & Dubois & 396.09 & 382.4 & Wells & 300 & 252.23 \\
\hline Noble & 160 & 160 & Floyd & 220 & 211.62 & Cass & 308.8 & 308.8 \\
\hline Madison & 421.72 & 421.72 & Jackson & 658.26 & 658.26 & Cass & 234 & 234 \\
\hline Jay & 189 & 189 & Howard & 287.88 & 287.88 & Floyd & 461.71 & 675.91 \\
\hline Adams & 3988.02 & 3988.02 & Monroe & 741.34 & 491.34 & White & 238.58 & 238.58 \\
\hline Warrick & 0 & 423.8 & Monroe & 745.54 & 250 & Warren & 100 & 100 \\
\hline Grant & 366.35 & 366.35 & St. Joseph & 448.8 & 448.8 & Dearborn & 335.79 & 335.79 \\
\hline Henry & 1125.69 & 1125.69 & Knox & 61.9 & 61.9 & Huntington & 144.29 & 127.2 \\
\hline Steuben & 2068.85 & 1996.35 & Daviess & 284.44 & 289.44 & Floyd & 400.05 & 392.5 \\
\hline Jennings & 420.31 & 168.88 & Tippecanoe & 908.64 & 590.66 & Vigo & 403.67 & 403.67 \\
\hline Warrick & 448.91 & 448.91 & Fulton & 78.71 & 78.71 & Dearborn & 337.14 & 337.14 \\
\hline White & 709.75 & 709.75 & Warrick & 509.62 & 509.62 & Tippecanoe & 445.29 & 445.29 \\
\hline $\begin{array}{l}\text { TOTAL in } \\
\$\end{array}$ & 27650.6 & 29273.6 & TOTAL in $\$$ & 33962.33 & 31028.53 & Shelby & 411.1 & 411.1 \\
\hline & & & & & & Montgomery & 1764.82 & 359.03 \\
\hline & & & & & & Spencer & 356.55 & 350.55 \\
\hline & & & & & & Jasper & 1741.83 & 1854.61 \\
\hline & & & & & & Lagrange & 415.5 & 409.26 \\
\hline & & & & & & TOTAL in $\$$ & 36832.49 & 33529.64 \\
\hline
\end{tabular}




\section{APPENDIX I}

Amounts Claimed and Paid for Settled Paint Claims

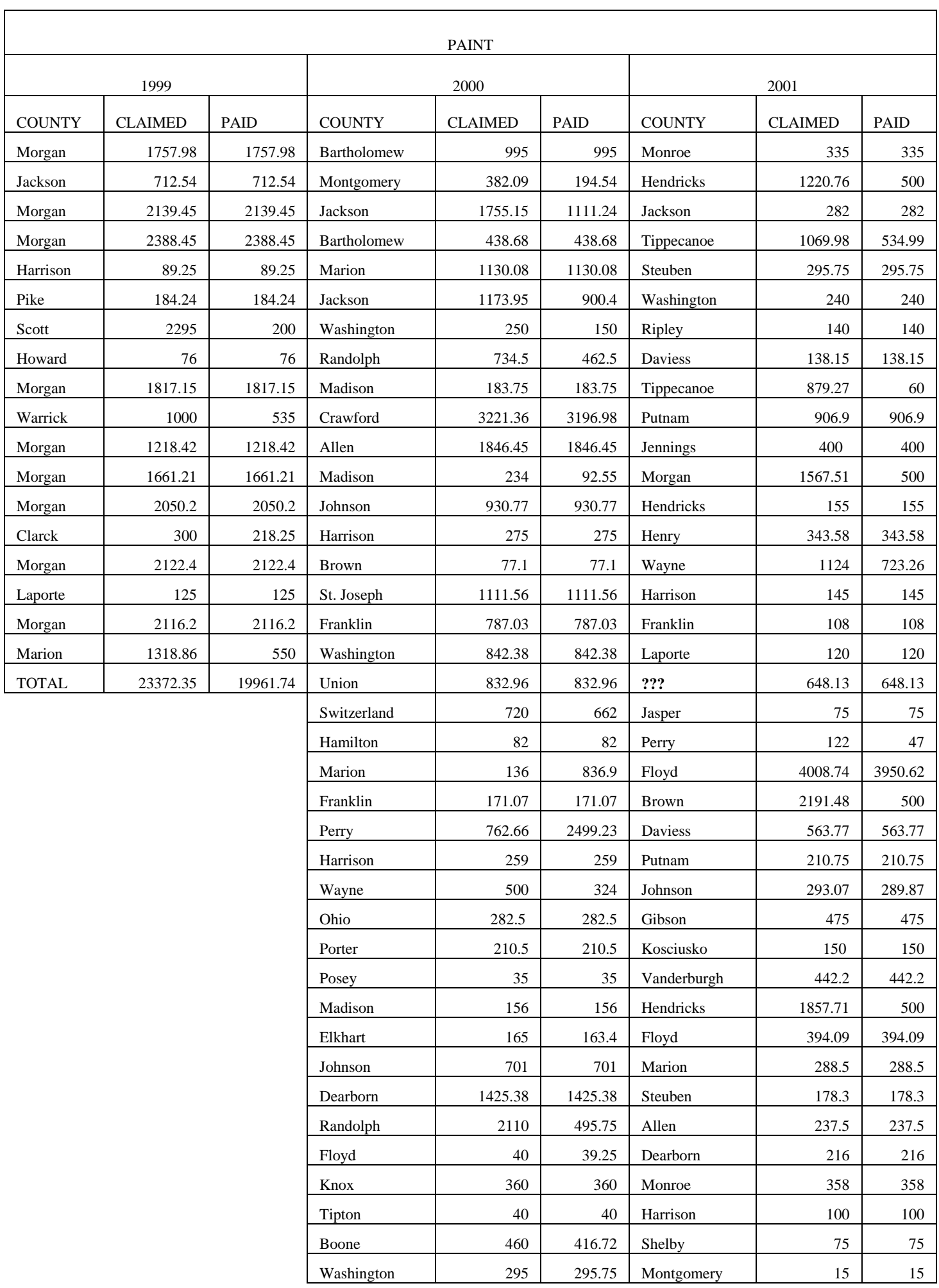


APPENDIX I (continued)

Amounts Claimed and Paid for Settled Paint Claims

\begin{tabular}{|c|c|c|c|c|c|c|c|c|}
\hline \multicolumn{9}{|c|}{ PAINT } \\
\hline \multicolumn{3}{|c|}{1999} & \multicolumn{3}{|c|}{2000} & \multicolumn{3}{|c|}{2001} \\
\hline COUNTY & CLAIMED & PAID & COUNTY & CLAIMED & PAID & COUNTY & CLAIMED & PAID \\
\hline & & & Jefferson & 316 & 316 & Hamilton & 300 & 291.25 \\
\hline & & & Marion & 1060.37 & 1060 & Dearborn & 314 & 314 \\
\hline & & & Bartholomew & 336.25 & 297 & Floyd & 1149.24 & 1149.24 \\
\hline & & & Allen & 120 & 120 & Floyd & 444.75 & 444.75 \\
\hline & & & TOTAL in\$ & 27663.04 & 26807.42 & Allen & 602 & 602 \\
\hline & & & & & & Dekalb & 377 & 377 \\
\hline & & & & & & Jennings & 1062.9 & 1062.9 \\
\hline & & & & & & Allen & 326 & 326 \\
\hline & & & & & & Morgan & 1102.95 & 1102.95 \\
\hline & & & & & & Scott & 297.25 & 297.25 \\
\hline & & & & & & Harrison & 1400 & 695.72 \\
\hline & & & & & & Dekalb & 75 & 75 \\
\hline & & & & & & Washington & 975.41 & 975.41 \\
\hline & & & & & & Floyd & 340 & 339.15 \\
\hline & & & & & & Ripley & 336.81 & 336.81 \\
\hline & & & & & & TOTAL in $\$$ & 30924.45 & 24031.79 \\
\hline
\end{tabular}




\section{APPENDIX J: INSTRUMENT USED FOR AGENCY SURVEY}

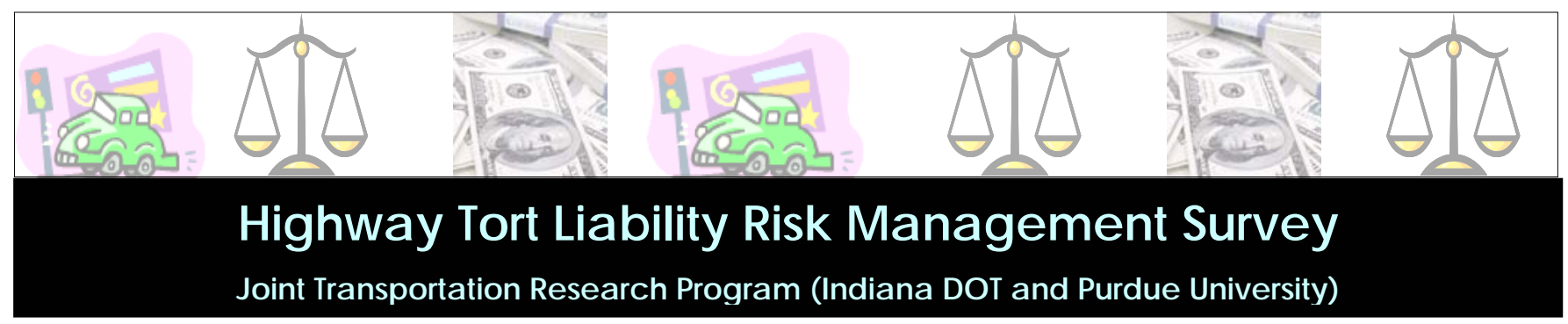

\section{GENERALINFORMATION}

State:

Name and title of person compiling response:

E-mail address:

\section{PURPOSE OF THIS OUESTIONNAIRE}

The purpose of this questionnaire is to obtain information on your agency's experiences, observations and evaluations, if any, on the ways you address highway-related tort liability issues. This is part of a study evaluating the need for a Risk Management System for Indiana Department of Transportation.

\section{BENEFIS OF THE OUESTIONNAIRE}

Information on nationwide tort liability risk management practices that will be collected through this survey will be collated and reported back to all respondents of this survey in the near future. It is expected that such information would be beneficial in assessing where a current program stands in relation to similar programs in other states.

The first part of the questionnaire requests you for information on the status of tort liability in your state. The second part focuses on the practices of any tort liability risk management program you may have in operation.

\section{OUESTIONNAIRE}

Please answer the following questions as completely as possible. Feel free to add any comments. If you need more space for any response, you may please attach an additional sheet.

\section{STATUS OF TORTUABIUTY IN YOUR STATE}

1. What kind of immunity does your state have against highway-related tort suits?

$$
\text { Full }
$$

$$
\text { Partial }
$$

No Immunity

If partial, please describe:

2. Do you have a monetary limit for highway-related tort claims?

$$
\text { Yes }
$$

No

If so, please indicate the payment amount limits, if any:

The limit amount paid for each individual is

The limit paid for each accident is 


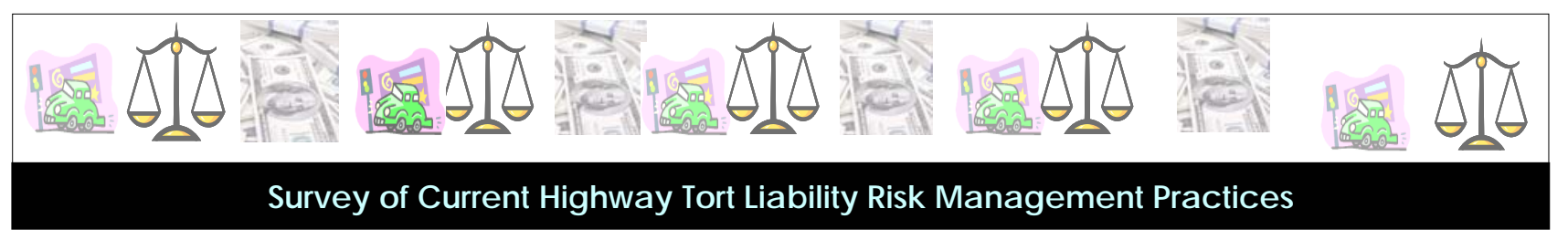

3. What kind of "negligence" law, if any, do you currently adopt? (check if applicable) Contributory Negligence Comparative Negligence Joint Negligence Other (please describe)

\section{STATUS OF RISK MANAGEMENT}

4. Has your state established a risk management program to address issues such as highway tort liability? Yes

If so, please describe (or attach any literature on) the organizational set-up and/or process of such program.

No (If not, please briefly describe how you manage highway-related tort liability risks).

5. Do you have staff in your agency specifically assigned to management of highway tort liability risks?

Yes No

If so, please provide a brief description (in a few words, diagram or attached literature) of their duties.

6. Does your agency have clearly established objectives for highway tort risk management? Yes No If so, please list them below or kindly forward any document that has such a list of objectives. 


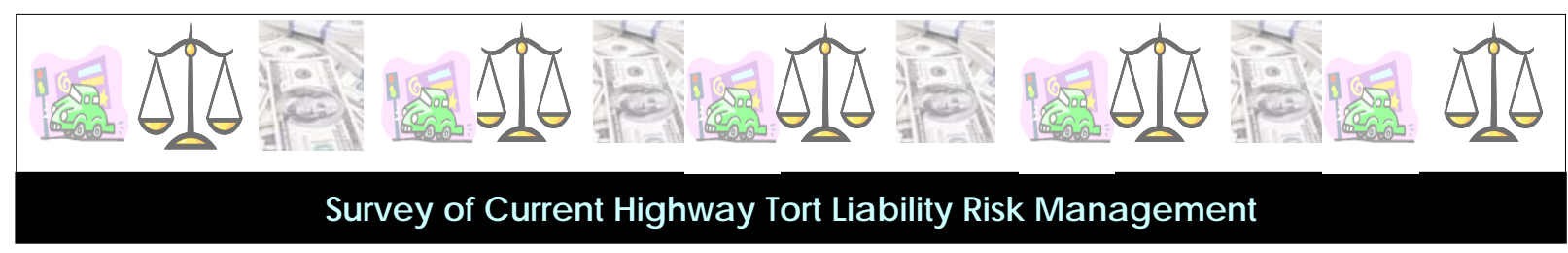

7. Which methods do you use to identify hazardous locations?

Citizen complaints

Accident investigations

Special design and maintenance procedures

Central operations center

Review of past tort claims

Other. Please specify:

8. What measures are taken after a potential hazardous location is identified?

9. How do you determine the priorities between competing potential hazardous locations (e.g., use of a mathematical formula or index, subjective approach, established ranking priorities)?

10. Do you have any time limit within which an identified hazardous location should be remedied?

For example, how long do your agency's maintenance crews generally take to fix a reported defect?

1-2 days
$2-4$ days
$4-7$ days
1 week or more

11. How often do you settle cases by arbitration instead of going to court? $0-10 \%$ of the time $30-40 \%$ of the time $60-70 \%$ of the time $10-20 \%$ of the time $20-30 \%$ of the time $40-50 \%$ of the time $70-80 \%$ of the time $50-60 \%$ of the time Over $80 \% \%$

12. Do you have a training/workshop/seminar program through which you advise employers in your DOT about risk management practices?

Yes No

If so, please describe briefly. 
13. Do you use any special risk management strategies that were not discussed above but merit mention and explanation?

14. Do you regularly evaluate the results and the performance of your risk management program?

$$
\text { Yes }
$$

No

If so, what criteria are used to measure the efficiency of the risk management program? Number (or rate) of accidents Total number of all claims filed or paid Total cost of all claims filed or paid The program is not evaluated Other. Please specify:

15. How do you determine the amount of funds that need to be set aside for paying future claims that may be deemed unavoidable?

16. Do you think your risk management program has helped in reducing tort liability costs in your DOT? Yes If so, to what extent? No

17. From which agency's budget are expenses paid for tort claims? General budget/special funds administered by the state Attorney General Funds administered by the state DOT

18. If you could please mail to us any documentation of your tort liability risk management practices, it would be greatly appreciated.

Please return (using enclosed self-addressed and stamped envelope) to:

Joint Transportation Research Program

1284 Civil Building, Purdue University

550 Stadium Mall Drive

West Lafayette, IN 47907

Phone: (765)494-2211

Email: sinha@ecn.purdue.edu

A response by April 15, 2003 would be greatly appreciated. 